\title{
WestVirginiaUniversity
}

THE RESEARCH REPOSITORY @ WVU

Graduate Theses, Dissertations, and Problem Reports

2004

\section{Hematotoxicity of heptachlor}

\author{
Sarah Vanessa Meads Dodson
}

West Virginia University

Follow this and additional works at: https://researchrepository.wvu.edu/etd

\section{Recommended Citation}

Dodson, Sarah Vanessa Meads, "Hematotoxicity of heptachlor" (2004). Graduate Theses, Dissertations, and Problem Reports. 2137.

https://researchrepository.wvu.edu/etd/2137

This Dissertation is protected by copyright and/or related rights. It has been brought to you by the The Research Repository @ WVU with permission from the rights-holder(s). You are free to use this Dissertation in any way that is permitted by the copyright and related rights legislation that applies to your use. For other uses you must obtain permission from the rights-holder(s) directly, unless additional rights are indicated by a Creative Commons license in the record and/ or on the work itself. This Dissertation has been accepted for inclusion in WVU Graduate Theses, Dissertations, and Problem Reports collection by an authorized administrator of The Research Repository @ WVU.

For more information, please contact researchrepository@mail.wvu.edu. 


\title{
Hematotoxicity of Heptachlor
}

\author{
Sarah Vanessa Meads Dodson
}

Dissertation submitted to the School of Medicine at West Virginia University in partial fulfillment of the requirements for the degree of

\author{
Doctor of Philosophy \\ in \\ Microbiology, Immunology, and Cell Biology \\ Kenneth Landreth, PhD, Chair \\ John Barnett, PhD \\ Laura Gibson, PhD \\ Michael Luster, PhD \\ Mark Reasor, PhD \\ David Weissman, MD
}

Department of Microbiology, Immunology, and Cell Biology

Morgantown, WV

2004

Keywords: Heptachlor, organochlorine pesticide, hematopoiesis, NF-kB, pro-B cell, pre-B cell, stromal cell 


\section{Abstract \\ Hematotoxicity of Heptachlor \\ Sarah Vanessa Meads Dodson}

Hematotoxicity has been documented in adults exposed to high levels of organochlorine pesticides. Our studies revealed that prenatal exposure to the organochlorine pesticide heptachlor resulted in alteration of lymphocyte development, while myeloid cell development was spared. To further investigate effects of heptachlor on lymphoid cells, we evaluated direct exposure of this compound on pro-B and pre-B cells. In these studies, the pro-B cell line $\mathrm{C} 1.92$ and the pre-B cell line 70Z/3 demonstrated concentration-dependent decreases in proliferation following heptachlor exposure. Pro-B cell viability decreased significantly; however, pre-B cell viability was not altered. Further investigation into mechanisms of diminished cell proliferation revealed that heptachlor exposure altered nuclear factor kappa B (NF-kB) localization in both cell lines. Pre-B cells exposed to heptachlor differentiated and expressed surface $\kappa$ immunoglobulin light chain. This exposure correlated with increased NF-kB in nuclei of pre-B cells. When NF-kB was retained in the cytoplasm of pre-B cells in the presence of capsaicin, heptachlor exposure failed to induce $\kappa$ light chain surface expression. This further indicated heptachlor induced differentiation of pre-B cells through altered NF-kB signaling. Exposure of pro-B cells to heptachlor alone resulted in decreased nuclear NF-kB translocation, decreased phosphorylation of $\mathrm{I}-\mathrm{kB}$, and apoptosis of these pro-B cells. These data have allowed us to construct a working hypothesis that exposure to heptachlor alters the normal development of lymphoid cells. 


\section{Dedication}

This dissertation is dedicated to my family. My mom, dad, and sister have always encouraged me to continue with my education and to strive for whatever I wanted in life. They are essential to who I am and for instilling in me the ability to prevail in tough situations.

My husband Jeffrey has encouraged me throughout, and we have both made great sacrifices in the process of working toward this doctorate degree. Obtaining this degree has been bittersweet for us as a couple, but our adventure as lifetime partners is now going to start another chapter as I use this as a stepping stool to begin my career.

Also....for every kid who digs through the pile of manure in search of the pony..... It is possible to find if you just keep on looking. 


\section{Acknowledgements}

Equipped with his five senses, man explores the universe around him and calls the adventure Science. Edwin Powell Hubble, The Nature of Science, 1954

There are many people that I must thank that have aided in the development of this dissertation. First of all, my advisor Kenneth Landreth has given me skills to examine problems through the formation of hypotheses and design of experiments that further

our knowledge. He also has given me....no...he has made me work toward improving my writing and presentation skills.....sentence by sentence. In addition, I regard Ken as a character who should someday write a book because he is always...and will continue.to be....involved in great adventures. Some of these adventures made me laugh and some of them made me wonder if I was going to have a mentor who would survive through them. I would also like to thank the members of my committee: John Barnett, Laura Gibson, Michael Luster, Mark Reasor, and David Weissman. I am very thankful to have input from each of your on this project. I have to give additional blessings to Laura Gibson who gave me an endless supply of encouraging words and hugs. Laura always believed in me, and I will always be thankful for having her as a "cheerleader".

I also have to give thanks to Debbie Piktel who has always keep the lab running smoothly. Debbie is invaluable as a resource in the lab and she has answered so many "stupid" questions.... and yes, I have had some doozies! A past member of my laboratory, Dr. Candice Damiani, also fielded many of my questions and has grown to become one of my best friends. I thank her for going before me, 
just as an older sister tramples the way for the younger sibling. You were very brave. Also, Ben Messinger also had his hands in some of the initial heptachlor studies, so I want to give a "shout out" to him for all his hard work.

I also have to give appreciation to the students in the department of Microbiology, Immunology, and Cell Biology at WVU. They have provided an environment that is supportive and on days on which we all wanted to scrap the research or the class work, we were able to commiserate together, laugh together....or at one another. So thank you I especially have to extend thanks to Melanie Sal, who has proven to be a true friend and who I think of as an adopted sister .....especially now that I have lived with her parents for six months. (Yes...thank you so much Mom and Dad Sal!) 


\section{Table of Contents}

HEMATOTOXICITY OF HEPTACHLOR ........................................................... I

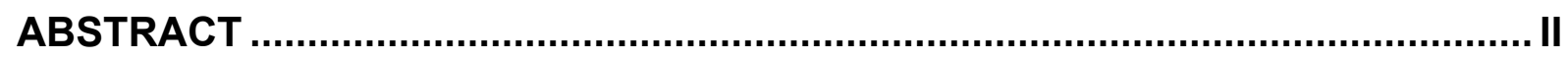

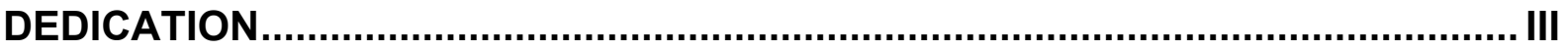

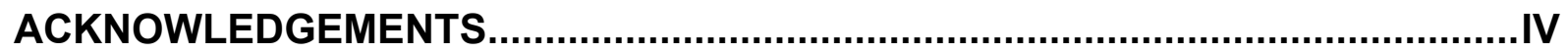

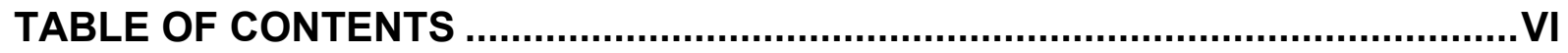

TABLE OF FIGURES ......................................................................................

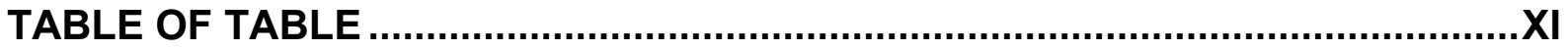

CHAPTER 1: LITERATURE REVIEW \& EXPERIMENTAL DESIGN ....................... 1

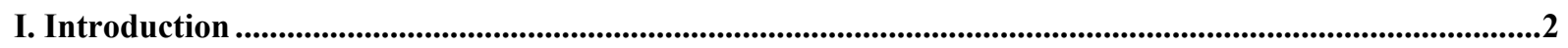

II. Organochlorine pesticides ...............................................................................................................................

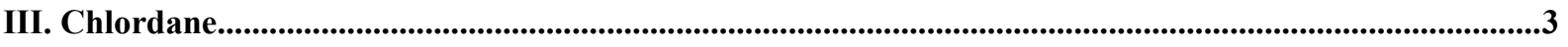

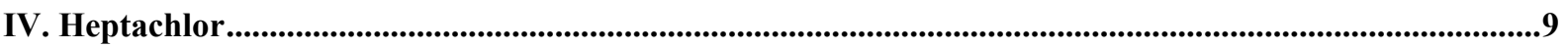

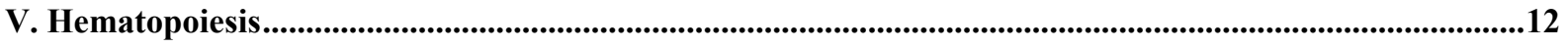

VI. Experimental Design ...........................................................................................................................................24

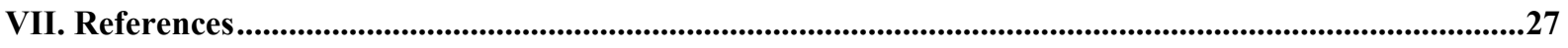




\section{CHAPTER 2: PRENATAL HEPTACHLOR EXPOSURE ALTERS LYMPHOID BUT}

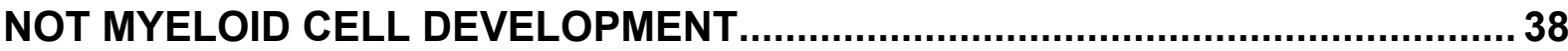

Abstract

Introduction.

Materials and Methods

Results . .45

Discussion

References . .62

CHAPTER 3: IN VITRO HEPTACHLOR EXPOSURE INDUCES MATURATION OF

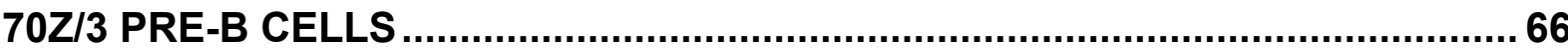

Abstract

Introduction .68

Materials and Methods

Results

Discussion . .92

References

CHAPTER 4: IN VITRO HEPTACHLOR EXPOSURE ALTERS NF-KB IN PRO-B

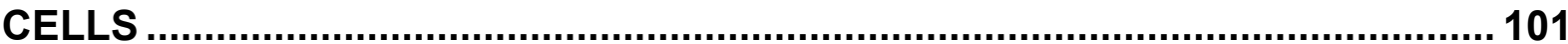

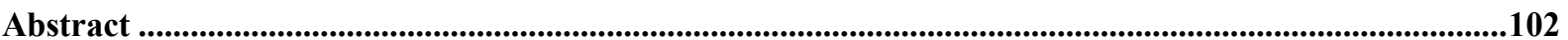


Introduction.

Results

Discussion

References.

CHAPTER 5: IN VITRO HEPTACHLOR EXPOSURE ALTERS STROMAL CELL FUNCTION

Abstract

Introduction.

Results

Discussion

References.

CHAPTER 6: OVERALL DISCUSSION

References. 185 


\section{Table of Figures}

\section{Chapter 1}

Figure 1: Chemical structures of chlordane and heptachlor ................................... 5

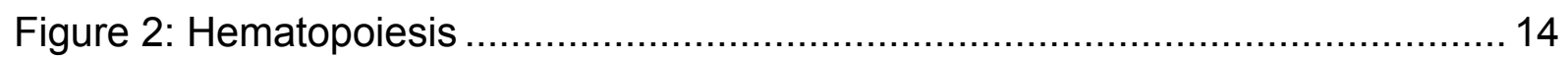

Figure 3: Murine Developmental Hematopoiesis ................................................. 17

Figure 4: Critical Windows in murine development ............................................. 20

\section{Chapter 2}

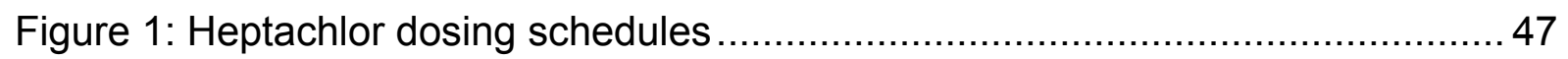

Figure 2: Prenatal heptachlor exposure did not affect cellularity of fetal livers.......... 49

Figure 3: Prenatal heptachlor exposure did not alter numbers of myeloid progenitor cells... 51

Figure 4: Prenatal heptachlor exposure increased numbers of lymphoid progenitor cells. 54

Figure 5: Prenatal heptachlor exposure altered numbers of lymphoid progenitor cells in lymphoid limiting dilution assay. 57

\section{Chapter 3}

Figure 1: Heptachlor exposure decreased proliferation of pre-B cells 75

Figure 2: Heptachlor exposure did not alter viability of pre-B cells. 77

Figure 3: Heptachlor exposure decreased numbers of pre-B cells in culture for 24

hours. 80

Figure 4: Heptachlor exposure altered kinetics of pre-B cells in culture 82

Figure 5: Heptachlor exposure induced $\kappa$ immunoglobulin light chain protein expression on pre-B cells. 84 
Figure 6: Heptachlor exposure increased nuclear abundance of NF-kB protein in pre-B cells 87

Figure 7: ELISA confirmed that heptachlor exposure increased nuclear NF-kB protein in pre-B cells 89

\section{Chapter 4}

Figure 1: Direct heptachlor exposure resulted in decreased pro-B cell proliferation 111

Figure 2: Negative heptachlor effects on pro-B cell proliferation were decreased in the presence of stromal cells 114

Figure 4: Heptachlor exposure resulted in apoptosis of pro-B cells 118

Figure 5: Heptachlor exposure diminished nuclear levels of NF-kB in pro-B cells .. 121

Figure 6: ELISA confirmed that heptachlor exposure decreased nuclear NF-kB levels in pro-B cells

Figure 7: Heptachlor exposure dose-dependently decreased phosphorylated I-אB protein 126

\section{Chapter 5}

Figure 1: Heptachlor exposure did not decrease viability of stromal cells 149

Figure 2: Heptachlor exposure diminished the capacity of stromal cells to support pro-B proliferation

Figure 3: Heptachlor exposure affected SCF mRNA abundance in stromal cells ... 154

Figure 4: Heptachlor exposure affected SCF protein in stromal cells 157

Figure 5: Heptachlor exposure decreased stromal cell VCAM-1 protein expression 159 
Figure 6: Heptachlor exposure decreased nuclear NF- B protein abundance in stromal cells.

\section{Table of Table}

Table 1: Cytokine and housekeeping gene primers sets 


\section{CHAPTER 1: Literature Review \& Experimental Design}




\section{Introduction.}

Pesticides and herbicides have been continually applied to buildings, crops, and fields in abundance in an attempt to prevent damage by insects. It is essential that we assess the outcome of pesticide exposure to embryonic tissues during fetal development (Diertert et al, 2000). Evaluation of chemical exposure during critical windows during development is essential to examine potential prenatal and postnatal impairment that results from such embryonic exposure (Dietert et al, 2000; Landreth, 2002).

Heptachlor is an organochlorine pesticide that is unusually persistent in the environment (IARC monographs, 1991). Embryonic exposure to heptachlor first became a major concern in Hawaii after the milk supply was contaminated with this pesticide through ingestion of contaminated plant material by dairy cattle (Le Marchand et al, 1986). In order to decipher potential effects of the pesticide on immune system development and function, we evaluated embryonic hematopoiesis following heptachlor exposure.

Hematopoiesis is the process of blood cell development from pluirpotential stem cells. Hematotoxicity, or impairment to normal homeostasis of blood cell formation, was documented in adults exposed to high levels of organochlorine pesticides (Furie and Trubwitz, 1976). This dissertation has intently focused on

investigating effects of heptachlor on hematopoiesis. This research has not only provided knowledge on how heptachlor affected embryonic hematopoiesis, but has 
also provided a basis for understanding potential effects of embryonic exposure to related organochlorine pesticides.

\section{Organochlorine pesticides.}

Organochlorine insecticides have been heavily used worldwide for insect control and are now thought to be at potentially toxic concentrations in the environment. Human exposure to organochorine pesticides has been correlated with gastrointestinal illness, migraine headaches, seizures, neuroblastoma, and leukemia (Furie and Trubwitz, 1976; Barnett and Rodgers, 1994). These chemicals all are lipid soluble, contain at least one carbon ring within the molecular structure, and are highly persistent in the environment. Organochlorine pesticides act primarily by altering the movement of ions across the nerve cell membranes, thus changing the ability of nerves to signal normally (IARC monographs, 1991). Organochlorine pesticides are divided into five classes: 1.) chlorinated cyclodiene insecticides 2.)

dichlorodiphenylethane 3.) cyclohexane 4.) toxaphene and 5.) mirex and chlordecone. Our laboratory has been interested in cyclodiene insecticides, specifically chlordane and heptachlor. These two pesticides are model cyclodiene insecticides and have similar chlorinated ring chemical structures (Figure 1).

\section{Chlordane.}

Chlordane was first manufactured in the United States in 1947 as a commercial insecticide. It is a broad-spectrum, contact insecticide used primarily for structural preservation against insects but also used on lawns, gardens, livestock, 
Figure 1: Chemical structures of chlordane and heptachlor. These organochlorine pesticides have similar molecular structures. 


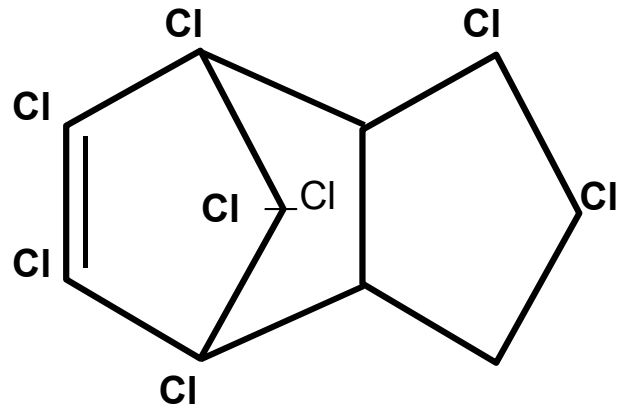

Chlordane

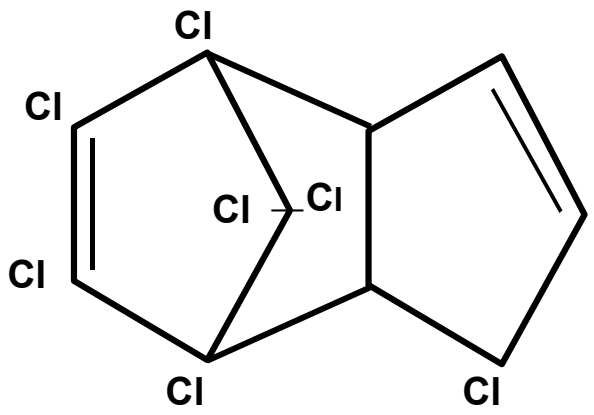

Heptachlor

Figure 1: Chemical structures of chlordane and heptachlor 
and crops, such as corn and potatoes. Buildings were protected against termite infestations by pouring or injecting chlordane in soil around structural foundations.

Chlordane was used abundantly from 1947 to 1983, and in 1974 alone, 9,500 tons of chlordane were commercially produced (IARC monographs, 1991). In 1988, the EPA prohibited chlordane use in the United States due to demonstrated toxicity and environmental stability of the pesticide. Chlordane is extremely persistent in the environment with a half-life of 20 to 30 years in soil (IARC monographs, 1991). However, chlordane continued to be exported to many countries where it is still in use. Vesicol Chemical Corporation, the sole producer of chlordane, voluntarily halted production and sale of the pesticide in 1989. Registration for chlordane production in the United States was not reissued, but the pesticide continued to be exported from the US to other countries until 1995 (Office of Pesticide Programs, 1995). Technicalgrade chlordane is composed of a mixture of cis- chlordane (19\%), trans-chlordane (24\%) along with heptachlor (10\%), nonachlor (7\%), chlordane isomers $(21.5 \%)$ and octachlorocyclopentene (1\%) (IARC monographs, 1991). The major metabolite of chlordane is oxychlordane, which is formed by oxidation of chlordane by p450 which is predominately located in liver.

Immunotoxicity of chlordane. Because chlordane quickly disrupts ion transport within nerve synapses of insects, it is an extremely effective pesticide. Unfortunately, this toxicity is not limited to insects. Chlordane is carcinogenic, causing leukemia and neuroblastoma, and hematotoxic, resulting in megaloblastic anemia (Infante and 
Newton, 1975; Furie and Trubwitz, 1976; Barnett et al, 2004). Johnson et al (1986) demonstrated that adult mice exposed to chlordane have little immunotoxic effects. No differences were noted between controls and chlordane-exposed mice when spleen cells were stimulated with LPS, the DTH reaction evaluated, or number of plaque-forming cells specific for erythrocytes determined (Johnson et al, 1986). Numbers of lymphocytes in circulation of adult mice increased after exposure to chlordane as demonstrated by the increase in $T$ cell stimulation in a mixed lymphocyte reaction (Johnson et al, 1986). Additionally, when offspring of dams were administered chlordane during pregnancy, the F1 generation had normal cytotoxic T-lymphocyte (CTL) and natural killer (NK) cell responses at 100 days of age (Blaylock et al, 1990). However, at 200 days, the male offspring exposed to chlordane in utero had decreased NK cell activity (Blaylock et al, 1990; Barnet, 1997). These data indicate differences in chlordane sensitivity depending on the age and gender of the postnatal mice (Barnett et al, 1985; Barnett et al, 1990a; Barnett et al, 1990b; Blyer et al, 1994).

Our lab examined the effects of chlordane on immune system development. Studies on the toxicity of chlordane by Barnett et al. (1997) have shown that, although chlordane was not immunotoxic to adult mice, prenatal exposure to chlordane resulted in persistent immunotoxicity, carried into postnatal life (Barnett, 1997; Johnson et al, 1986). For example, the tumoricidial capababilities of macrophages were delayed in postnatal animals when mice were exposed to chlordane in utero (Theus et al, 1992). Literature has shown that embryos exposed 
to chlordane (4 mg/kg and $8 \mathrm{mg} / \mathrm{kg}$ of mouse weight) and the offspring evaluated at 100 days of age have depressed delayed-type hypersensitivity reactions (DTH) as measured by ear swelling after topical exposure to non-specific allergens (Barnett et al, 1985; Spyker-Cranmer et al, 1982). In these experiments, both female and male offspring were affected. The mitogen response of lymphoid cells from 100 day-old mice treated in utero with chlordane showed no change in B cells as measured by assays using lipopolysaccharide (LPS) stimulation but did result in an increase in T cell stimulation using concanavalin A (Con A) (Barnett et al, 1985). However, these increases were observed only in female offspring. Stem cells were reduced in postnatal mice that were exposed to chlordane in utero as measured by colony formation unit assays in spleen (CFU-S) (Barnett et al, 1990a; Barnett et al, 1990b). This stem cell reduction was noted in both postnatal mice at 100 and 200 days of age. These results demonstrate long-lasting immunotoxicity in developing embryos exposed to chlordane.

Hematotoxicity of chlordane to humans. A well-documented case describing hematotoxic effects of chlordane exposure indicated that such pesticides interfere with normal blood cell development. A 47 year-old male exposed to chlordane after applying the pesticide to his dental office had an onset of symptoms of fever and fatigue (Furie et al, 1976). This individual was exposed to chlordane for approximately 300 hours within a time period of 6 months. This contact directly resulted from chlordane application by the individual to his office followed by continual time spent in the building. Reductions of red blood cells, along with 
megaloblastic anemia, were both correlated with chlordane exposure (Furie et al, 1976). Seven months after initial symptoms were noted, erythrocyte numbers rebounded to normal levels after removal from the chlordane-treated area.

\section{Heptachlor.}

Heptachlor (Figure 1) was discovered as a component in technical-grade chlordane. Technical-grade heptachlor is composed of heptachlor $(72 \%)$, transchlordane (20\%), and nonachlor (8\%) (IARC monographs, 1991). Similar to chlordane, half-life of heptachlor ranges from 20 to 30 years in soil, making human exposure to the pesticide a significant concern. The major metabolite of heptachlor, heptachlor epoxide, is yielded from oxidation of the parent compound, and this metabolite is likewise persistent in the environment (IARC monographs, 1991). Heptachlor production and usage began in 1952, which included control of malaria, soil and building application in pest prevention, and crop protection. The use of heptachlor was restricted in 1984 to the prevention of fire ant infestation of utility boxes. In 1989, the production of heptachlor, like chlordane, was voluntarily stopped in the United States based on concern of the persistent nature of the compound.

Effects of heptachlor on the immune system. Heptachlor is known to have effects on the immune system. Prenatal or postnatal heptachlor exposure of rats resulted in suppression of primary IgM and secondary IgG responses (Smialowicz et al, 2001). No effects were observed on natural killer cell activity, delayed type or contact hypersensitivities, or lymphocyte to proliferation in response to mitogens (Smialowicz 
et al, 2001). Rought et al (1999) found that heptachlor exposure of human CEM-174 cells, a B and $T$ hybrid cell line, resulted in reduced retinoblastoma $(\mathrm{Rb})$ gene expression within 12 hours. $\mathrm{Rb}$ is a protein that acts as a regulator of cell proliferation and a tumor suppressor and reduction of $\mathrm{Rb}$ results in uncontrolled cell growth. These CEM-174 cells were induced to initiate apoptosis after exposure to heptachlor (Rought et al, 2000). Cell proliferation was decreased in Rhesus monkey lymphocytes exposed to either heptachlor or chlordane in vitro; interleukin-2 (IL-2) production was also decreased in these lymphocytes (Chuang et al, 1992). Primate lymphocytes were found to have altered progression through cell cycle after heptachlor treatment (Chuang et al, 1999).

Effect of heptachlor on cellular communication. Several studies have documented effects of heptachlor on cellular communication. Yamaguchi et al (1980) found that heptachlor epoxide, the metabolite of heptachlor, alters levels of intracellular calcium in synaptic vesicles in rat brain neurons causing increased neurostimulation. Reports in the literature state that heptachlor and heptachlor epoxide have been found to alter gap junctional intercellular communication in human breast epithelial cells (Nomanta et al, 1996). Parallel with these observations, were studies by Montecino-Rodriguez and Dorshkind that reported regulation of hematopoiesis by gap junction intercellular communication (Montecio-Rodrigez et al, 2001). These correlative studies support additional potential mechanisms heptachlor could impact hematopoiesis. 
Environmental pesticide contamination. Environmental stability of chlordane and heptachlor demonstrates that contamination may result at all levels of the food chain by these pesticides. Plankton cultured in water with heptachlor resulted in high pesticide levels in bodies of crustaceans. Planktavivorious fish have high levels of heptachlor in tissues as a result of ingesting contaminated plankton and water (Ridal et al, 2001; Guruge et al, 2001). Since these pesticides are lipophillic in nature, they accumulate in adipose tissue of animals exposed (Senthilkumar et al, 2001). Endemic human populations that consume large amounts of fish and whale blubber, such as Inuit peoples, maintain high levels of organochlorine pesticides in blood and also in adipose tissue (Dewailly et al, 1999).

The most common route of human exposure to heptachlor is through oral ingestion, although inhalation or direct dermal absorption occurs when pesticides are applied to fields or buildings by individuals not wearing proper protective clothing. Exposure can occur when soil surrounding buildings previously treated with chlordane or heptachlor are disturbed. Heptachlor and chlordane have been detected in house dust of homes treated with these pesticides (Lewis et al, 1999). Studies have documented pesticide air levels in buildings that were treated with chlordane and heptachlor were above levels deemed safe by the Environmental Protection Agency (EPA) (Lewis et al, 1999). Contamination of public water sources with detectable levels of these pesticides have been documented repeatedly (DeLorenzo et al, 2001). The risk of human exposure to chlordane or heptachlor still exists due to the extreme stability of both pesticides in the environment. It is 
estimated that millions of homes and buildings in the United States alone have been treated with these pesticides (Office of Pesticide Programs, 1995). The risk of heptachlor and chlordane exposure to young children remains great because children may come in contact more with pesticides in soil and also ingest these pesticides through nursing (Dietert et al, 2000; Stuetz et al, 2001).

In 1983, the milk supply in Hawaii was significantly contaminated with heptachlor for 26 months (Le Marchand et al, 1986). This resulted from use of heptachlor-treated pineapple plants as feed for dairy cattle. Levels of heptachlor in

milk were above EPA guidelines and high levels of heptachlor were also detected in human breast milk. Pregnant women were at unusually high-risk because doctors had encouraged consumption of milk during the pregnancies. The developing fetus represents an unusually venerable target for organochlorine toxicity and long-term effects of this exposure have been investigated (Dietert et al, 2000; Barnett et al,1990a; Barnett et al, 1990b).

\section{Hematopoiesis.}

Hematopoiesis describes the development of functional blood cells, including immunocompetent cells, from pluripotential stem cells (Figure 2). It is necessary to understand the progressive sequence of stages involved in embryonic development that precedes and directly impacts immune function in order to understand the effects environmental agents have on immune system development and function (Landreth, 
Figure 2: Hematopoiesis. All blood cells develop from pluripotent stem cells. Progeny from these stem cells commit to either the myeloid or lymphoid lineage. B and $\mathrm{T}$ cells form from differentiation of lymphoid-committed stem cells. Myeloidcommitted stem cells differentiate into mature erythocytes, platelets, monocytes, neutrophils, eosinophils and basophils. 


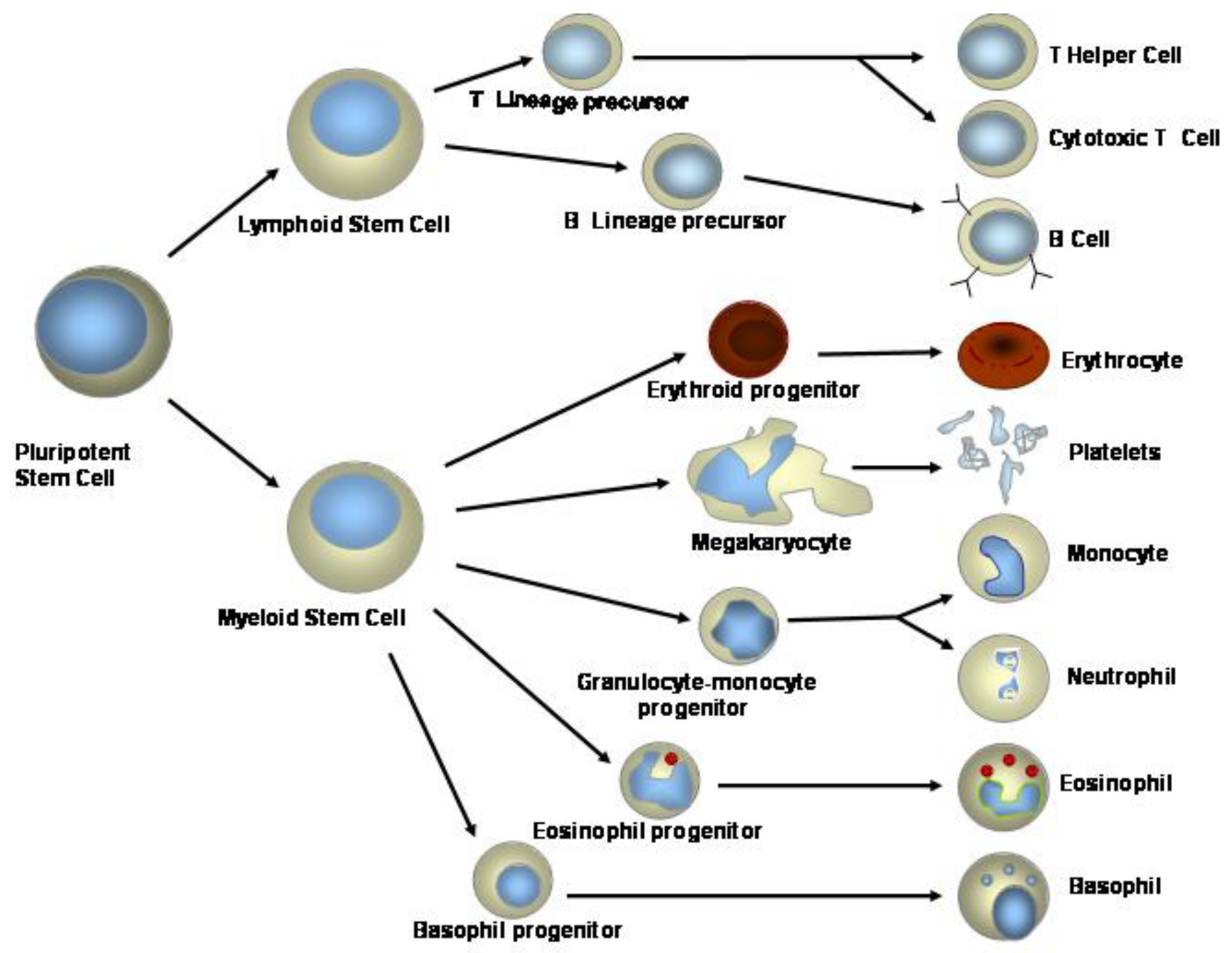

Figure 2: Hematopoiesis 
2002). The succession of events involved in embryonic blood cell development is well characterized, and the emergence and migration of cells through multiple tissue compartments of the embryo yields immune competent offspring (Landreth, 2002; Landreth and Dodson, 2004).

Developmental hematopoiesis. Although much of the initial studies which defined blood cell development were conducted in avian species, rodents rapidly replaced birds as the animal model of choice for studying development of the immune system (Glick et al, 1956; Cooper et al, 1965; Yoder MC, Dexter and Lajitha, 1974; Dorshkind and Witte, 1987; Whitlock and Witte, 1987; Dorshkind and Landreth, 1997; 2002; Smialowicz, 2004). Murine and human fetal hematopoiesis are similar, and mice have proven to be reliable models for studying embryonic development of the hematopoietic system (Ghia et al, 1998). Murine gestation is completed in a 21-day period, during which hematopoiesis migrates through several sites within developing embryos (Godin et al, 1999; Tavassoli, 1991). Murine embryonic hematopoiesis, depicted in Figure 3, begins multifocally in hemangioblasts, or blood islands of the yolk sac, and in the paraarotic spanchnopleura (P-Sp) (Ghatpande et al, 2002; Ling and Dzierzak, 2002). Extraembryonic cells from the yolk sac are capable of reconstituting an irradiated mouse but for only a short amount of time (Cumano et al, 2001b). Hematopoietic long-term repopulating cells (LTRCs) can be found within the P-Sp from day 7.5 to day 10 postcoitus (p.c.) (Cumano et al, 2001a; Cumano et al, 2001b). The P-Sp, the area of the embryo that comprises the dorsal aorta and surrounding mesoderm, is the location from which the aortogonadomesonephros 
Figure 3: Murine Developmental Hematopoiesis. Hematopoiesis stem cells arise in the AGM region approximately on day 7.5 of gestation and migrate into the fetal liver on day 10. Fetal liver is the chief compartment of embryonic hematopoiesis. Both the spleen and thymus are minor hematopoietic organs. Cells seed the bone marrow beginning on gestational day 17 and residing in this tissue for the life of the postnatal animal. 


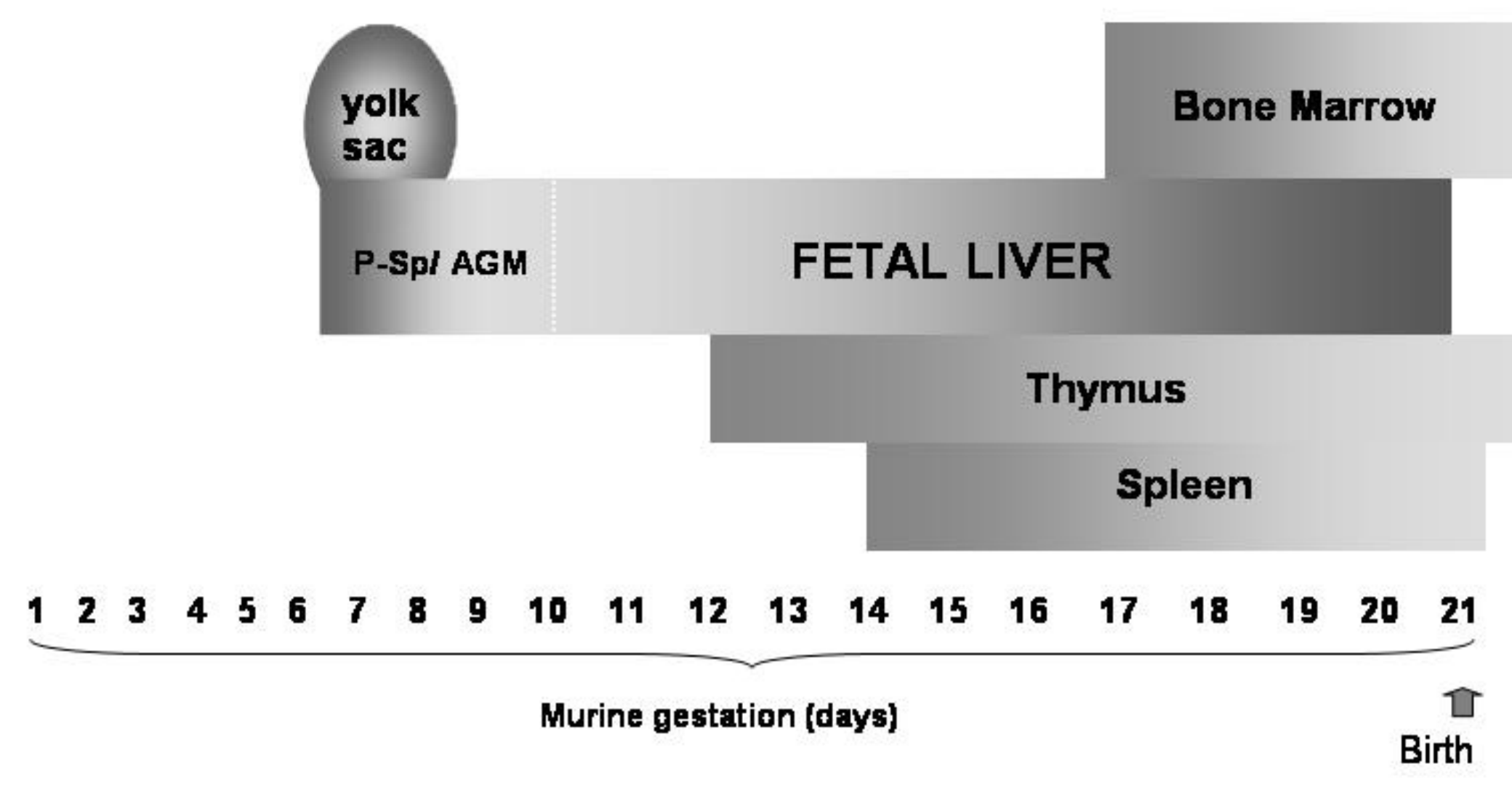

Figure 3: Murine Developmental Hematopoiesis 
(AGM) region develops (Cumano et al, 2001a; Cumano et al, 2001b; Ling and Dzierzak, 2002). The AGM region is where LTRCs are found after day 10 of gestation (Cumano et al, 2001a; Moore et al, 1970). Cells travel via the blood stream into the liver where hematopoiesis resides after day 10 for the majority of fetal development (Jordan et al, 1995; Weissman, 2000). Days 11 and 12 of gestation are characterized by extensive hematopoietic cell expansion (Cumano et al, 2001a). Fetal liver hematopoiesis then peaks around days 13 and 14 of development. In addition to fetal liver, the spleen also functions as a supplementary hematopoietic organ from day 15 of gestation until just after birth (Cumano et al, 2001a). After that hematopoietic cells begin seeding bone marrow approximately on day 17 of gestation (Sasaki and Sonoda, 2000). Bone marrow is the site of hematopoiesis after birth as the liver ceases to function as a hematopoietic organ into postnatal life (Cumano et al, 2001a).

Development of hematopoiesis resulting in immune competence represents an unusually venerable target for organochlorine toxicity (Dietert et al, 2000). Critical windows during murine development have been defined (Figure 4) (Diertert et al, 2000; Landreth and Dodson, 2004). The time period between days 7.5 and 10 of gestation are marked by stem cell formation. Expansion of progenitor cells along with cell migration through embryonic tissues occurs from gestational days 10 through 16. Maturation of the bone marrow compartment and the thymus occurs between days 17 and birth of the animal. Newborns mature until approximately postnatal day 30 when the immune system is fully competent. Finally, postnatal days 
Figure 4: Critical Windows in murine development. Five separate critical windows of hematopoiesis are defined for murine development. First, hematopoiesis is established between days 7 and 9 following conception. Days 9 to 16 of gestation are characterized by migration of hematopoietic stem cells into the fetal liver along with expansion of committed progenitor cells. Hematopoiesis is established in bone marrow and thymus from days 13 until after birth of the animal. Newborns, which are immune compromised, mature until approximately postnatal day 30 when cells of the immune system are fully competent. Finally, days 30 to 60 mark formation of memory cells of the immune system in these postnatal animals (Diertert et al, 2000). 


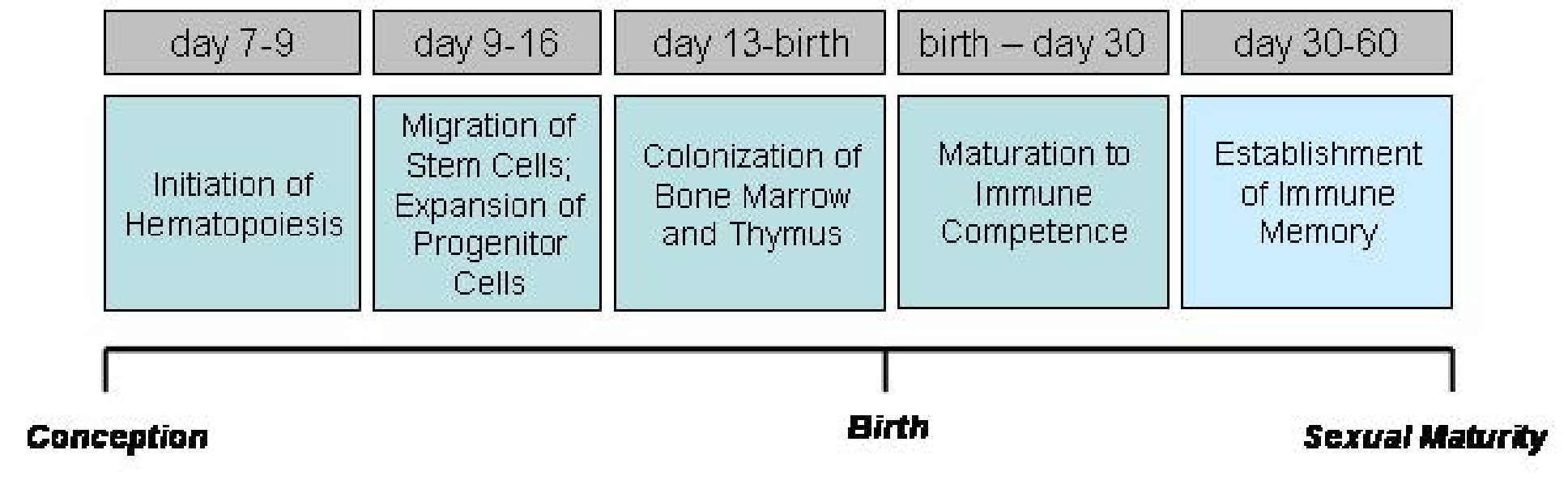

Figure 4: Critical Windows in murine development 
30 through 60 involve formation of memory cells, which provide long-term immunological protection (Landreth and Dodson, 2004).

Hematopoietic stem cells. Hematopoietic stem cells (HSC) are cells uncommitted to any one hematopoietic cell lineage (Smith et al, 1991; Morrison et al, 1995; Osawa et al, 1996; Dorshkind, 2002; Wright et al, 2001). Stem cells have two main characteristics. First, they are pluripotent with the ability to produce all other blood cells (Dexter 1987; Morrison et al, 1995). Secondly, stem cells are self-renewing and are responsible for repopulating the pool of mature cells (Potten and Loeffler, 1990; Jordan and Lemischka, 1990). Repopulation occurs through maintenance of an undifferentiated population of uncommitted HSC while a portion of the progeny from HSC cell divisions undergoes differentiation into progenitor cells of both myeloid and lymphoid lineages (Cooper at al, 1993). HSC are capable of sustaining long-term hematopoiesis in irradiated or otherwise immunocompromised animals whereas more mature cells cannot give rise to all cell types to repopulate all necessary cell populations (Quesenberry et al, 1998; Jordan et al, 1995). These stem cells originate in the P-Sp of the developing embryo and then migrate to the fetal liver after day 10 of gestation (Godin et al, 1999). Beginning on day 17 of gestation, hematopoietic stem cells seed the bone marrow microenvironment and produce all hematopoietic cell populations throughout postnatal animals (Jordan and Lemischka, 1990). It is estimated that hematopoietic stem cells comprise $0.05 \%$ of cells within the bone marrow compartment (Spangrude et al,1988). 
Hematopoietic progenitor cells. Lineage-committed progenitor cells are progeny from stem cells that have begun to differentiate into mature cells but are at early stages of cell development (Ling and Dzierzak, 2002). Progenitor cells differ from HSC by progressive loss of self-renewal capacity and by commencement of lineage commitment. Lymphoid and myeloid progenitor cells differentiate through a series of stages to form precursor cells, immature cells, and finally mature cells of the immune system. These mature effector cells, which have a finite lifespan, are continuously repopulated from committed progenitor cells to maintain hematopoietic homeostasis. Maturation of progenitor cells occurs in response to cytokine signals and physical interaction with supporting cells that direct progenitor cell development (Akashi et al, 1998). Progenitor cells are assayed using colony forming unit (CFU) assays in which hematopoietic cells are cultured in a semi-solid medium (Bradley et al, 1996). Cytokines are incorporated in these cultures that specifically stimulate proliferation of particular hematopoietic cell lineages.

Hematopoietic microenvironment. The hematopoietic microenvironment is comprised of nonhematopoietic cells, including endothelial cells, adipocytes, and fibroblasts, which support blood cell production (Lichtman, 1984; Klein, 1995). It is within this microenvironment that hematopoietic cells interact with stromal cells of the microenvironment to expand in number and differentiate to become functional end cells (Chen and Weiss, 1975). Survival, proliferation, and maturation of B lymphocytes depend on regulatory signals from cells of the bone marrow 
microenvironment (Johnson and Dorshkind, 1986; Schatz and Malissen, 2002; Borowski et al, 2002; Nutt et al, 1999). Adhesion molecules expressed on the surface of stromal cells and proximally released cytokines direct development of mature cells from early progenitor cells (Chen and Weiss, 1975; Dorshkind, 1990; Dorshkind et al, 1992). Regulation of hematopoiesis involves contact through cellular adhesion molecules, such as fibronectin, CD44, and VCAM-1, expressed on stromal cells and interacting receptors present on hematopoietic cells (Dorshkind, 1990; Dorshkind et al, 1992; Hall and Gibson, 2004). This binding interaction transfers signals via cell signaling molecules interacting with transmembrane receptors on hematopoietic cells to result in survival, proliferation, or differentiation of these cells. Cytokines produced by stromal cells regulate hematopoietic cell proliferation and differentiation (Kierney et al, 1987; Billips et al, 1992; Namen et al, 1998). Changes within the hematopoietic microenvironment resulting in alterations in cytokine production or adhesion molecule expression have the potential to alter hematopoiesis. Proliferation of lymphoid cells is dependent on the cytokine interleukin-7 (IL-7) in conjunction along with a series of co-stimulatory cytokines including insulin-like growth factor-1 (IGF-1) and interleukin-4 (IL-4) (Billips et al, 1992; Gibson, 1993; Akashi et al, 1998). Stem cell factor (SCF), also referred to as c-kit ligand, is expressed on stromal cells and interacts with the tyrosine kinase receptor c-kit expressed on hematopoietic cells. Mice lacking SCF or c-kit fail are deficient in fetal liver hematopoiesis (Nagasawa,1996). Expression of both the antiapoptotic gene $b c l-2$ and the pro-apoptotic gene bax found in pro-B cells is also regulated by interaction with stromal cells (Gibson, 1996). 


\section{Experimental Design.}

Due to the abundant application of heptachlor to buildings and crops, it has become necessary to investigate the potential effects of heptachlor on human health. Even though heptachlor production has halted in the United States, supplies of heptachlor were still utilized in other countries for many years (Office of Pesticide Programs, 1995). The vast amount of pesticide historically applied in combination with the persistent nature of this chemical, makes examination of heptachlor vital to supplement the minute sum of knowledge characterizing the toxicological effects of heptachlor. Neonates and children are two populations that are high risk groups for coming into contact with pesticides (Dietert et al, 2000). In the case of heptachlor exposure, fetuses were potentially exposed following contamination of the milk supply with heptachlor (Le Marchand et al, 1986). Unfortunately, children in Hawaii that were exposed in utero were not monitored. This terrible event in history created an indispensable requirement to examine effects of prenatal heptachlor exposure.

Our laboratory has extensive experience in studies of hematopoiesis, both in postnatal animals and in developing fetuses. We combined this interest with the desire to investigate the effect of heptachlor exposure on blood cell formation in developing embryos. The overall working hypothesis was that prenatal heptachlor exposure altered development of hematopoiesis. In addition to evaluating the effect of heptachlor in utero we also investigated specific cellular alterations which occurred following treatment of hematopoietic cells with heptachlor. 
The first goal of this project was to determine the effects of heptachlor on development of hematopoiesis. We investigated if heptachlor, similar to chlordane, altered hematopoiesis using a murine in utero exposure model. Pregnant dams were administered heptachlor and myeloid and lymphoid cells were examined from the embryos. CFU assays were employed in these in vivo studies to enumerate myeloid and lymphoid progenitor cells in comparing control and heptachlor-exposed embryos.

The second project goal was to determine the direct effects of heptachlor on lymphoid cells. We examined if altered lymphopoiesis observed in embryos exposed in utero to heptachlor were due to direct effects of the pesticide on lymphoid cells. It is essential for hematopoietic cells to survive, expand and mature to functional cells of the immune system. Using these fundamental properties of hematopoietic cells, we evaluated cell survival, proliferation, and differentiation of lymphoid cells following direct exposure to heptachlor. Through proliferation and cell viability assays, we examined two lymphoid cells lines: $70 Z / 3$, a pre-B cell line, and C1.92, a pro-B cell line. Both of these cell lines have been thoroughly characterized and represent two different stages of B cell development (Paige et al, 1978; Mains and Siley, 1983; Giri et al, 1984; Gibson et al, 1993; Gibson et al, 1996).

The third goal of this dissertation project was to determine the effects of heptachlor on cells of the hematopoietic microenvironment. The hematopoietic microenvironment consists of stromal cells that, through production of cytokines and expression of adhesion molecules, function to regulate hematopoietic progenitor cell 
survival, proliferation, and maturation (Schatz and Malissen, 2002; Borowski et al, 2002; Nutt et al, 1999). Damage to the capacity of stromal cells to support blood cell development would disrupt hematopoietic homeostasis. S10, a well-characterized stromal cell line, was evaluated for ability to support pro-B cell survival and proliferation along with cytokine production subsequent to in vitro heptachlor exposure (Collins and Dorshkind, 1987; Landreth and Dorshkind, 1988; Henderson et al, 1990).

The fourth and final project goal was to determine the mechanism of heptachlor hematotoxicity. Lymphoid cells and stromal cells were examined for altered cell signaling as a result of exposure to heptachlor. Pre-B cells were induced to differentiate, as demonstrated by increased kappa light chain surface expression. The transcription regulator nuclear factor kappa B (NF-kB) directly controls kappa light chain gene transcription (Sen and Baltimore, 1986a; Sen and Baltimore, 1986b; Sen and Baltimore, 1987). Upon examination of heptachlor-exposed pre-B cells, we determined that signaling by NF-kB was increased in these cells. These data examining $70 Z / 3$ pre-B cells brought us to hypothesize that heptachlor may affect NF-kB signaling in other cells. Protein collections of nuclear and cytoplasmic cell fractions were examined after heptachlor treatment for levels of NF-kB protein using immunoblotting and ELISA assays. Taken together, these studies have contributed to a unifying hypothesis of the effect of heptachlor on hematopoietic cell development. 


\section{References}

Akashi, K, K Motonari, I Weissman. 1998. Role of interleukin-7 in T-cell development from hematopoietic stem cells. Immunol Rev 165:13.

Barnett, JB. 1997. Age-related susceptibility to immunotoxicants: animal data and human parallels. Environ Toxicol Pharm. 4:315.

Barnett, JB, KE Rodgers. 1994. Pesticides: In Immunotoxicology and Immunopharmacology, $2^{\text {nd }}$ edition, JH Dean, MI Luster, AE Munson, and I Kimber (eds), Raven Press, New York. p.191.

Barnett, JB, LF Gibson, KS Landreth. 2004. Developmental Immunotoxicity of Chlordane: In Developmental Toxicology, SD Holladay (ed). CRC Press, Boca Raton.

Barnett, J, L Soderberg, J Menna. 1985. The effect of prenatal chlordane exposure on the delayed hypersensitivity response of BALB/c mice. Toxicol Lett 25:173.

Barnett, J, B Blaylock, J Gandy, J Menna, R Denton, L Soderberg. 1990a. Long-term alteration of adult bone marrow colony formation by prenatal chlordane exposure. Fund Appl Toxicol 14:688.

Barnett, J. B Blaylock, J Gandy, J Menna, R Denton, L Soderberg. 1990b. Short Communication: Alteration of fetal liver colony formation by prenatal chlordane exposure. Fund Appli Toxicol 15:820. 
Billips, L, D Petitte, K Dorshkind, R Narayanan, C Chiu, K Landreth. 1992. Differential roles of stromal cells, interleukin-7, and kit-ligand in the regulation of $B$ lymphopoiesis. Blood 79(5):1185.

Blaylock BL, L Soderberg, J Gandy, J Menna, R Denton, J Barnett. 1990. Cytotoxic T-lymphocyte and NK responses in mice treated prenatally with chlordane. Toxicol Lett 51(1):41.

Blyer, G, KS Landreth, and JB Barnett. 1994. Gender-specific effects of prenatal chlordane exposure on myeloid cell development. Fund Appl Toxicol 23:188.

Borowski, C, C Martin, F Gaunari, L Haughn, I Aifantis, F Grassi, H von Boehmer. 2002. On the brink of becoming a T cell. Curr Opin Immunol 14:200.

Bradley, T, D Metcalf.1966. The growth of bone marrow cells in vitro. Aust J Exp Biol Med Sci 44:287.

Chen LT, L Weiss. 1975. The development of vertebral bone marrow of human fetuses. Blood 46:389.

Chuang, L, Y Liu, K Killam Jr, R Chuang. 1992. Modulation by the insecticides heptachlor and chlordane of the cell-mediated immune proliferative responses of Rhesus monkeys. In vivo 6:29.

Chuang, L, S Rought, R Chuang. 1999. Differential regulation of the major cyclindependent kinases, cdk2 and cdc2 during cell cycle progression in human lymphocytes exposed to heptachlor. In vivo 13:455.

Collins, L, and K Dorshkind. 1987. A stromal cell line from myeloid long-term bone marrow cultures can support myelopoiesis and B lymphopoiesis. J Immunol 138(4):1982. 
Cooper, E, C Muller-Sieburg, G Spangrude. 1993. Stem Cells: In Developmental Immunology, EL Cooper and E Nisbet-Brown, Oxford University Press, New York. p.177.

Cooper MD, Peterson RDA, Good RA. 1965. Definition of the thymic and bursal lymphoid systems in the chicken. Nature 205:143.

Cumano, A, and I Godin. 2001a. Pluripotent hematopoietic stem cell development during embryogenesis. Curr Opin Immunol 13:166.

Cumano, A, C Ferraz, M Klaine, J Santo, I Godin. 2001b. Intraembryonic, but not yolk sac hematopoietic precursors, isolated before circulation, provide long-term multilineage reconstitution. Immunity 15:477.

DeLorenzo, M, G Scott, P Ross. 2001. Toxicity of pesticides to aquatic microorganisms: A review. Environ Toxicol Chem 20(1):84.

Dewailly, E, G Mulvad, H Pedersen, P Ayotte, A Demers, J Weber, J Hansen. 1999. Concentration of organochlorines in human brain, liver, and adipose tissue autopsy samples from Greenland. 107(10):823.

Dexter, TM. 1987. Stem Cells in normal growth and disease. $\mathrm{Br}$ Med J 295(6607):1192.

Dexter, T, L Lajtha. 1974. Proliferation of haemopoietic stem cells in vitro. Brit J Haematol 28:525.

Dietert, R, R Etzel, D Chen, M Halonen, S Holladay, A Jarabek, K Landreth, D Peden, K Pinkerton, R Smialowicz, T Zoetis. 2000. Workshop to identify critical windows of exposure for children's health: Immune and respiratory systems work group summary. Environ Health Perspect 108(3):483. 
Dorshkind, K. 1990. Regulation of hemopoiesis by bone marrow stromal cells and their products. Annual Rev Immunol 8:111.

Dorshkind, K. 2002. Multilineage development from adult bone marrow cells. Nature Immunol 3(4):311.

Dorshkind, K, K Landreth. 1992. Regulation of B cell differentiation by bone marrow stromal cells. Internat J Cell Clon 10:12.

Dorshkind, K, K Landreth. 1997. The Immunology Methods Manual: 11.5 Use of longterm bone marrow cultures and cloned stromal cell lines to grow $B$ lineage cells. Academic Press Ltd.

Dorshkind, K, O Witte. 1987. Long-term murine hemopoietic cultures as model systems for analysis of B lymphocyte differentiation. Current Topics Microbiol Immunol 135:25.

Furie, B, and S Trubwitz. 1976. Insecticides and blood dyscrasias: Chlordane exposure and self-limited refractory megaloblastic anemia. JAMA. 235:1720.

Ghatpande, S, A Ghatpande, J Sher, MH Zile, T Evans. Retoid signaling regulates primitive (yolk sac) hematopoiesis. Blood 99(7):2379.

Ghia, P, E Boekel, A Rolink, F Melchers. 1998. B-cell development: a comparison between mouse and man. Immunol Today 19(10):480.

Gibson, LF, D Piktel, KS Landreth. 1993. Insulin-like growth factor-1 potentiates expansion of interleukin-7-dependent pro-B cells. Blood 82(10):3005.

Gibson, L, D Piktel, R Narayanan, G Nunez, K Landreth. 1996. Stromal cells regulate bcl-2 and bax expression in pro-B cells. Exp Hematol 24:628. 
Giri JG, Kincade PW, Mizel SB. 1984. Interleukin 1-mediated induction of kappa-light chain synthesis and surface immunoglobulin expression on pre-B cells. J Immunol 132(1):223.

Glick B, TS Chang, RG Jaap. 1956. The bursa of Fabricius and antibody production in the domestic fowl. Poultry Sci 35:224.

Godin, I, J Garcia-Porrero, F Dieterlen-Lievre, A Cumano. 1999. Stem cell emergence and hemopoietic activity are incompatible in mouse intraembryonic sites. J Exp Med 190(1):43.

Guruge, K, S Tanabe. 2001. Contamination by persistent organochlorines and butyltin compounds in the West Coast of Sri Lanka. Marine Poll Bull 42:179.

Hall, BM, LF Gibson. 2004. Regulation of lymphoid and myeloid leukemic cell survival: role of stromal cell adhesion molecules. Leuk Lymphoma 45(1):35.

Henderson, AJ, A Johnson, K Dorshkind. 1990. Functional characterization of two stromal cell lines that support B lymphopoiesis. J Immunol 145(2):423.

IARC Monographs Evaluating Carcinogenic Risks in Humans. 1991. Chlordane and heptachlor. 53: 115.

Infante, P, and W Newton, Jr. 1975. Letter: Prenatal chlordane exposure and neuroblastoma. New Eng J Med 293(6):308.

Johnson, A, K Dorshkind. 1986. Stromal cells in myeloid and lymphoid long-term bone marrow cultures can support multiple hemopoietic lineages and modulate their production of hemopoietic growth factors. Blood 68(6):1348. 
Johnson K, M Holsapple, A Munson. 1986. An immunotoxicological evaluation of gamma-chlordane. Fundam Appl Toxicol 6(2):317.

Jordan CT, IR Lemischka. 1990. Clonal and systemic analysis of long-term hematopoiesis in the mouse. Genes Dev 4(2):220.

Jordan CT, CM Astle, J Zawadzki, K Mackarehtschian, IR Lemischka, DE Harrison. 1995. Long-term repopulating abilities of enriched fetal liver stem cells measured by competitive repopulation. Exp Hematol 23:1011.

Jordan, CT, IR Lemischka. 1990. Clonal and systemic analysis of long-term hematopoiesis in the mouse. Genes Dev 4(2):220.

Kierney, P, K Dorshkind. 1987. B lymphocyte precursors survive in diffusion chamber cultures but $B$ cell differentiation requires close association with stromal cells. Blood 70:1418.

Klein, G. 1995. The extracellular matrix of the hematopoietic microenvironment. Experientia 51:914.

Landreth, KS. 2002. Critical windows in development of the rodent immune system. Human and Exp Toxicol 21:493.

Landreth,KS, SVM Dodson. 2004. The Rodent Immune System: In Developmental Toxicology, SD Holladay (ed). CRC Press, Boca Raton, p.1.

Landreth, K, K Dorshkind. 1988. Pre-B cell generation potentiated by soluble factors from a bone marrow stromal cell line. J Immunol 140(3);845. 
Le Marchand, L, L Kolonel, B Siegel, W Dendle III. 1986. Trends in birth defects for a Hawaiian population exposed to heptachlor and for the United States. Arch Environ Health 41(3):145.

Lewis, R. C Fortune, R Willis D Camann, J Antley. 1999. Distribution of pesticides and polycyclic aromatic hydrocarbon in house dust as a function of particle size. Environ Health Perspect 107(9):721.

Lichtman, M. 1984. The relationship of stromal cells to hemopoietic cells in marrow. Kroc Found Ser 18:3.

Ling, KW, E Dzierzak. 2002. Ontogeny and genetics of the hemato/lymphopoietic system. Curr Opinion Immunol 14(2):186.

Mains P, C Sibley. 1983. LPS-nonresponsive variants of mouse B cell lymphoma, 70Z/3: isolation and characterization. Cell Genet 9(6):699.

Moore, M., and D Metcalf. 1970. Ontogeny of the haemopoietic system: yolk sac origin of in vivo and in vitro colony forming cells in the developing mouse embryo. Brit J Haemetol 18:279.

Montecino-Rodriguez, E, K Dorshkind. 2001. Regulation of hematopoiesis by gap junction-mediated intercellular communication. J Leukoc Biol. 70(3):341.

Morrison, SJ, N Uchida, IL Weissman. 1995. The biology of hematopoietic stem cells. Annu Rev Cell Dev Biol 11:35. 
Nagasawa, T, S Hirota, K Tachibana, N Takakura, S Nishikawa, Y Kitamura, N Yoshida, H Kikutani, T Kishimoto.1996. Defects of B-cell lymphopoiesis and bonemarrow myelopoiesis in mice lacking the CXC chemokine PBSF/SDF-1. Nature 382(6592):635.

Namen, A, S Lupton, K Hjerrild, J Wignall, D Mochizuki, A Schmierer, B Mosley, C March, D Urdal, S Gullis, D Cosman, R Goodwin. 1998. Stimulation of B-cell progenitors by cloned murine interleukin-7. Nature 333(9):571.

Nomata, K, K Kang, T Hayashi, D Matesic, L Lockwood, C Chang, J Trosko. 1996. Inhibition of gap junctional intercellular communication in heptachlor and heptachlor epoxide-treated normal human breast epithelial cells. Cell Biol Toxicol 12:69.

Nutt, SL, AG Rolink, M Busslinger. 1999. The molecular basis of B-cell lineage commitment In: Symposium on Quantitaive Biology. Volume LXIV. Cold Spring Harbor. pp. 51.

Office of Pesticide Programs. 1995. Internal Pesticide Notice. US Environmental Protection Agency.

Osawa, M, K Hanada, H Hamada, H Nakauchi. 1996. Long-term lymphohematopoietic reconstitution by a single CD34-low/ negative hematopoietic stem cell. Science 273(5272):242.

Page, C, P Kincade, P Ralph. 1978. Murine B cell leukemia line with inducible surface immunoglobulin expression. J Immunol 121(2):641. 
Potten, CS, M Loeffler. 1990. Stem Cells: attributes, cycles, spirals, pitfalls and uncertainties. Lessons for and from the crypt. Development 110(4):1001.

Quesenberry PJ, Becker P, Stewart FM. 1998. Phenotype of the engrafting stem cell in mice. Stem Cells 16(Suppl 1):33.

Ridal, J, A Mazumder, D Lean. 2001. Effects of nutrient loading and planktivory on the accumulation of organochlorine pesticides in aquatic food chains. Environ Toxicol Chem 20(6):1312.

Rought, S, P Yau, L Chuang, R Doi, R Chuang. 1999. Effect of the chlorinated hydrocarbons heptachlor, chlordane, and toxaphene on retinoblastoma tumor suppressor in human lymphocytes. Toxicol Lett 104:127.

Rought, S, P Yau, X Guo, L Chuang R Doi, R Chuang. 2000. Modulation of CPP32 activity and induction of apoptosis in human CEM $\times 174$ lymphocytes by heptachlor, a chlorinated hydrocarbon insecticide. J Biochem Molecul Toxicol 14(1):42.

Sasaki K, Y Sonoda. 2000. Histometrical and three-dimensional analyses of liver hematopoiesis in the mouse embryo. Arch Histol Cytol 63:137.

Schatz, DG, B Malissen. 2002. Lymphocyte development. Curr Opin Immunol 14:183.

Sen, R, D Baltimore. 1986a. Inducibility of kappa immunoglobulin enhancer-binding protein NF-kB by a posttranslational mechanism. Cell 47:921.

Sen R, D Baltimore.1986b. Multiple nuclear factors interact with the immunoglobulin enhancer sequences. Cell 46(5):705. 
Sen R, D Baltimore. 1987. In vitro transcription of immunoglobulin genes in a B-cell extract: effects of enhancer and promoter sequences. Mol Cell Biol 7(5):1989.

Senthilkumar, K, K Kannan, A Subramanian, S Tanabe. 2001. Accumulation of organochlorine pesticides and polychlorinated biphenyls in sediments, aquatic organisms, birds, bird eggs, and bats collected from South India. Environ Sci Pollut Res 8:1.

Smialowicz, RJ. 2004. The Rat as a Model for Developmental Immunotoxicology: In Developmental Immunotoxicology, SD Holladay (ed). CRC Press, Boca Raton.

Smialowicz, R, W Williams, C Copeland, M Harris, D Overstreet, B Davis, and R Chapin. 2001. The effects of perinatal/juvenile heptachlor exposure on adult immune and reproductive system function in rats. Toxicol Sci 61:164.

Smith, LG, IL Weissman, S Heimfeld. 1991. Clonal analysis of hematopoietic stemcell differentiation in vivo. Proc Natl Acad Sci USA 88(7):2788.

Sprangrude, G, S Heimfeld, I Weissman. 1988. Purification and characterization of mouse hematopoietic stem cells. Science 59:58.

Spyker-Cranmer, J, J Barnett, D Avery, M Cranmer. 1982. Immunoteratology of Chlordane: Cell-mediated and humoral immune responses in adult mice exposed in utero. Toxicol Appl Pharmacol 62:402.

Stuetz, W, T Prapamontol, J Erhardt, H Classen. 2001. Organochlorine pesticide residues in human milk of a Hmong hill tribe living in Northern Thialand. Sci Total Environ 273:53.

Tavassoli, M. 1991. Embryonic and fetal hemopoiesis: An overview. Blood Cells 17(2):282. 
Theus, S, D Tabor, L Soderberg and J Barnett. 1992. Macrophage tumoricidal mechanisms are selectively altered by prenatal chlordane exposure. Agents Actions. $37: 140$.

Weissman, I. 2000. Stem cells: Units of development, units of regeneration and units in evolution. Cell 100:157.

Whitlock, C, O Witte. 1987. Long-term culture of murine bone marrow precursors of $B$ lymphocytes. Meth Enzymol. 150:275.

Wright, DE, AJ Wagers, AP Gulati, FL Johnson, IL Weissman. 2001. Science 294(30):1933.

Yamaguchi, I, F Matsumura, A Kadous.1980. Heptachlor epoxide: Effects on calcium-mediated transmitter release from brain synaptosomes in rat. Tech Pharmacol 29:1815.

Yoder MC. 2002. Embryonic hematopoiesis in mice and humans. Acta Paediatr Suppl 91(438):5. 
CHAPTER 2: Prenatal Heptachlor Exposure Alters

Lymphoid But Not Myeloid Cell Development 


\begin{abstract}
Hematotoxicity has been documented in adults exposed to high levels of organochlorine pesticides. We have evaluated the effects of heptachlor on the developing murine immune system using an in utero exposure model. Pregnant mice were fed $24 \mathrm{mg} / \mathrm{kg}$ of heptachlor orally using two exposure regimens. In the first dosing schedule, heptachlor exposure was concentrated on gestation prior to migration of hematopoiesis to the fetal liver. In the second dosing regimen, heptachlor exposure began on gestational day 12. Fetal livers from heptachlor or control embryos were removed and evaluated on day 17 of gestation.
\end{abstract}

Lymphoid and myeloid progenitor cells were enumerated in embryonic liver of mice exposed to heptachlor in utero. Heptachlor did not alter myeloid progenitor cell numbers with either dosing regimen. However, exposure of dams to heptachlor after the migration of hematopoiesis to fetal liver resulted in increased numbers of lymphoid progenitor cells as measured by colony forming cell assays and also limiting dilution IL-7-responsive cell assays. Exposure of dams to heptachlor beginning on gestational day 6 did not alter subsequent migration or expansion of these cells in fetal liver. These data suggest that embryonic mice are particularly susceptible to heptachlor toxicity as these cells establish and expand in the fetal liver microenvironment. 


\section{Introduction}

Heptachlor is a cyclodiene insecticide used for many years in structural preservation against termite damage and for crop protection. It is a long-lived compound with a half-life in soil of 20 to 30 years (Agency for Toxic Substances and Disease Registry, 1992). Application of heptachlor to pineapple fields and subsequent feeding of crop silage to dairy cattle resulted in contaminated milk supplies in Hawaii for more than two years (Baker et al, 1991). During this time, many children were exposed to heptachlor in utero through the consumption of contaminated milk by pregnant women (Le Marcchand et al, 1986). The purpose of the current study was to evaluate the hematotoxicity that results from prenatal heptachlor exposure.

Related studies examining the effects of chlordane, a similar organochlorine compound, demonstrated that exposure of adult mice did not result in immunotoxicity. However, prenatal in utero exposure to chlordane resulted in stem cell deficiencies and alterations of leukocyte function (Barnett et al, 1985; Barnett et al, 1990a; Barnett et al, 1990b; Barnett et al, 1997). Several studies involving in utero murine exposure to chlordane have demonstrated immunotoxicity of the pesticide. The tumoricidial capababilities of macrophages from mice exposed to chlordane in utero are delayed (Theus et al, 1992). When embryos were exposed to chlordane $(4 \mathrm{mg} / \mathrm{kg}$ and $8 \mathrm{mg} / \mathrm{kg}$ of mouse weight) and the postnatal animals evaluated at 100 days of age, depressed delayed-type hypersensitivity reactions 
(DTH) were measured by ear swelling after topical exposure to a non-specific allergen (Barnett et al, 1985; Spyker-Cranmer et al, 1982). Stem cells were reduced in postnatal mice that were exposed to chlordane in utero as measured by colony formation unit in the spleens (CFU-S) (Barnett et al, 1990a; Barnett et al, 1990b). This reduction in stem cells was found in both postnatal mice at 100 and 200 days of age. These studies demonstrated long-lasting immunotoxicity in developing embryos exposed to chlordane.

In the current study, heptachlor was administered orally to pregnant mice beginning either before or after day 10 of gestation when hematopoiesis is established in fetal liver. The purpose of two dosing regimes was to ascertain if the window of heptachlor exposure affected hematopoiesis in the developing embryo. In preliminary studies, heptachlor was administered to pregnant dams beginning on day 10 of gestation and these studies consistently revealed changes in the population of lymphoid, but not myeloid, progenitor cells (data not shown). Even though lymphoid progenitor cells were consistently different from control groups, some experiments yielded increases and others yielded decreases in lymphoid cell numbers. We hypothesized that these contradictory data were the result of different initiation coitus times, resulting from a 12 hour breeding allowance. In addition, data presented here revealed that this time period during establishment of fetal murine hematopoiesis is critical to development of hematopoiesis. 


\section{Materials and Methods}

Cell culture conditions: Standard cell culture medium used in all studies is $\alpha-$ modification of Eagle's medium ( $\alpha-M E M)$ (Mediatech, Inc., Herndon,VA) with $5 \%$ fetal bovine serum (FBS) (Summit, Collins, CO; Lot \# 30P41), 1\% penicillin/ streptomycin, $1 \%$ I-glutamine, and $0.1 \% 2$-mercaptoethanol. Cultures were incubated at $37^{\circ} \mathrm{C}$ in a humidified incubator at $6 \% \mathrm{CO}_{2}$. Cells were diluted in counting fluid $(2 \%$ acetic acid with $0.01 \%$ methylene blue) and enumerated using a hemocytometer.

Heptachlor exposure animal model: Female 8-week old BALB/c female and male mice (Taconic Laboratories, Germantown, NY) were housed in separate husbandry rooms. Estrous cycles of female mice were synchronized to obtain maximal number of timed-pregnancies by introducing male cages into the female husbandry room 72 hours prior to mating. Male mice were housed with female mice for 18 hours. Pregnant mice were identified by appearance of vaginal plugs following copulation. Pregnant mice were divided into two groups with both groups containing at least 3 mice. Dams were administered $0.3 \mathrm{mls}$ of peanut butter containing either heptachlor (Chem Service, West Chester, PA) diluted in peanut oil (Planters, East Hanover, NJ) or an equivalent volume of peanut oil once daily. On the day of evaluation, dams were euthanized via cervical dislocation and embryos removed by caesarian collection. Pregnant dams in all experiments held at least five embryos. 
Heptachlor in vivo dosing schedules: Heptachlor was administered to pregnant dams utilizing two different dosing schemes (A and B), as indicated in Figure 1. All mice exposed, regardless of dosing schedule, received a total of $24 \mathrm{mg}$ of heptachlor per $\mathrm{kg}$ of mouse weight or an equivalent volume of the vehicle, peanut oil. Dose A targeted heptachlor exposure to the time of initiation of hematopoiesis in the embryo, while Dose B incorporated the largest amount administered as hematopoiesis established in the fetal liver. Dose A consisted of administration of $8 \mathrm{mgs}$ of heptachlor per kg of mouse weight on days 6 and 7 post coitus (pc) followed by 0.9 mgs per $\mathrm{kg}$ weight on days 8 to $16 \mathrm{pc}$. Dose $\mathrm{B}$ consisted of $8 \mathrm{mgs}$ per $\mathrm{kg}$ doses on days 12 and 13 pc followed by 2.7 mgs per kg weight given on days 14 to 16 pc.

Fetal liver cell preparation: Fetal livers were collected from individual embryos and each separately dispersed into single-cell suspensions by pushing livers through sterile 0.5-micron mesh (USA Scientific Laboratories, Rochester, NJ). Single-cell suspensions of fetal liver cells were then introduced into colony forming unit (CFU) assays for enumeration of lymphoid and myeloid progenitor cells.

Colony forming unit (CFU) assays: CFU assays were utilized to enumerate numbers of lymphoid and myeloid progenitor cells that proliferate in response to cytokines (Bradley et al, 1966). Fetal liver cells $\left(2.0 \times 10^{5} / \mathrm{ml}\right)$ were cultured in Iscove's media with 15\% FBS, 1\% penn/strep, $1 \%$ I-glutamine, $0.1 \% 2-\mathrm{ME}$, and $1 \%$ methylcellulose. CFU cultures had recombinant murine granulocyte-macrophage colony stimulating factor (rGM-CSF, $40 \mathrm{ng} / \mathrm{ml}$ ), recombinant murine interleukin-3 
(rlL-3, $40 \mathrm{ng} / \mathrm{ml}$ ), or recombinant murine interleukin-7 (rlL-7, $20 \mathrm{ng} / \mathrm{ml}$ ) (Biosource International, Camarillo, CA) added to the medium in CFU-GM, CFU-IL-3, and CFUIL-7 assays, respectively. Recombinant murine stem cell factor ( $\mathrm{rSCF}, 50 \mathrm{ngs} / \mathrm{ml}$ ) (Biosource International, Camarillo, CA) was added to both cytokine groups. Control cultures with no added cytokine established background colony formation in the assays without exogenous cytokine stimulation. Colonies were counted after 7 days in culture using a dissecting light microscope.

Lymphoid limiting dilution assay: One day prior, S10, a cloned stromal cell line (Landreth and Dorshkind, 1988) was plated at 50\% confluency in 96 well flat-bottom plates containing $\alpha$-MEM with $5 \%$ serum, $1 \%$ penn/strep, $1 \%$ I-glutamine, and $0.1 \%$ 2-ME. rlL-7 was added to a final concentration of $25 \mathrm{ngs} / \mathrm{ml}$. An additional 25 ngs/ml rlL-7 was added every other day of culture. Wells were examined under a tissue-culture microscope for positive or negative colony expansion after 5 days in culture.

Statistical Analysis: Data were analyzed using Instat statistical software (GraphPad Software, Inc., San Diego, CA). Data are presented from representative experiments with means \pm standard errors of the means (SEMs). One-way ANOVA and student's T-test were utilized to determine statistical significance between groups. Statistical significance was determined by $p$ values less than 0.05 . 


\section{Results}

\section{Prenatal heptachlor exposure did not alter fetal liver cellularity.}

The fetal liver is the main compartment of hematopoiesis during development. Following exposure to heptachlor from day 6 to day 16 pc (Figure 1: Dose A) or day 12 to day 16 pc (Figure1: Dose B), the total cellularity was evaluated for individual murine fetal livers. Fetal liver cells were separated into single cell suspensions before enumeration with a hemocytometer. After Dose A, fetal liver cell counts from control embryos $(n=6)$ had a mean of $44.3 \times 10^{6}$ cells $(\mathrm{SEM} \pm 2.96)$ and embryos exposed to heptachlor $(n=5)$ had a mean of $48.3 \times 10^{6}$ cells (SEM \pm 2.91$)$ (Figure 2$)$. Following Dose $B$, fetal liver cellularity from control embryos $(n=6)$ had a mean of $45.0 \times 10^{6}$ cells $(S E M \pm 1.73)$ and heptachlor-exposed embryos had a mean of $42.3 \times$ $10^{6}$ cells (SEM \pm 1.86 ) (Figure 2). No statistical differences were noted in the numbers of fetal liver cells from heptachlor or vehicle-treated embryos for either of the heptachlor administration schedules.

Prenatal heptachlor exposure resulted in no differences in numbers of myeloid progenitor cells.

In order to examine the potential of myeloid cells to proliferate in response to myeloid-lineage specific cytokines, fetal liver cells were cultured with the cytokines GM-CSF or IL-3 as described. No differences were observed between numbers of 


\section{Figure 1: Heptachlor dosing schedules.}

Heptachlor was administered to embryos in utero to separate groups of BALB/c mice using two dosing regimens. The pregnant mice orally received the same amount of total heptachlor in both dosing regiments. Dose A consisted of $8 \mathrm{mgs} / \mathrm{kg}$ mouse weight administered on days 6 and 7 pc followed by $0.9 \mathrm{mgs} / \mathrm{kg}$ on days 8 to 16 postcoitus (pc). Dose B consisted of an $8 \mathrm{mgs} / \mathrm{kg}$ of mouse weight on days 12 and $13 \mathrm{pc}$ followed by $2.7 \mathrm{mgs} / \mathrm{kg}$ given on days 14 to $16 \mathrm{pc}$. Control mice received the equivalent volume of vehicle (peanut oil). $E=$ Evaluation of fetal livers 


\title{
Murine Gestational Timeline
}

\author{
(days post coitus)
}

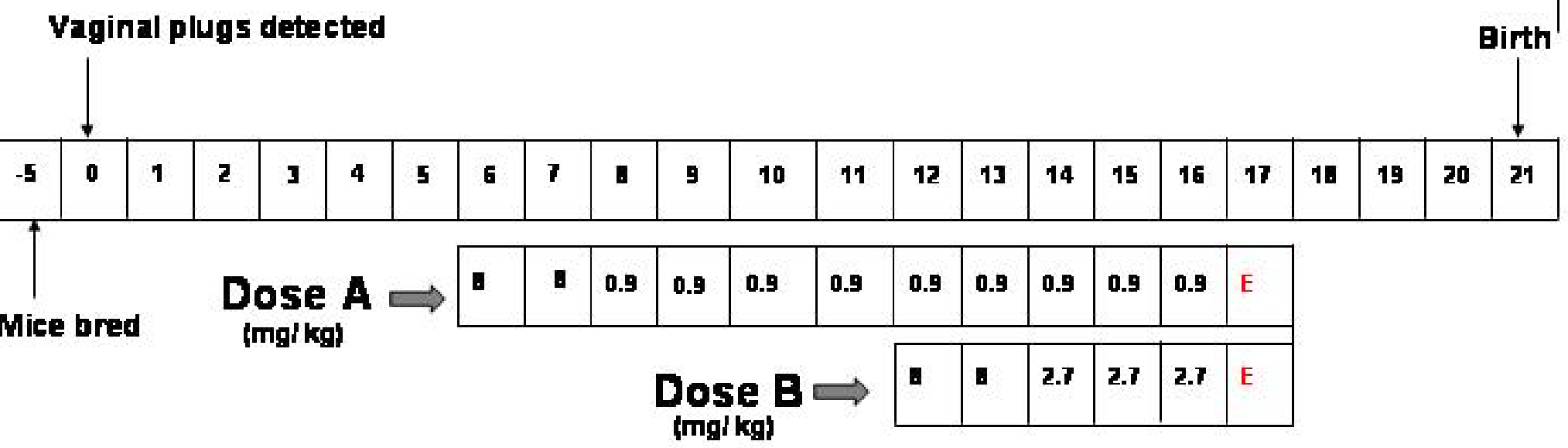

Figure 1: Heptachlor dosing schedules 
Figure 2: Prenatal heptachlor exposure did not affect cellularity of fetal livers.

Following exposure to heptachlor from day 6 to day $16 \mathrm{pc}$ (Dose A) or day 12 to day 16 pc (Dose B), pregnant dams were euthanized and total cellularity of livers from individual embryos were evaluated. Data presented are representative of one experiment. 


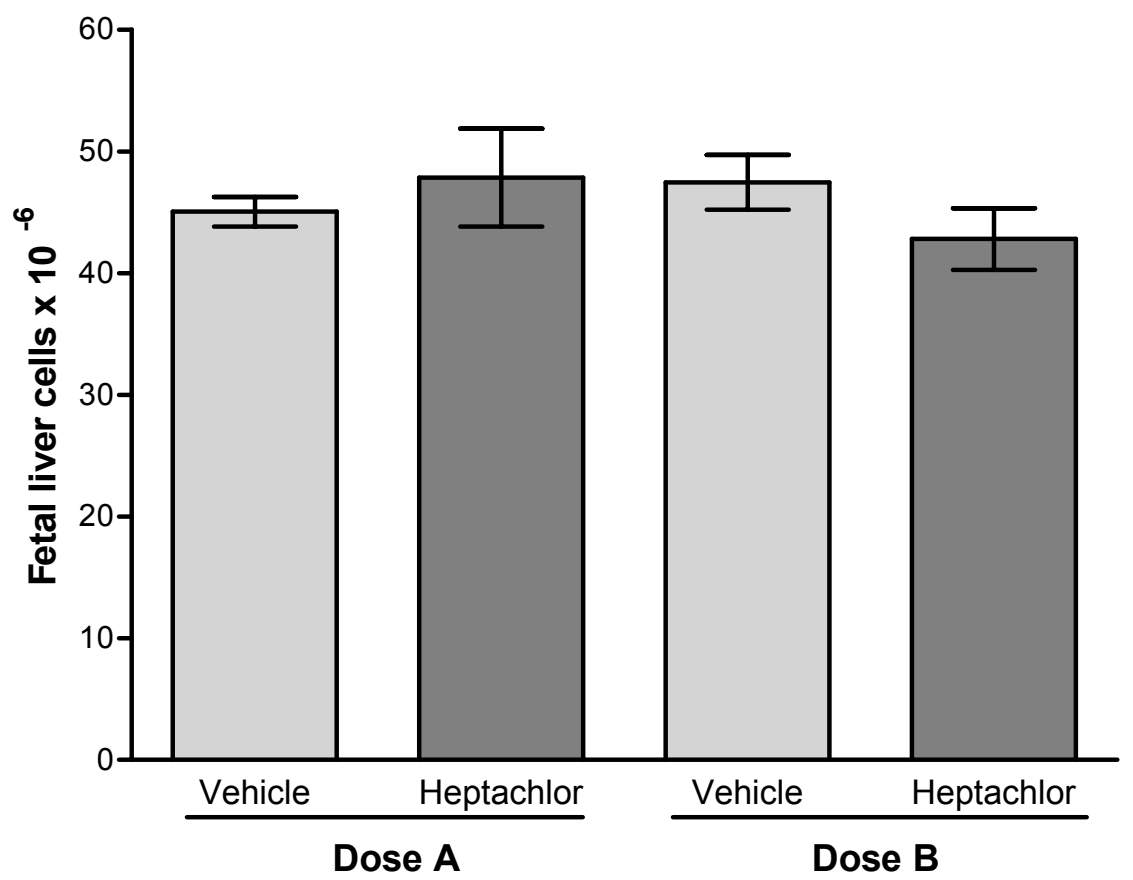

Figure 2: Prenatal heptachlor exposure did not affect cellularity of fetal livers 
Figure 3: Prenatal heptachlor exposure did not alter numbers of myeloid progenitor cells.

Fetal liver cells from gestational day 17 murine embryos exposed in utero to heptachlor or vehicle were cultured in methylcellulose containing either: A.) $40 \mathrm{ng} / \mathrm{ml}$ GM-CSF or B.) $40 \mathrm{ng} / \mathrm{ml} \mathrm{IL-3.} \mathrm{Colonies} \mathrm{of} \mathrm{lymphoid} \mathrm{cells} \mathrm{were} \mathrm{counted} \mathrm{on} \mathrm{day} 7$. Data represent means and SEMs from one representative experiment after control groups were normalized to $100 \%$. 
A

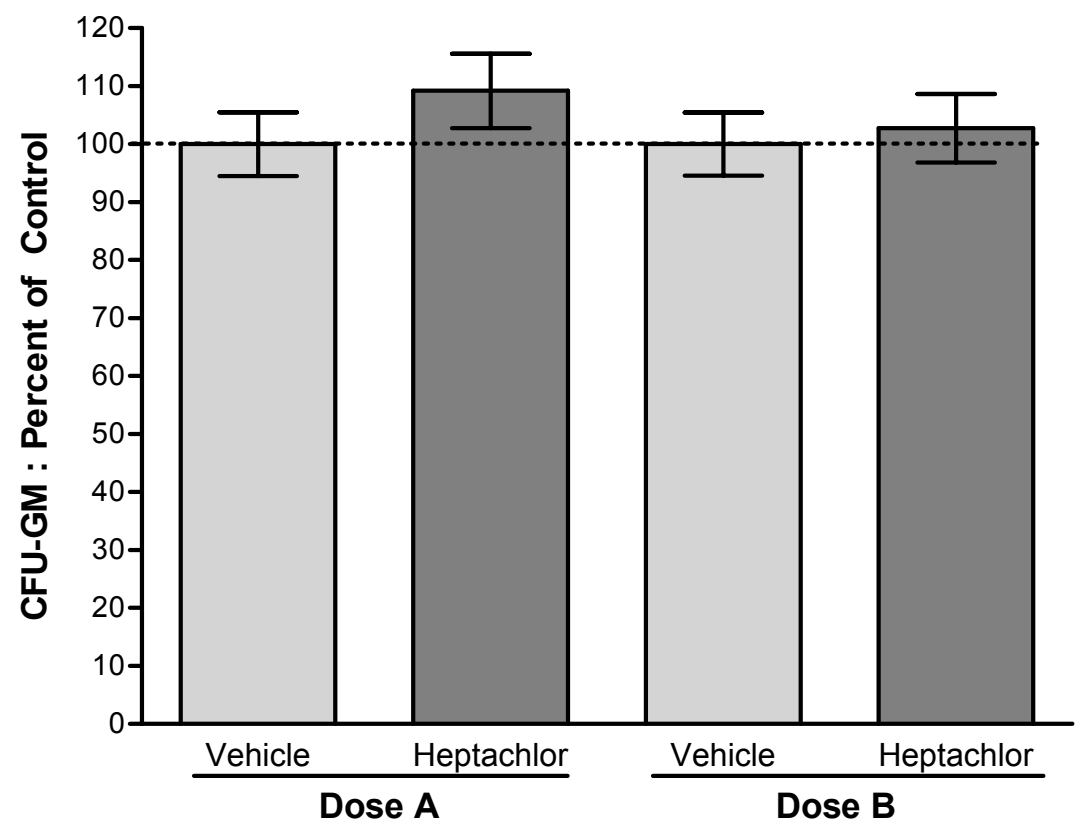

B

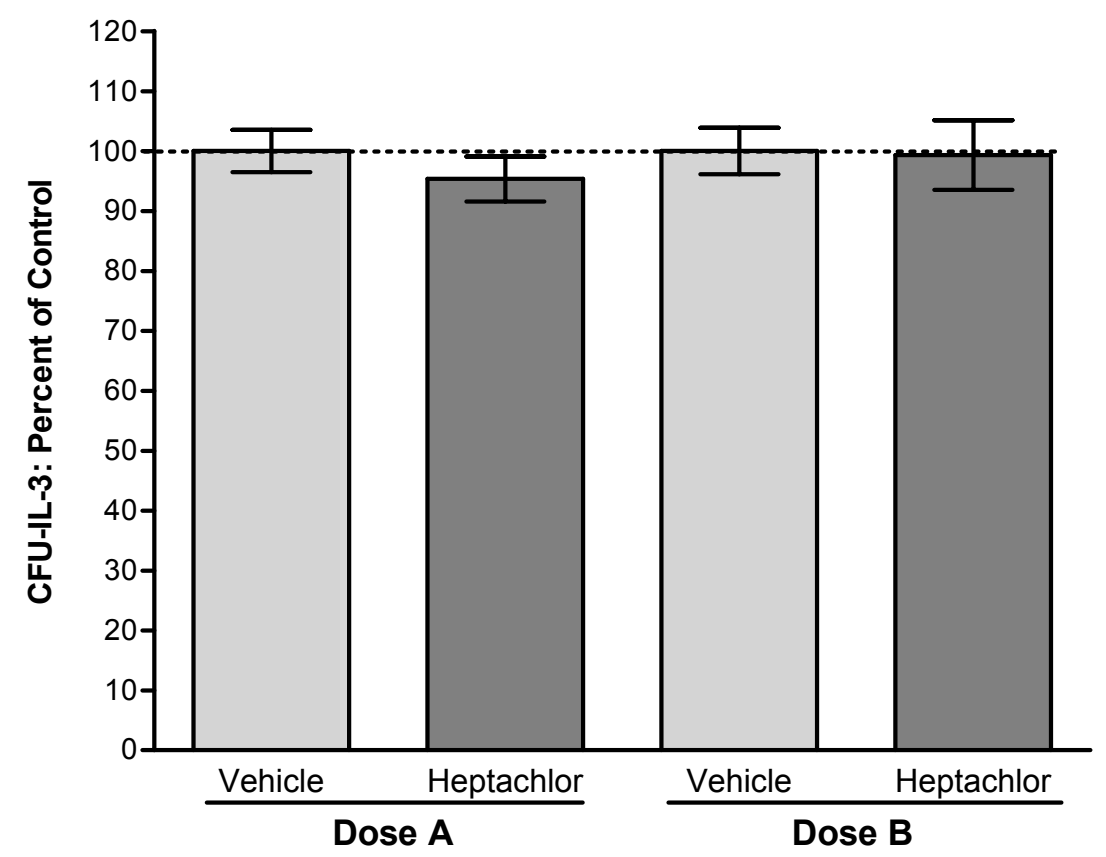

Figure 3: Prenatal heptachlor exposure did not alter numbers of myeloid progenitor cells 
myeloid progenitor cells, as measured by CFU-GM from control or heptachlor exposed embryos (Figure 3). No differences were noted in numbers of myeloid cells

between heptachlor Dose A or Dose B. Additionally, data obtained from CFU-IL-3 assays supported that numbers of myeloid cells were not affected following heptachlor exposure at either Dose A or Dose B (Figure 3). Statistical differences were not found in either myeloid CFU assay between heptachlor-treated and control cultures.

\section{Prenatal heptachlor exposure administered from day 12 to 16 during gestation resulted in increased numbers of lymphoid progenitor cells.}

We investigated whether exposure to heptachlor altered lymphoid cell development differently when administered before or after initiation of hematopoiesis in the fetal liver. Heptachlor Dose A resulted in no differences in the numbers of lymphoid cells as compared to vehicle controls (Figure 4). However, examination of Dose B resulted in a two-fold increase in the number of lymphoid progenitor cells (Figure 4). These data indicated that exposure to heptachlor from day 12 to 16 of gestation was a critical window during development that resulted in increased lymphopoiesis.

We also evaluated the effect of heptachlor on lymphoid cells using a limiting dilution lymphoid cell assay. Fetal liver cells were overlaid on existing S10 stromal cells at concentrations of 10 and 100 fetal liver cells per culture. Embryos exposed to heptachlor in Dose A had a reduction in the number of early lymphoid cells as 
Figure 4: Prenatal heptachlor exposure increased numbers of lymphoid progenitor cells.

Fetal liver cells from gestational day 17 murine embryos exposed in utero to heptachlor or vehicle were cultured in CFU assays containing $25 \mathrm{ng} / \mathrm{ml} \mathrm{rlL-7}$. Colonies of lymphoid cells were counted following 7 days of culture. Control groups were normalized to $100 \%$, and data represent means and SEMs from one representative experiment. 


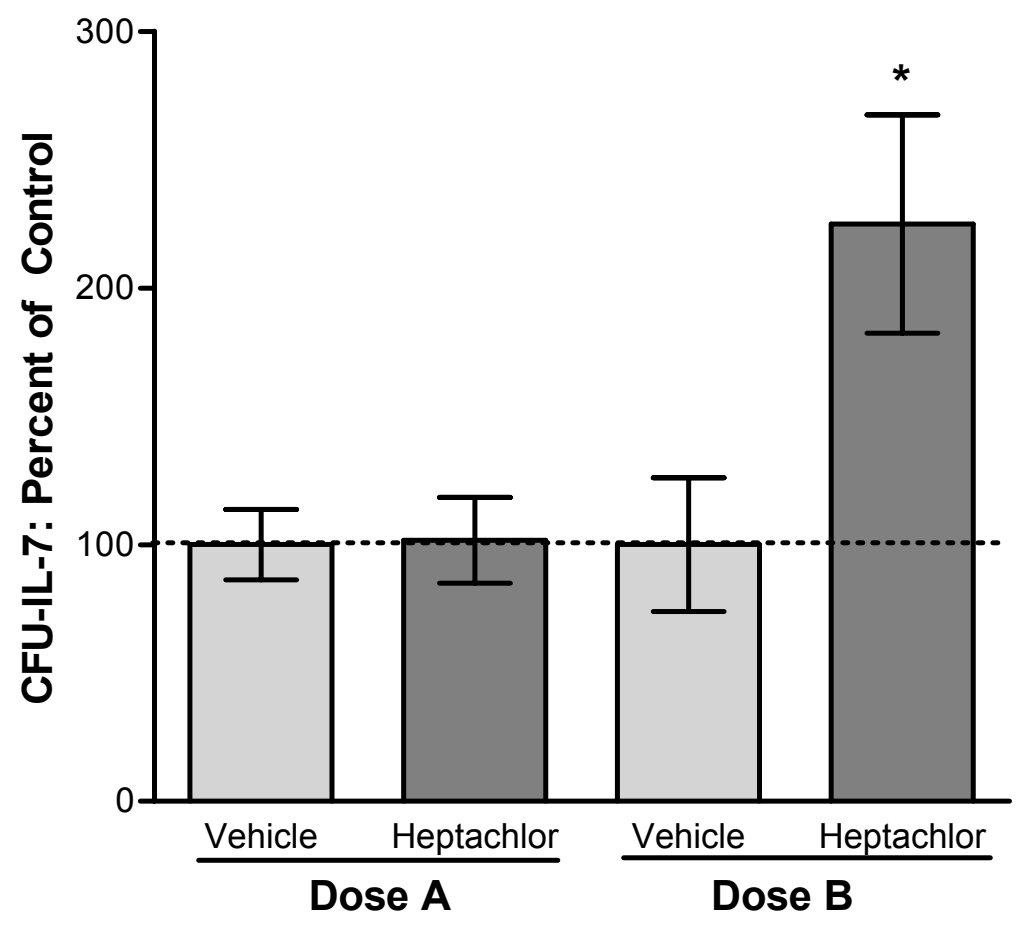

Figure 4: Prenatal heptachlor exposure increased numbers of lymphoid progenitor cells 
compared to fetal liver cells from control embryos (Figure 5). This decrease was not observed in data from the CFU-IL-7 assay (Figure 4). However, data from the limiting dilution assay examining Dose B was consistent with demonstrating increased lymphoid cell numbers. These data indicate that exposure to heptachlor at various windows during gestation can have differential outcomes on lymphoid cells in the developing fetal liver.

\section{Discussion}

The current study was designed to determine whether exposure to heptachlor early versus later in embryonic development altered lymphopoiesis. Using a prenatal mouse exposure model, we previously demonstrated that murine exposure to heptachlor resulted in significant alterations in early lymphoid progenitor cells in fetal

liver, but the numbers of myeloid progenitor cells from heptachlor-exposed embryos was no different from control animals in all previous studies. Data indicating both increased and decreased numbers of lymphoid progenitor cell numbers were obtained in these prior studies following heptachlor administration from day 10 to day 16 of gestation. Gestational day 10 marks establishment of hematopoiesis in murine fetal liver. We hypothesized that inconsistent data could possibly be related to this critical window during development in which we began heptachlor dosing in prior 
Figure 5: Prenatal heptachlor exposure altered numbers of lymphoid progenitor cells in lymphoid limiting dilution assay.

Fetal liver cells from gestational day 17 murine embryos exposed in utero to heptachlor or vehicle were cultured in lymphoid limiting dilution assays. Fetal liver cells were co-cultured with a cloned stromal cell line, S10, and $25 \mathrm{ng} / \mathrm{ml}$ rlL-7. Colonies of lymphoid cells were counted after 5 days of culture. Cells from control groups administered the vehicle were normalized to $100 \%$ and SEMs from one representative experiment. 


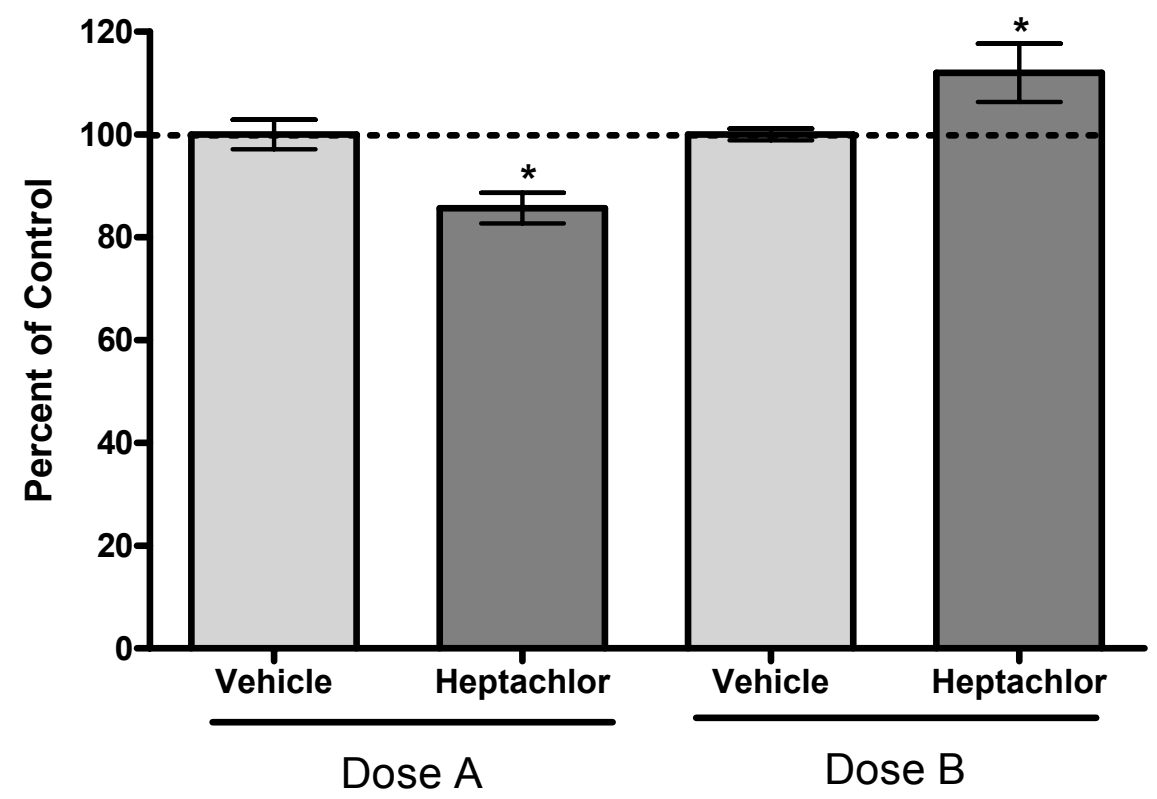

Figure 5: Prenatal heptachlor exposure altered numbers of lymphoid progenitor cells in lymphoid limiting dilution assay 
studies. The current study evaluated embryonic heptachlor exposure before and after this critical window in hematopoietic development.

Murine gestation consists of a 21-day period during which hematopoiesis migrates through several sites within the developing embryo (Godin et al, 1999; Tavassoli, 1991). Murine embryonic hematopoiesis begins in the blood islands of the yolk sac and also in the paraarotic spanchnopleura (P-Sp). The P-Sp comprises the dorsal aorta and surrounding mesoderm, approximately at day 7 of murine gestation, and is the location from which the aortogonadomesonephros (AGM) region develops (Cumano et al, 2001a; Moore et al, 1970). Cells from the extraembryonic yolk sac have the capability to reconstitute an irradiated mouse but only for a short duration of time (Cumano et al, 2001b). Long-term repopulating cells (LTRCs) are found within the AGM region from day 8.5 postcoitus (pc) (Cumano et al, 2001a; Cumano et al, 2001b). Cells migrate via the blood stream into the liver where hematopoiesis resides after day 10 and for the majority of fetal development (Weissman, 2000; Godin et al, 1999). Hematopoiesis initiates in the bone marrow on approximately day 17 of murine gestation. Bone marrow is the major site of hematopoiesis after birth as the liver ceases hematopoietic function (Cumano et al, 2001a). During hematopoiesis, stem cells, which are uncommitted, self-renewing cells, proliferate to generate progeny that differentiate into progenitor cells of either the myeloid or lymphoid lineages (Cooper at al, 1993). Lineage-committed progenitor cells differentiate into precursor cells, immature cells, and finally mature cells of the 
immune system. Progenitor cells mature in response to cytokine signals and direct contact with other cells that direct hematopoietic cell differentiation (Akashi et al, 1998). In our research, we have utilized CFU assays to assess numbers of lineagespecific progenitor cells by culturing fetal liver cells with cytokines specific to myeloid (GM-CSF and IL-3) or lymphoid (IL-7) lineages.

In the present study, two dosing schemes were designed to examine if the window of exposure during gestation was important in how heptachlor exposure affected hematopoiesis. Dose A consisted of heptachlor administration to pregnant dams from day 6 to day 16 of embryonic development. Dose A accounted for embryos that received heptachlor before hematopoiesis seeded into the fetal livers. Heptachlor Dose B began on day 12 of gestation, which was after the establishment of hematopoiesis in the fetal liver. In both doses, a larger heptachlor amount was prescribed for the first two days in the dosing schemes. This dosing schedule was designed to insure that the majority of heptachlor exposure was received either before or after the day 10 window. Additionally, we could not give the entire $24 \mathrm{mgs}$ of heptachlor in fewer doses since the pregnant dams would not have eaten such a large amount of the pesticide. The amount was tapered off over the first two days to maintain continual heptachlor exposure until the embryos were evaluated on day 17.

Following administration of Dose A or Dose B, fetal liver cells from heptachlorexposed and control embryos were evaluated. No differences were found in numbers of cells in fetal liver of mice administered heptachlor or the vehicle with 
either dosing schedule. Additionally, no differences in size or coloring were noted between fetal livers from heptachlor and control embryos (unpublished data). Results from the CFU-IL-7 assays demonstrated significantly more lymphoid progenitor cells in fetal livers from mice exposed to heptachlor later in gestation (Dose B). This dose administered during the later developmental window, beginning at day 12 , coincides with hematopoiesis located primarily in fetal liver. Elevated lymphoid cell numbers from embryos exposed to heptachlor Dose B were additionally confirmed by IL-7-responsive limiting dilution assays.

In contrast to effects of heptachlor found on lymphoid cells, myeloid cells were not affected by heptachlor treatment. This was determined in the present study by CFU-GM and CFU-IL-3 assays. In prior studies, in which mice were exposed to heptachlor from day 10 to day 16 of gestation, numbers of myeloid progenitor cells were not different from control embryos (data not shown). Myeloid-lineage cells were further examined by culturing fetal liver cells under culture conditions permissive for myeloid cell development (Dexter and Lajtha, 1974). No differences were found between these cultured myeloid cells from heptachlor-treated or control embryos in the proliferation response to GM-CSF, G-CSF, IL-3, or M-CSF (data not shown). These data give further support to the current study implicating that myeloid cell development in the embryo is not impacted by heptachlor exposure like cells committed to the lymphoid lineage. This apparent resistance of myeloid cells could be due to the predominance of myeloid hematopoiesis in developing embryos. 
Taken together, these data suggest that fetal liver hematopoiesis is susceptible to heptachlor-induced toxicity. This increase observed in lymphoid progenitor cells may be the result of hematopoietic rebound which occurs following extreme damage to a cell population. The in vivo model implemented in these studies is multi-layered due to indirect exposure of embryos to heptachlor. The complexity presents difficulties in investigating specific mechanisms by which heptachlor alters lymphoid cell development. Further studies examining the addition of heptachlor to lymphoid cell cultures will clarify the direct effects of heptachlor on lymphopoiesis.

\section{Acknowledgements}

This research was supported by the Hawaii Heptachlor Research and Education Foundation. 


\section{References}

Agency for Toxic Substances and Disease Registry. 1992. Toxicological Profile for Heptachlor. US Public Health Service, US Department of Health and Human Services, Atlanta, Georgia.

Akashi, K, K Motonari, I Weissman. 1998. Role of interleukin-7 in T-cell development from hematopoietic stem cells. Immunol Rev 165:13.

Baker, DB, S Loo, and J Barker. 1991. Evaluation of human exposure to the heptachlor epoxide contamination of milk in Hawaii. Hawaii Med J 50:108.

Barnett, J, L Soderberg, J Menna. 1985. The effect of prenatal chlordane exposure on the delayed hypersensitivity response of BALB/c mice. Toxicol Lett 25:173.

Barnett, J, B Blaylock, J Gandy, J Menna, R Denton, and L Soderberg. 1990a. Longterm alteration of adult bone marrow colony formation by prenatal chlordane exposure. Fund Appl Toxicol 14:688.

Barnett, J, B Blaylock, J Gandy, J Menna, R Denton, and L Soderberg. 1990b. Alteration of fetal liver colony formation by prenatal chlordane exposure. Fund Appl Toxicol 15:820.

Barnett, J. 1997. Age-related susceptibility to immunotoxicants: animal data and human parallels. Environ Toxicol Pharm 4:315.

Blaylock BL, L Soderberg, J Gandy, J Menna, R Denton, J Barnett. 1990. Cytotoxic T-lymphocyte and NK responses in mice treated prenatally with chlordane. Toxicol Lett 51(1):41. 
Blyer, G, KS Landreth, and JB Barnett. 1994. Gender-specific effects of prenatal chlordane exposure on myeloid cell development. Fund Appl Toxicol 23:188.

Bradley, T, D Metcalf.1966. The growth of bone marrow cells in vitro. Aust J Exp Biol Med Sci 44:287.

Collins L., and K. Dorshkind. 1987. A stromal cell line from myeloid long-term bone marrow cultures can support myelopoiesis and B lymphopoiesis. J Immunol 138:1082.

Cooper, E, C Muller-Sieburg, G Spangrude. 1993. Stem Cells: In Developmental Immunology, E.L. Cooper and E. Nisbet-Brown, Oxford University Press, New York. pp.177-197.

Cumano, A, and I Godin. 2001a. Pluripotent hematopoietic stem cell development during embryogenesis. Curr Opin Immunol 13:166.

Cumano, A, C Ferraz, M Klaine, J Santo, I Godin. 2001b. Intraembryonic, but not yolk sac hematopoietic precursors, isolated before circulation, provide long-term multilineage reconstitution. Immunity 15:477.

Dexter, T, L Lajtha. 1974. Proliferation of haemopoietic stem cells in vitro. Brit J Haematol 28:525.

Furie, B., and S. Trubwitz. 1976. Insecticides and blood dyscrasias: Chlordane exposure and self-limited refractory megaloblastic anemia. JAMA 235:1720.

Godin, I, J Garcia-Porrero, F Dieterlen-Lievre, A Cumano. 1999. Stem cell emergence and hemopoietic activity are incompatible in mouse intraembryonic sites. J Exp Med 190(1):43. 
IARC Monographs Evaluating Carcinogenic Risks in Humans. 1991. Chlordane and heptachlor. 53:115.

Infante, P., and W Newton Jr. 1975. Letter: Prenatal chlordane exposure and neuroblastoma. New England J Med 293(6):308.

Landreth, K, K Dorshkind. 1988. Pre-B cell generation potentiated by soluble factors from a bone marrow stromal cell line. J Immunol 140(3):845.

Le Marcchand, L, KN Kolonel, BZ Siegel, and WH Dendle. 1986. Trends in birth defects for a Hawaiian population exposed to heptachlor and for the United States. Arch Environ Health 41(3):145.

Moore, M, and D Metcalf. 1970. Ontogeny of the haemopoietic system: yolk sac origin of in vivo and in vitro colony forming cells in the developing mouse embryo. Brit J Haemetol 18:279.

Office of Pesticide Programs. 1995. Internal Pesticide Notice. US Environmental Protection Agency.

Rolink, AG, C Schaniel, M Busslinger, SL Nutt, F Melchers. 2000. Fidelity and infidelity in commitment to B-lymphocyte lineage development. Immunol Rev 175:104.

Tavassoli, M. 1991. Embryonic and fetal hemopoiesis: An overview. Blood Cells 17(2):282.

Theus, S, D Tabor, L Soderberg and JB Barnett. 1992. Macrophage tumoricidal mechanisms are selectively altered by prenatal chlordane exposure. Agents Actions $37: 140$. 
Senthilkumar, K, K Kannan, A Subramanian, S Tanabe. 2001. Accumulation of organochlorine pesticides and polychlorinated biphenyls in sediments, aquatic organisms, birds, bird eggs, and bats collected from South India. Environ Sci Pollut Res 8:1.

Smialowicz, R, W Williams, C Copeland, M Harris, D Overstreet, B Davis, R Chapin. 2001. The effects of perinatal/juvenile heptachlor exposure on adult immune and reproductive system function in rats. Toxicol Sci 61:164.

Weissman, I. 2000. Stem cells: Units of development, units of regeneration and units in evolution. Cell 100:157. 
CHAPTER 3: In Vitro Heptachlor Exposure Induces Maturation of $70 Z / 3$ Pre-B Cells 


\begin{abstract}
Hematotoxicity has been documented in adults exposed to high levels of organochlorine pesticides. Our previous studies suggested that prenatal exposure to heptachlor resulted in alteration of lymphocyte development, while myeloid cell development was spared. To investigate effects of heptachlor on lymphoid cells, we evaluated direct exposure of this compound on the pre-B cell line $70 Z / 3$. $70 Z / 3$ pre-B cells exposed to heptachlor remained viable but failed to proliferate. Following exposure to heptachlor, $70 Z / 3$ cells expressed increased levels of immunoglobulin kappa light chain, an indicator of pre-B cell maturation. Nuclear factor-kappa B (NFкB) was increased in nuclei of $70 \mathrm{Z} / 3$ cells following heptachlor exposure. Nuclear shuttling of NF-kB and subsequent kappa light chain expression were blocked by pretreatment of $70 Z / 3$ cells with capsaicin, coincident with a loss of heptachlorinduced pre-B cell maturation. These data suggest that heptachlor exposure interrupted pre-B cell proliferation and resulted in premature differentiation through alteration of NF-kB localization and Ig expression.
\end{abstract}




\section{Introduction}

Heptachlor is a cyclodiene insecticide that was abundantly applied to buildings to prevent termite damage and to crops to protect from insect destruction for several decades (Agency for Toxic Substances, 1992). Heptachlor is extremely stable in the environment, and accumulates in adipose tissue due to the lipophilic nature of the molecule (Office of Pesticide Programs, 1995; IARC, 1991). Heptachlor is toxic to humans, causing acute symptoms of vomiting, gastrointestinal distress, and chronic episodes of seizures and sinusitis (Agency for Toxic Substances, 1992). Previous studies in our lab determined that administration of heptachlor to mice in utero resulted in increased numbers of early lymphoid progenitor cells in fetal liver of embryonic day 17 BALB/c mice (Chapter 2). In utero heptachlor exposure did not affect myeloid progenitor cells in the same animals.

In order to determine the mechanism of heptachlor toxicity to B lineage cells in hematopoietic tissues, we evaluated the effect of heptachlor on proliferation and survival of a pre-B cell line, $70 Z / 3$, in vitro. The pre-B cell line $70 Z / 3$ expresses characteristic B linage markers and have completed rearrangement of both immunoglobulin (Ig) heavy and light chain genes but do not transcribe or translate light chain protein or express cell surface Ig (slg) (Paige et al, 1978; Giri et al, 1984). Heptachlor blocked cell proliferation of $70 Z / 3$ cells without affecting cell survival suggesting that these cells may have differentiated as a result of heptachlor treatment. Results presented here demonstrate that heptachlor exposure induced 
expression of kappa light chain on the surface of these cells. Because kappa light chain expression requires gene transcription, we evaluated the effect of heptachlor on nuclear factor kappa B (NF-кB), a well-characterized intracellular molecule which regulates kappa transcription (Sen and Baltimore, 1986). NF-kB is formed from complexes of NF-kB family protein subunits. The most common complexes consist of p65 and p50 proteins, both of which are retained in the cytoplasm by $1 \kappa-B$, an inhibitor of nuclear translocation of this molecule (Gerondakis and Strasser, 2003; Kucharczak et al, 2003). Phosphorylation of $\mathrm{I}_{\kappa}-\mathrm{B}$ by receptor-mediated signaling results in release of $\mathrm{NF}-\mathrm{kB}$, translocation of this complex to the nucleus, binding to NF-kB-specific binding sites in DNA, and subsequent gene transcription (Turco et al, 2004). Studies presented here reveal that exposure of $70 Z / 3$ cells to heptachlor

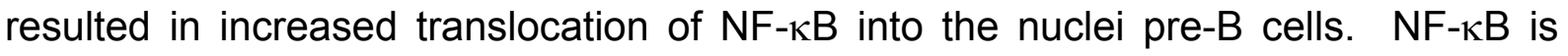

known to regulate transcription of a number of gene complexes in a wide-array of eukaryotic cell types (Turco et al, 2004). For that reason, results presented here with lymphoid cells may have broader implications for understanding the effect of heptachlor on multiple organ systems.

\section{Materials and Methods}

Cell lines and cell culture conditions: $70 \mathrm{Z} / 3$ pre-B cells were obtained through ATCC (Manassas, VA). Standard cell culture medium was $\alpha$-modification of Eagle's medium with $10 \%$ fetal bovine serum (FBS), $1 \%$ penicillin/ streptomycin, $1 \%$ I- 
glutamine, and $0.1 \%$ 2-mercaptoethanol. Cultures were incubated at $37^{\circ} \mathrm{C}$ in a humidified incubator at $6 \% \mathrm{CO}_{2}$. Cells were enumerated using a hemocytometer, and cell viability was assessed using trypan blue,

Heptachlor exposure: Stock heptachlor solutions (Chem Service, West Chester, PA) were prepared at $10 \mu \mathrm{gs} / \mu \mathrm{l}$ in $95 \%$ ethanol. Cells were exposed to 0 to $25 \mu \mathrm{M}$ heptachlor concentrations in standard cell culture medium for 24 hours. Viability was assessed by enumerating cells using trypan blue dye exclusion. When used, lipopolysaccharide (LPS) was added to $70 Z / 3$ cultures at $20 \mu \mathrm{gs} / \mathrm{ml}$.

Nuclear protein extraction: Nuclear protein extracts were prepared by hypotonic lysis of cytoplasmic membranes, followed by centrifugation $(14,000 \mathrm{rpm})$ at $4^{\circ} \mathrm{C}$ for 10 minutes and removal of cytoplasmic fractions. The remaining pellets were treated with a high salt lysis buffer to disrupt the nuclear membranes, and following similar centrifugation, nuclear proteins were subsequently collected (Andrews and Faller, 1991). Briefly, the hypotonic lysis buffer contained $10 \mu \mathrm{M}$ HEPES-KOH (pH 7.9), 1.5 $\mu \mathrm{M} \mathrm{Mg} \mathrm{Cl} 2,10 \mu \mathrm{M} \mathrm{KCl}, 0.5 \mu \mathrm{M}$ DTT , $0.2 \mu \mathrm{M}$ PMSF, $100 \mu \mathrm{M}$ pepstatin A, $100 \mathrm{mM}$ leupeptin, $100 \mu \mathrm{M}$ aprotinin, $0.2 \mu \mathrm{M}$ EGTA, and $0.2 \mu \mathrm{M}$ EDTA (pH 8). The high salt lysis buffer contained $20 \mu \mathrm{M}$ HEPES-KOH (pH 7.9), $25 \%$ glycerol (v/v), $420 \mu \mathrm{M} \mathrm{NaCl}$, $1.5 \mu \mathrm{M} \mathrm{MgCl}_{2}, 0.2 \mu \mathrm{M}$ EDTA (pH 8), $0.2 \mu \mathrm{M}$ EGTA, $0.5 \mu \mathrm{M}$ DTT, $0.2 \mu \mathrm{M}$ PMSF, 100 $\mu \mathrm{M}$ pepstatin $\mathrm{A}, 100 \mu \mathrm{M}$ leupeptin, and $100 \mu \mathrm{M}$ aprotinin. Protein extracts were quantitated using BioRad Protein Assay (Hercules, CA). 
Proliferation Assay: $70 \mathrm{Z} / 3$ pre-B cells $\left(1.25 \times 10^{5} / \mathrm{ml}\right)$ were exposed to heptachlor, pulsed with ${ }^{3} \mathrm{H}-\mathrm{TdR}$ after 18 hours in culture, and harvested 6 hours later. Cells were lysed and DNA collected on glass filter strips by means of a PHD cell harvester (Cambridge Technology, Inc, Cambridge, MA). Presence of radioactivity was evaluated by a Wallac 1410 liquid scintillation counter (Perkin Elmer, Downers Grove, IL). Each experiment included three replicate wells for each treatment group.

Flow cytometric analysis: Cell immunofluorescent surface staining of kappa light chain was conducted by incubating $10^{6}$ cells with $1 \mu \mathrm{g}$ of FITC-conjugated goat antimouse kappa light chain (Southern Biotechnology, Birmingham, Alabama). Controls of unstained cells were also included in each experiment. Cells were washed with PBS containing $0.01 \%$ FBS and fixed in $2 \%$ paraformaldehyde. Cell surface staining was analyzed using a FACScan (Becton Dickinson, San Jose CA).

Immunoblotting: Protein samples (15 $\mu \mathrm{gs})$ were separated on $10 \%$ SDS-PAGE gels. Proteins were then transferred to $0.45 \mu \mathrm{M}$ nitrocellulose membranes (Schleicher and Schuell, Keene, NH) and probed with specific antibodies to p65 and Sin3A (Upstate Biotechnology, Lake Placid, NY). Protein-bound membranes were incubated with HRP-conjugated goat anti-rabbit antibody (Santa Cruz, Santa Cruz, CA) and detected using chemiluminescence (Amersham Biosciences, Piscataway, NJ). Following exposure of membranes to film (Kodak, Rochester, NY), densitometries of protein bands were evaluated using Eagle Eye II software (Stratagene, La Jolla, CA). Sin3A, a protein component of the deacetylation complex 
involved in DNA accession, is expressed constitutively and was used as the internal loading control for all immunoblots. In all experiments, densitometry values for p65 were normalized to $\operatorname{Sin} 3 \mathrm{~A}$ for each sample.

NF-кB ELISA: 70Z/3 nuclear extracts were assayed for p65 levels using a commercial available detection system (TransAM, Active Motif, Carlsbad, CA). NFКB-specific oligonucleotides were incubated with samples of nuclear extracts from cells exposed to $25 \mu \mathrm{M}$ heptachlor. Blocking or scrambled oligonucleotides were incubated with these samples before proteins were allowed to bind in p65-specific ELISA assays. Preincubation with oligonucleotides specific for p65 blocked binding of NF-kB protein in ELISA plates. T cell lysates supplied with the detection system were used for positive controls in p65 detection.

Capsaicin pretreatment: Where indicated, cells were pretreated with $0.2 \mathrm{M}$ capsaicin (Sigma-Aldrich, St. Louis, MO) for 24 hours before experiments to block NF-kB nuclear translocation (Singh et al, 1996). Following capsaicin pretreatment, cells were centrifuged and washed to remove capsaicin.

Statistics: Data were analyzed using Instat statistical software (GraphPad Software, Inc., San Diego, CA). Data are presented as means \pm standard errors of the means (SEMs). Statistical differences were assessed using ANOVA to compare multiple treatment groups, and Dunnett's test was utilized to evaluate these means. Student's 
T-test was used to determine statistical significance between individual groups. Statistical significance was indicated by $p$ values less than 0.05 .

\section{Results}

\section{In vitro heptachlor exposure altered pre-B cell proliferation.}

In order to determine whether heptachlor exposure affected proliferation of cell proliferation, we exposed the pre-B cell line $70 Z / 3$ to increasing concentrations of heptachlor in vitro. As shown in Figure 1, exposure of $70 Z / 3$ cells to heptachlor resulted in significantly decreased proliferation at concentrations ranging from 5 to 25 $\mu \mathrm{M}$. This effect appeared to be concentration-dependent, with cell proliferation abrogated at $25 \mu \mathrm{M}$ heptachlor. These studies suggested that heptachlor interfered with cell proliferation at even low concentrations.

\section{Heptachlor exposure did not affect pre-B cell viability.}

To assess whether decreased proliferation resulted from direct toxicity to $70 Z / 3$ cells, we examined cell viability following heptachlor exposure. As shown in Figure 2, exposure of pre-B cells to $25 \mu \mathrm{M}$ heptachlor for 24 hours did not affect cell viability, as assessed by trypan blue dye exclusion of viable cells. Viability remained above $90 \%$ after exposure to all concentrations of heptachlor (Figure 2). 
Figure 1: Heptachlor exposure decreased proliferation of pre-B cells.

Proliferation of $70 \mathrm{Z} / 3$ cells was determined using ${ }^{3} \mathrm{H}-\mathrm{TdR}$ incorporation following exposure to heptachlor ( -- ) or vehicle controls (-- $\square--$ ) for 24 hours. Increasing concentrations of heptachlor $(5,12.5$, and $25 \mu \mathrm{M})$ were added to pre-B cell cultures. Data presented here are representative of three experiments. Significant differences are indicated by $\left(^{*}\right)=p<0.05$ and $\left(^{* *}\right)=p<0.005$. 


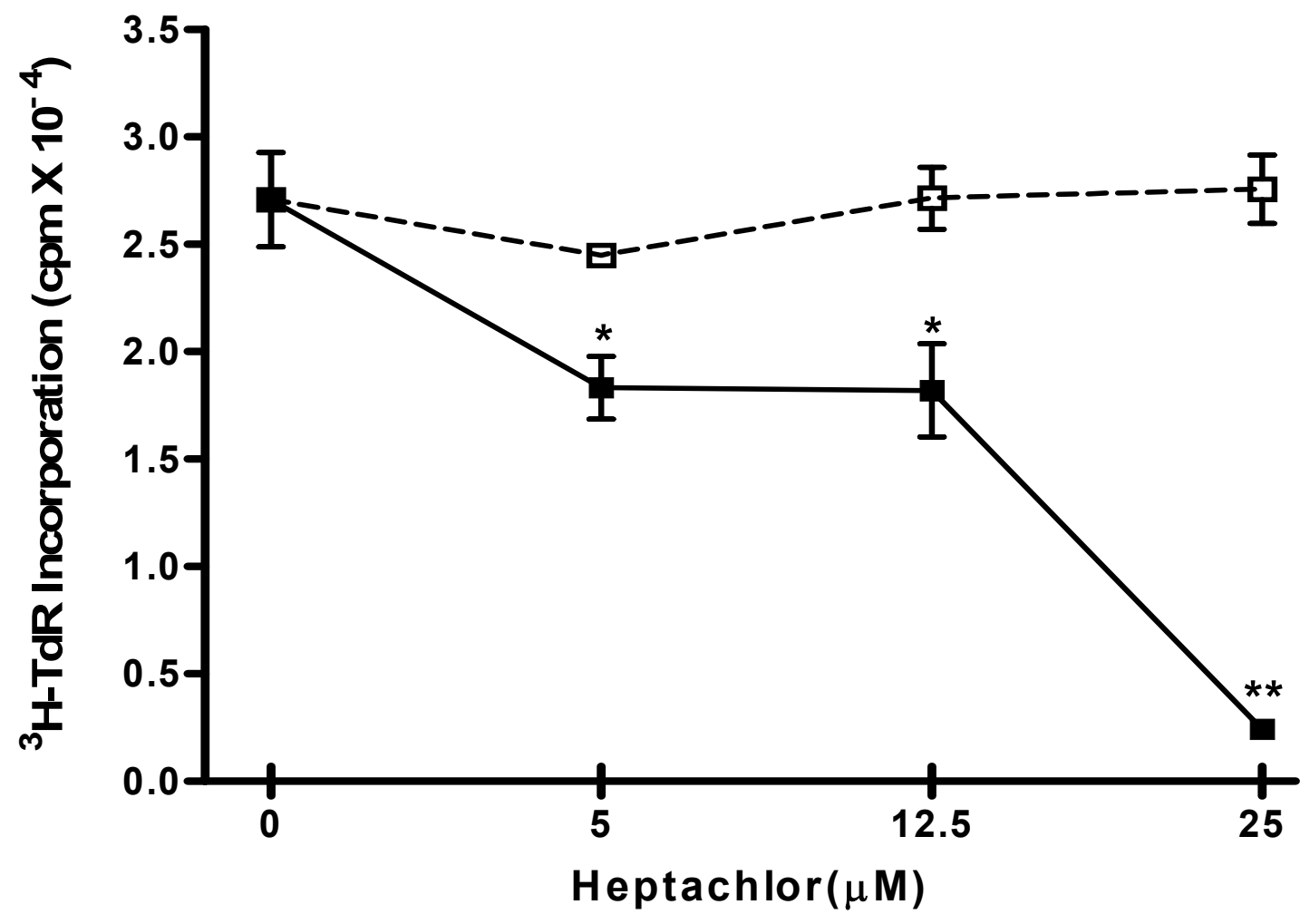

Figure 1: Heptachlor exposure decreased proliferation of pre-B cells 
Figure 2: Heptachlor exposure did not alter viability of pre-B cells.

Viable $70 Z / 3$ cells were assessed for viability by trypan blue dye exclusion after 24 hours following exposure to heptachlor ( $-\square)$ ) or vehicle ( -- $\square--$ ). No statistical significant differences $(p>0.05)$ in pre-B cell viability were found between vehicle and heptachlor treatment groups. 


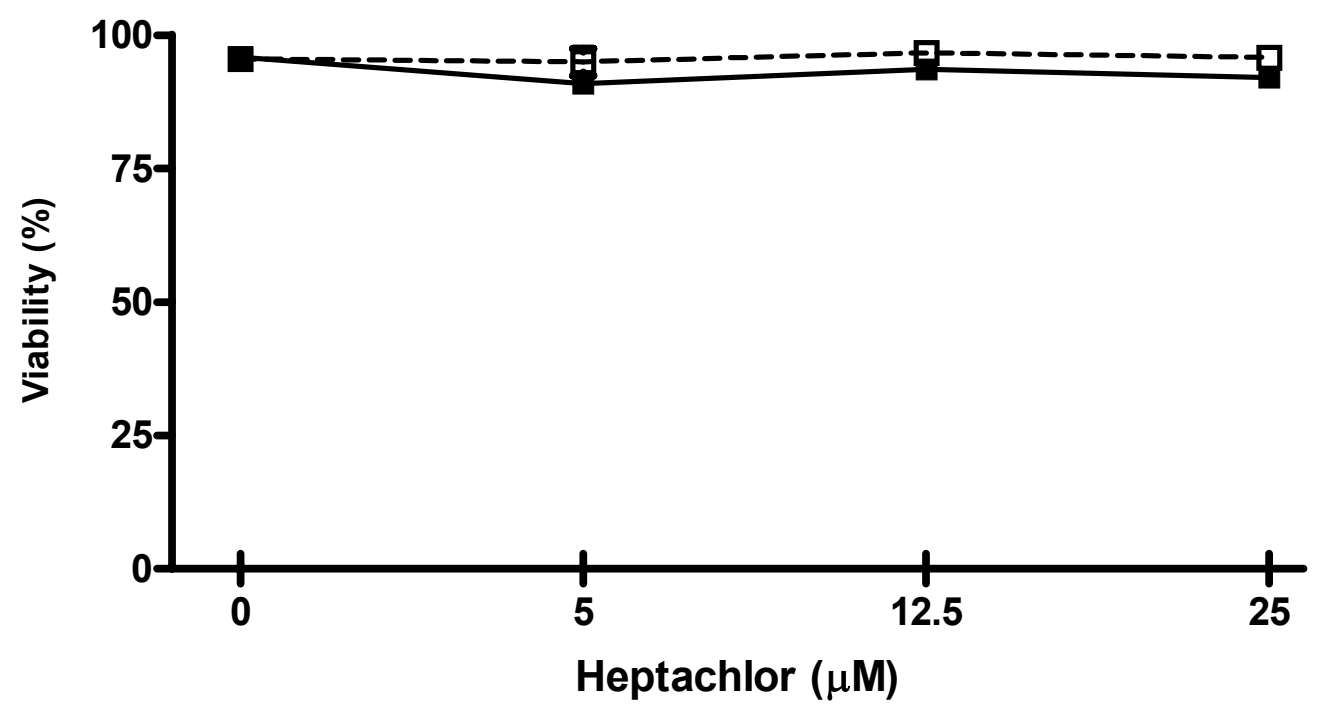

Figure 2: Heptachlor exposure did not alter viability of pre-B cells 


\section{Heptachlor exposure resulted in failure of pre-B cell expansion.}

Cultures were initiated with $1.25 \times 10^{5}$ cells per $\mathrm{ml}$ in the presence or absence of heptachlor. In the absence of heptachlor, $70 \mathrm{Z} / 3$ cells expanded four-fold (Mean=9.8 $\times 10^{4}$; SEM=0.173) in 24 hours (Figure 3). Exposure to increasing concentrations of heptachlor resulted in failure of cells to expand in cultures. Following addition of heptachlor to cultures, enumeration of cells at 6,12 , and 24 hour time points revealed failure of pre-B cells to expand, and cell cultures exposed to $25 \mu \mathrm{M}$ heptachlor for 24 hours contained viable cell numbers similar to $70 Z / 3$ cells introduced at initiation of cultures (Figure 4). These data suggested that decreased pre-B cell proliferation was not due to decreased viability following heptachlor exposure.

\section{Heptachlor induced kappa light chain protein expression on pre-B cells.}

$70 Z / 3$ cells are known to differentiate and express cell surface immunoglobulin kappa (к) light chain in response to lipopolysaccharide (LPS) exposure (Paige et al, 1978). We questioned whether failure to proliferate in the presence of heptachlor was accompanied by pre-B cell differentiation. In untreated cultures, $2.8 \%$ of $70 Z / 3$ cells had detectable $\kappa$ light chain expression (Figure 5). In cultures treated with $25 \mu \mathrm{M}$ heptachlor, $26.1 \%$ had detectable $\kappa$ light chain protein. These data suggest that exposure to heptachlor resulted in alteration of intracellular mechanisms that regulate pre-B cell differentiation. 
Figure 3: Heptachlor exposure decreased numbers of pre-B cells in culture for 24 hours.

Numbers of viable $70 Z / 3$ cells in culture were determined after 24 hours following exposure to heptachlor ( $-\square$ ) or the vehicle control (-- $\square--$ ). Data presented here are representative of three experiments. Pre-B cell cultures were initiated with $2.5 \mathrm{X}$ $10^{4}$ cells $(----)$. Significant differences are indicated by $\left({ }^{*}\right)=p<0.05$ and $\left({ }^{* *}\right)=p<$ 0.01 . 


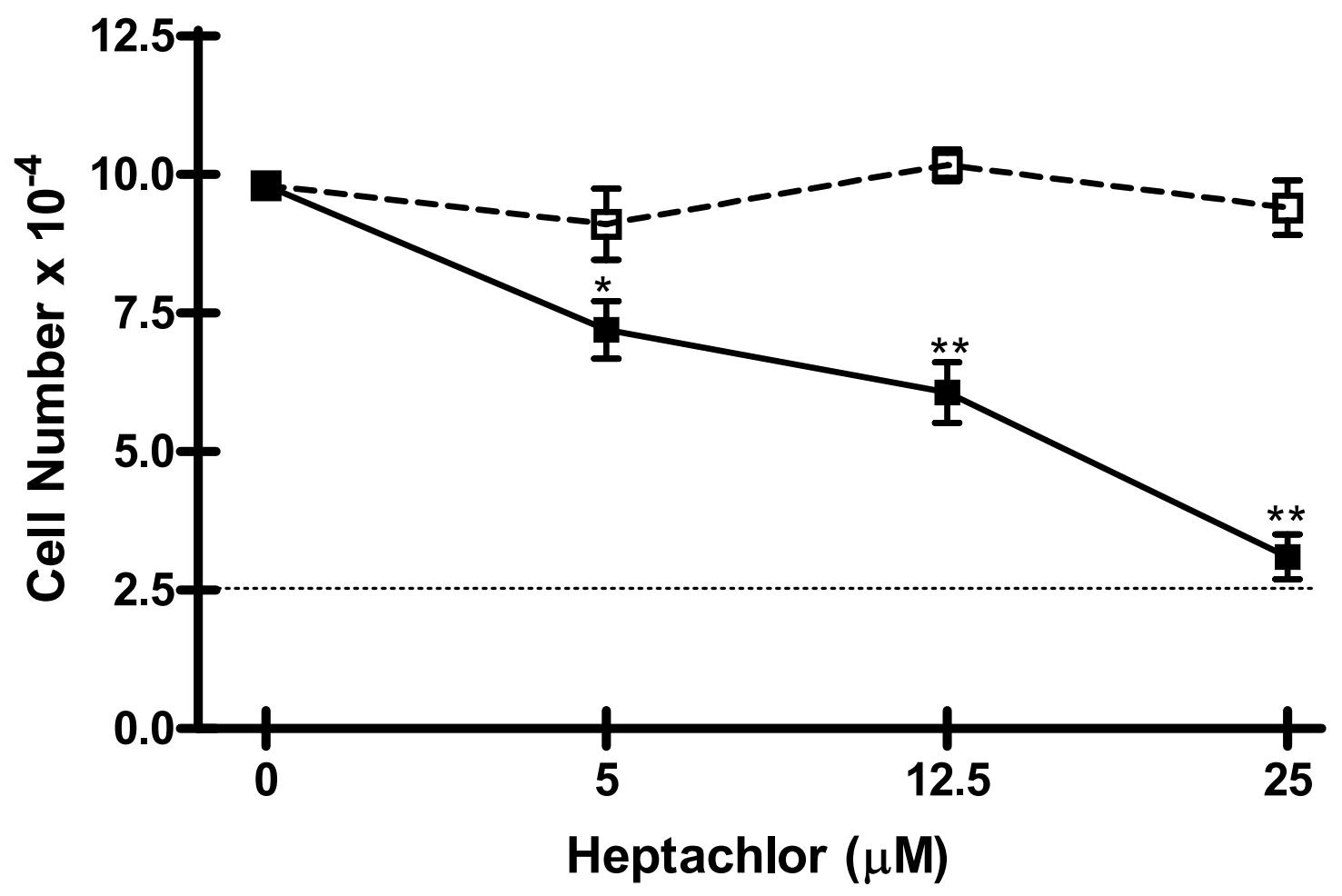

Figure 3: Heptachlor exposure decreased numbers of pre-B cells in culture for 24 hours 
Figure 4: Heptachlor exposure altered kinetics of pre-B cells in culture.

To further examine expansion and numbers of viable cells in these pre-B cell cultures, $70 \mathrm{Z} / 3$ cells were enumerated after 6,12 , and 24 hours following exposure to heptachlor or the vehicle. Heptachlor was added to cultures at $5 \mu \mathrm{M}(\square / \mathbf{\square}), 12.5 \mu \mathrm{M}$ $(\bigcirc / \bullet)$, or $25 \mu \mathrm{M}(\diamond / \diamond)$ concentrations of heptachlor (shaded shapes) or ethanol (open shapes). Medium controls $(+)$ are also indicated. Significant differences between heptachlor-exposed and control cultures are indicated by $\left(^{*}\right)=p<00.5$ and $\left(^{* *}\right)=p<0.01$. 


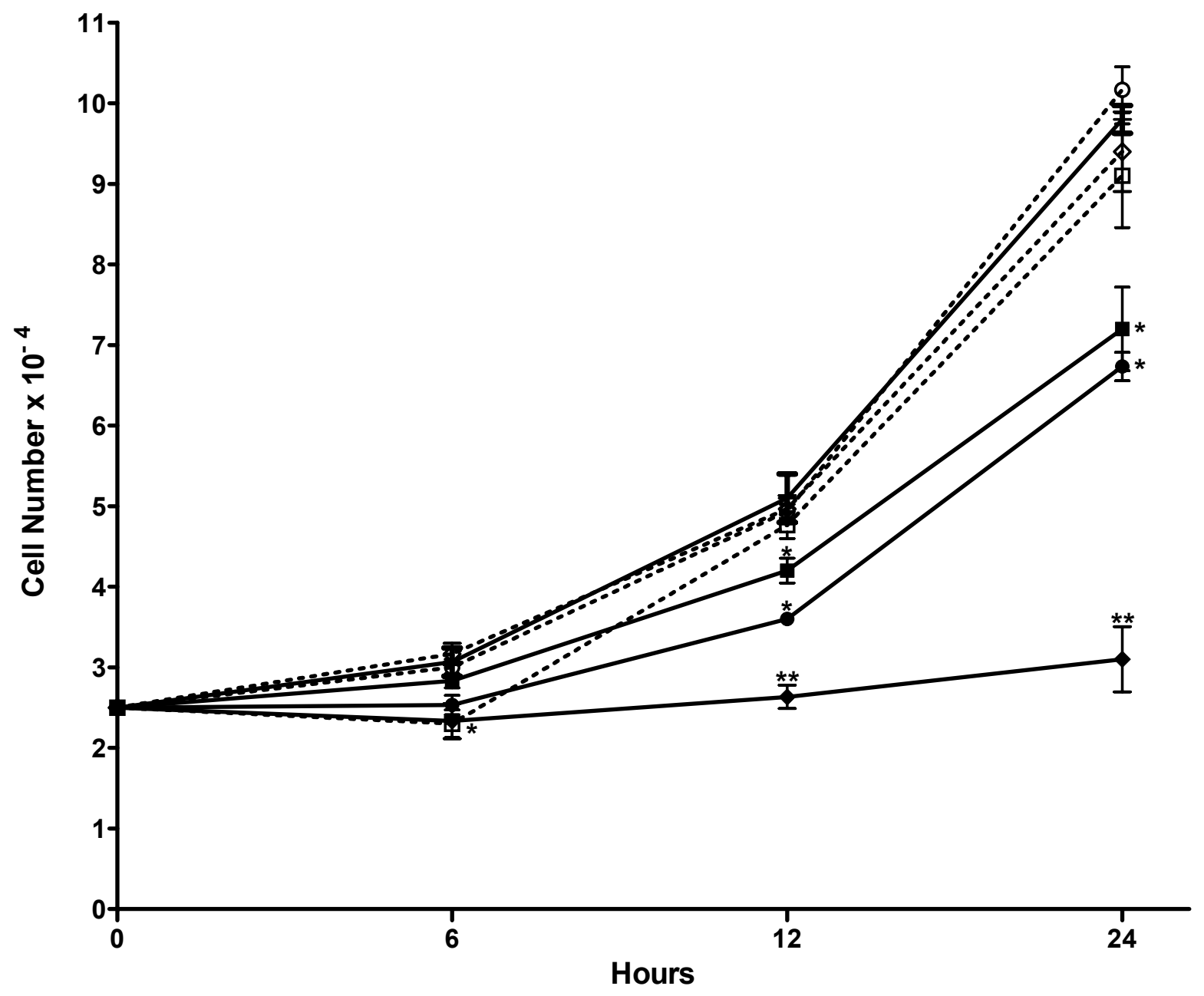

Figure 4: Heptachlor exposure altered kinetics of pre-B cells in culture 
Figure 5: Heptachlor exposure induced $\kappa$ immunoglobulin light chain protein expression on pre-B cells.

Pre-B cells were examined for kappa protein using flow cytometric analysis. (A) Histograms representative of one experiment indicate increased cell surface expression of $\kappa$-light chain following exposure to heptachlor. (B) Data from 3 experiments demonstrated that kappa light chain expression increased following heptachlor treatment. Significant differences were found $(p<0.05)$ between control cultures and pre-B cells treated with 12.5 and $25 \mu \mathrm{M}$ heptachlor concentrations. 
A
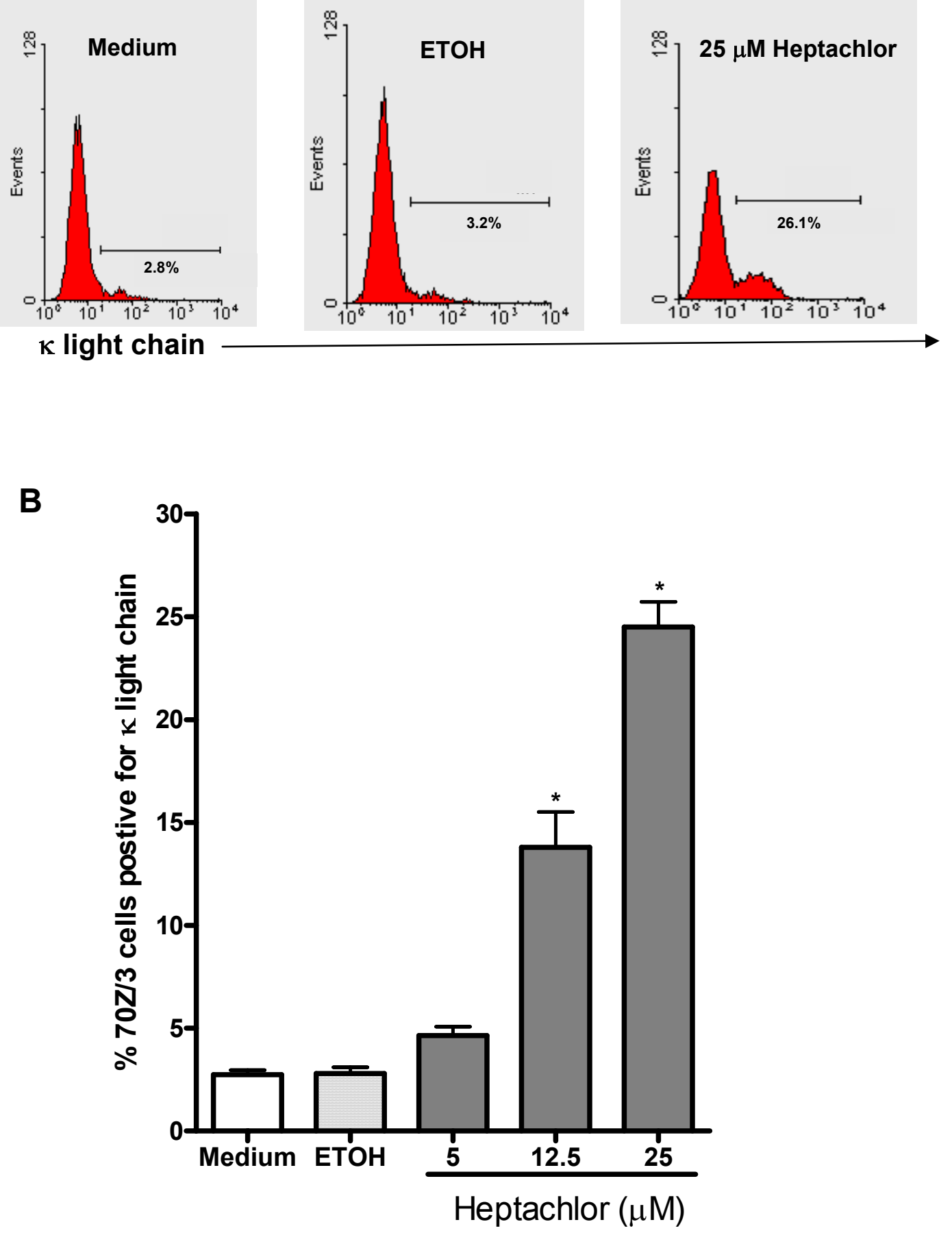

Figure 5: Heptachlor exposure induced $\kappa$ immunoglobulin light chain protein expression on pre-B cells 


\section{Heptachlor exposure increased nuclear NF-kB signaling in pre-B cells.}

In order to further understand the effect of heptachlor on pre-B cell differentiation, we

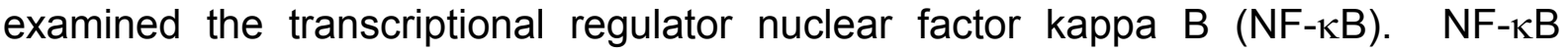
translocates to the nucleus following LPS stimulation, binds to Rel homology DNA sequences, and induces transcription of $\kappa$ light chain genes. Protein levels of $\sin 3 \mathrm{~A}$, the internal control, were not altered after treatment with heptachlor (Figure 6). Wefound that following $25 \mu \mathrm{M}$ heptachlor exposure, the p65 subunit of NF- B increased $66 \%$ in nuclei of pre-B cells (Figure 6). This alteration of NF-kB appeared to be concentration responsive (Figure 6). Increased nuclear shuttling of NF-kB in heptachlor-treated pre-B cells was confirmed by ELISA (Figure 7). By interrupting binding of p65, we demonstrated specific binding capability of this assay. Addition of specific NF-kB-binding oligonucleotides resulted in complete loss of detection in

these assays (Figure 7) confirming assay specificity. Scrambled sense oligonucleotides were used as controls to further demonstrate binding was sequence specific and NF-kB protein was not blocked following incubation with these scrambled sequences.

\section{Blockade of NF-kB nuclear translocation abrogated heptachlor-induced pre-B}

\section{cell differentiation.}

In order to determine the role of NF-kB nuclear shuttling in heptachlor-induced differentiation of $70 Z / 3$ cells, NF-кB nuclear translocation was blocked by capsaicin, an inhibitor of I-kappa B kinase activation. Exposure of cells to this inhibitor dramatically reduced levels of p65 in nuclei of heptachlor-treated cells (Figure 8A) 
Figure 6: Heptachlor exposure increased nuclear abundance of NF-kB protein in pre-B cells.

A.) Nuclear protein levels of p65 were detected in $70 Z / 3$ cells at 30 minutes after heptachlor exposure by immunoblotting. B.) Densitometry of p65 protein bands was analyzed for 3 experiments and values normalized to $\sin 3 \mathrm{~A}$ protein bands for all samples. Statistically significant differences in p65 protein levels between control and heptachlor treatment groups are indicated by $\left({ }^{*}\right)=p<0.05$. 


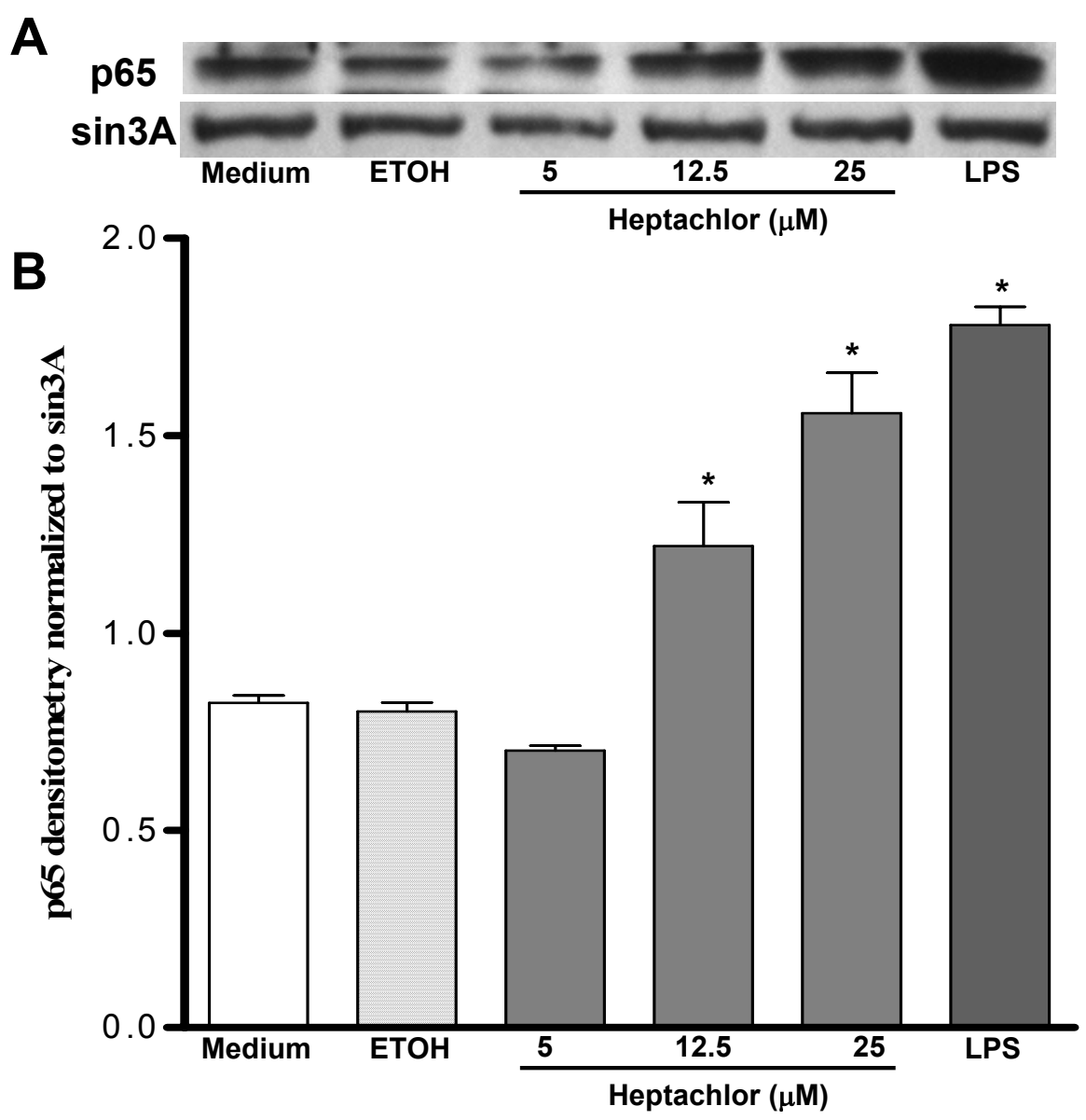

Figure 6: Heptachlor exposure increased nuclear abundance of NF-KB protein in pre-B cells 
Figure 7: ELISA confirmed that heptachlor exposure increased nuclear NF-kB protein in pre-B cells.

NF-kB-specific ELISAs were used to confirm nuclear levels of p65 in 70Z/3 cells exposed to increasing concentrations of heptachlor for 30 minutes. Nuclear protein samples from $25 \mu \mathrm{M}$-treated groups were incubated with blocking or scrambled oligonucleotides to demonstrate assay specificity. Statistically significant differences in p65 protein levels between control and heptachlor treatment groups are indicated by $\left({ }^{*}\right)=p<0.05$. Statistically significant differences in $p 65$ protein levels between 25 $\mu \mathrm{M}$ heptachlor treatment groups with and without blocking oligonucleotides are indicated by $(\#)=p<0.05$ 


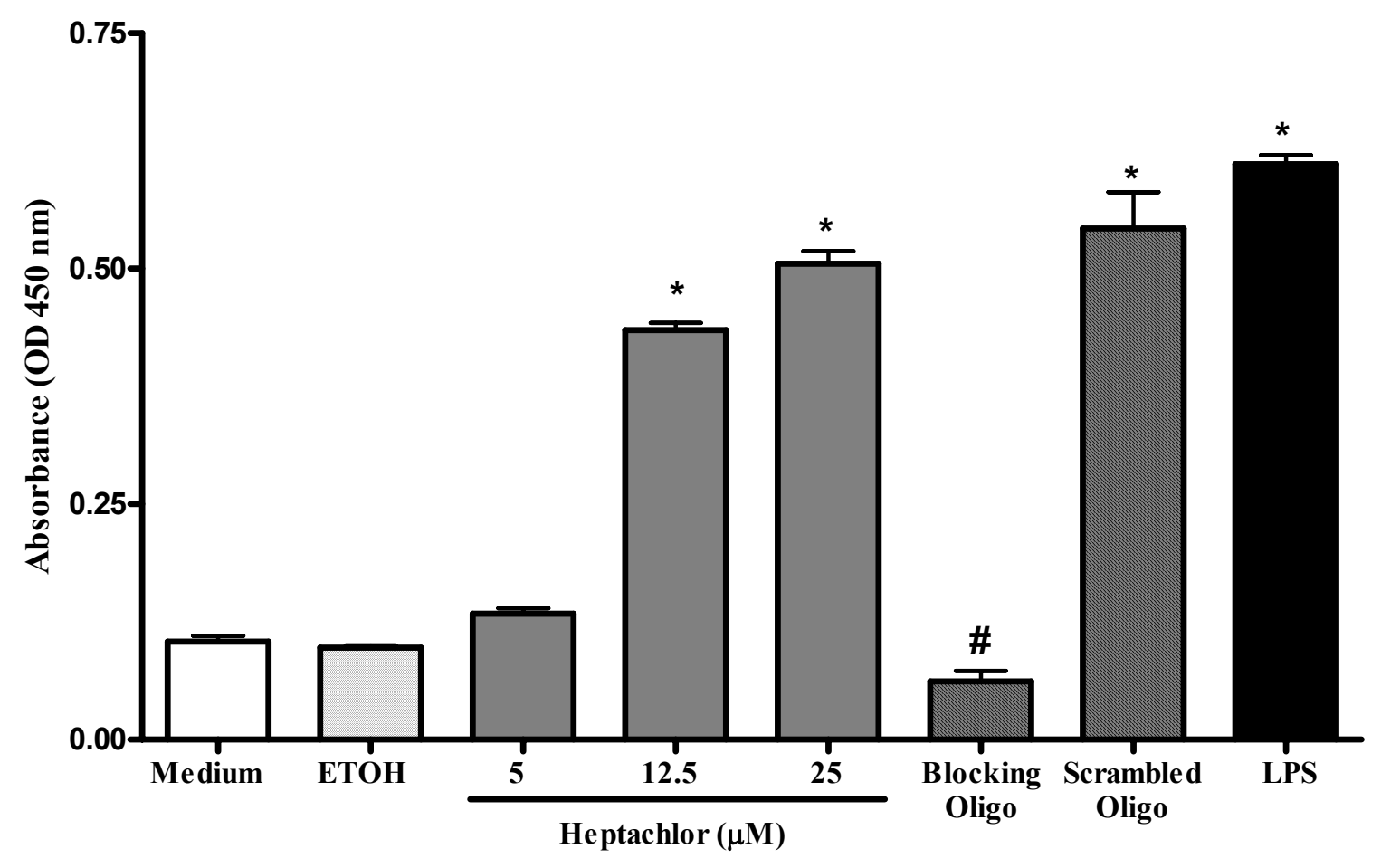

Figure 7: ELISA confirmed that heptachlor exposure increased nuclear NF-kB protein in pre-B cells 
Figure 8: Blockade of NF-kB nuclear translocation prevented differentiation of pre-B cells exposed to heptachlor.

$70 Z / 3$ cells were treated with capsaicin before heptachlor exposure to inhibit NF- B nuclear localization. A.) NF-kB was detected by immunoblotting in untreated and capsaicin-treated pre-B cells at 30 minutes following heptachlor exposure. B.) Untreated and capsaicin-treated $70 Z / 3$ cells exposed to heptachlor for 24 hours were examined for kappa protein using flow cytometric analysis. $\quad$ C.) Data from 3 experiments are shown examining $25 \mu \mathrm{M}$ heptachlor exposure in combination with capsaicin pretreatment. Statistically significant differences are indicated $\left({ }^{*}=p<0.05\right)$ in pre-B cell $\kappa$ protein expression between control and heptachlor treatment groups. 

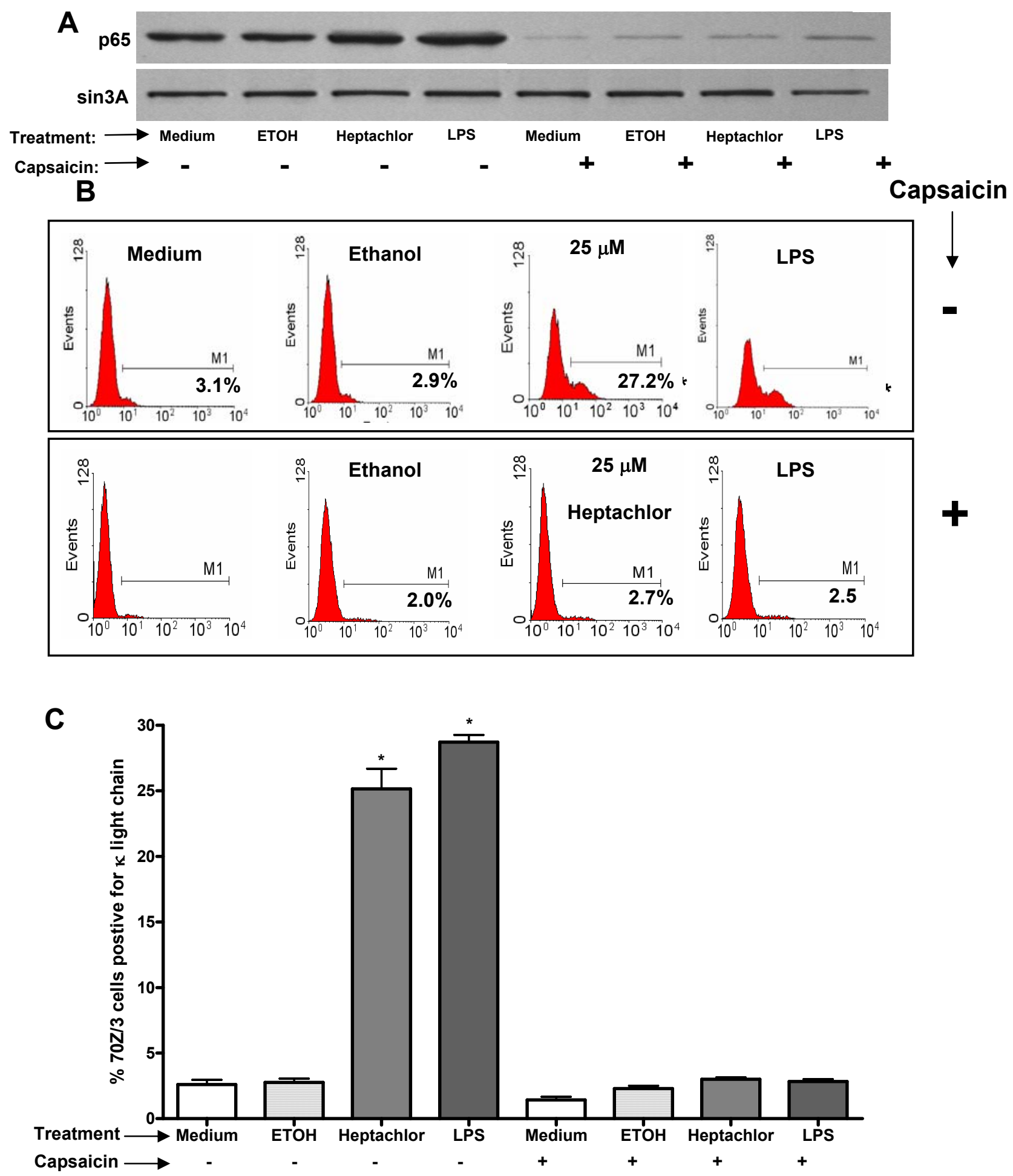

Figure 8: Blockade of NF-kB nuclear translocation prevented differentiation of pre-B cells exposed to heptachlor 
without reductions in pre-B cell viability (data not shown). Examination of kappa light chain expression after capsaicin treatment (Figures $8 \mathrm{~B}$ and $8 \mathrm{C}$ ) indicated that $70 \mathrm{Z} / 3$ cells did not express kappa immunoglobulin light chain protein following exposure to heptachlor. These data suggest that heptachlor exposure induced pre-B cell differentiation by altering nuclear shuttling of NF- $\mathrm{kB}$ and transcription of $\kappa$ genes.

\section{Discussion}

Prenatal exposure to organochlorine pesticides results in lifelong damage to the immune system (Barnett et al, 1990a; Barnett et al, 1990b; Barnett 1997; Dietert et al, 2000). We previously determined that prenatal exposure to heptachlor specifically altered lymphoid development without affecting myeloid cells. In the present study, we examined direct effects of heptachlor on the pre-B cell line 70Z/3. These pre-B cells rapidly proliferate and have a doubling time of approximately 8 to 10 hours. 70Z/3 cells can be induced to differentiate in the presence of LPS (Paige et al, 1978). We determined that exposure of $70 Z / 3$ cells to heptachlor resulted in withdrawal from replication, nuclear translocation of NF-kB, and expression of surface immunoglobulin (slg) at concentrations that did not alter cell viability. These data suggest that prenatal exposure to heptachlor damages development of the immune system, at least in part, by inducing premature differentiation of these lymphoid cells. 
Stages of B cell development are classified by rearrangement and expression of immunoglobulin genes (Rolink et al, 2000). In order to survive and form a B lymphocyte, developing cells must have productive immunoglobulin gene rearrangement of the heavy chain loci as well as productive rearrangement of the light chain gene. The heavy chain genes are rearranged first, followed by rearrangement of the light genes. Immunoglobulin gene rearrangement involves joining of a diversity $\left(D_{H}\right)$ loci to a joining $\left(J_{H}\right)$ loci. After completion of the $D_{H}$ to $J_{H}$ joining, the $D J_{H}$ segment is combined with a variable $\left(V_{H}\right)$ region. The sequence located between the newly formed $\mathrm{V}_{\mathrm{H}}-\mathrm{D}_{\mathrm{H}}-\mathrm{J}_{\mathrm{H}}$ segment and the constant (C) loci undergoes post transcriptional processing to remove intervening sequences. With the exclusion of a diversity region, light chain genes rearrange in the same manner as heavy chain genes. The $\mathrm{\kappa}$ heavy chain and the light chain assemble to form the $\mathrm{Ig}$ molecule which is then expressed on the cell surface (Rolink et al, 2000; Martensson et al, 2002).

$70 Z / 3$ cells have completed both heavy and light chain rearrangement, but do not actively express surface Ig protein (Paige et al, 1978). Regulation of kappa light chain gene transcription was described in pre-B cells by Sen and Baltimore (1986a) and involves NF-kB binding of specific recognition sequences upstream of kappa genes (Sen and Baltimore, 1986b; Gerondakis and Strasser, 2003). Based on previous literature describing activation of NF-kB regulating kappa light chain expression, we further characterized the effect of heptachlor on pre-B cells. We examined the possibility of heptachlor acting to block the NF-kB signaling pathway. 
$\mathrm{NF}-\kappa \mathrm{B}$, which is retained in the cell cytoplasm by inhibitor of kappa $\mathrm{B}(\mathrm{I}-\mathrm{k} \mathrm{B})$, is

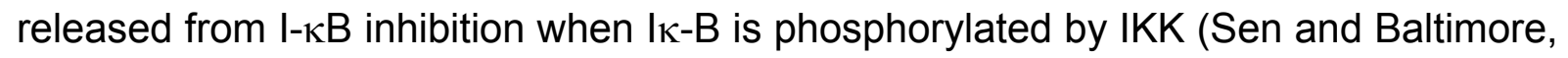
1986a; Sen and Baltimore, 1987). Upon phosphorylation by IKK and subsequent proteosomal degradation of $\mathrm{I}-\mathrm{\kappa B}$, the nuclear localization signal is unmasked, allowing NF-kB to translocate to the nucleus, and promote gene transcription through direct DNA interactions (Turco et al, 2004).

In the current study, $70 z / 3$ cells were induced to express kappa light chain along with heavy chain on the cell surface following heptachlor exposure. It was determined that $26 \%$ of $70 Z / 3$ cells expressed kappa light chain after heptachlor exposure for 24 hours indicating further differentiation of these pre-B cells to mature slg-expressing B cells. The entire cell population was not positive for kappa light chain protein possibly due to the lack of cell cycle synchrony within the cell cultures. We observed that in pre-B cells exposed to LPS, a stimulus known to induce kappa light chain expression, protein expression was similar when compared to cells exposed to heptachlor. It is known that LPS binds toll-like receptors on the surface of cells to stimulate NF-kB-involved cell signaling pathways (Krutzik et al, 2001; Medzhitov et al, 2001). Information regarding how heptachlor specifically interacts with these pre-B cells is lacking. Heptachlor could bind to cell receptors like LPS. Because of the highly lipophilic nature of heptachlor, it would also be plausible that heptachlor could pass through or intercalate into lipid-rich cell membranes. Even in the absence of information describing interactions between heptachlor and these 
lymphoid cells, these data indicate that heptachlor is a potent activator of NF-kB nuclear shuttling in these pre-B cells.

It is intriguing that, although both lymphoid and myeloid cells express NF-kB, in utero exposure to heptachlor differentially affected lymphoid cells, and myeloid progenitor cells were spared. Other investigators have recently published similar results (Nagashima et al, 2004; Feng et al, 2004). When mice were treated in vivo with pharmacological inhibitors of IKK, Nagashima et al (2004) reported lymphoid cell depletion of both the spleen and bone marrow. B lineage cells were affected in these mice, but in these same animals, myeloid cell production was unaffected. Taken together, these studies strongly suggest that NF-kB signaling is either not essential to myeloid cell development in hematopoietic tissues, or redundant mechanisms exist in myeloid cells which compensate for the loss of NF-kB signaling in cells exposed to heptachlor or an inhibitor of IKK function.

These data can be used to construct a unifying hypothesis of multiple tissue toxicity resulting from heptachlor exposure. In the present study, exposure of a preB cell line to heptachlor resulted in altered NF-kB signaling, diminished cell proliferation, and premature differentiation of treated cells. Many vertebrate cell

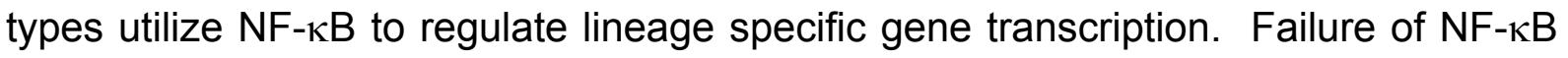
function in each of these cell types can be expected to lead to varied results and contribute to an array of maladies which characterize animals or humans exposed to heptachlor and other organochlorine pesticides. 


\section{Acknowledgements}

This research was supported by the National Institute of Environmental Health Sciences Training Grant ES010953. 


\section{References}

Agency for Toxic Substances and Disease Registry. 1992. Toxicological Profile for Heptachlor. US Public Health Service, US Department of Health and Human Services, Atlanta, Georgia.

Andrews, NC, DV Faller. 1991. A rapid micropreparation technique for extraction of DNA-binding proteins from limiting numbers of mammalian cells. Nucleic Acids Res 19(9):2499.

Barnett, J. 1997. Age-related susceptibility to immunotoxicants: animal data and human parallels. Environ Toxicol Pharm 4:315.

Barnett, J, B Blaylock, J Gandy, J Menna, R Denton, L Soderberg. 1990a. Long-term alteration of adult bone marrow colony formation by prenatal chlordane exposure. Fund Appl Toxicol 14:688.

Barnett, J. B Blaylock, J Gandy, J Menna, R Denton, L Soderberg. 1990b. Short Communication: Alteration of fetal liver colony formation by prenatal chlordane exposure. Fund Appli Toxicol 15:820.

Blaylock BL, L Soderberg, J Gandy, J Menna, R Denton, J Barnett. 1990. Cytotoxic T-lymphocyte and NK responses in mice treated prenatally with chlordane. Toxicol Lett 51(1):41.

Feng, B, S Cheng, WS Pear, HC Liou. 2004. NF-kB inhibitor blocks B cell development at two checkpoints. Medical Immunol 3(1):1.

Gerondakis S, and A Strasser. 2003. The role of Rel/NF-kappaB transcription factors in B lymphocyte survival. Semin Immunol 15(3);159. 
Giri, JG, PW Kincade, and SB Mizel. 1984 Interleukin 1-mediated induction of $\kappa$-light chain synthesis and surface immunoglobulin expression on pre-B cells. J Immunol 132(1): 223.

Han SS, Keum YS, Chun KS, Surh YJ. 2002. Suppression of phorbol ester-induced NF-kappaB activation by capsaicin in cultured human promyelocytic leukemia cells. Arch Pharm Res 25(4):475.

IARC Monographs Evaluating Carcinogenic Risks in Humans. 1991. Chlordane and heptachlor.53: 115.

Krutzik, S.R., Sieling, P.A., and Modlin, R.L. 2001. The role of toll-like receptors in host defense against microbial infection. Curr Opin Immunol 13: 104.

Kucharczak J, MJ Simmons, Y Fan, C Gelinas. 2003. To be, or not to be: NF-kappaB is the answer--role of Rel/NF-kappaB in the regulation of apoptosis. Oncogene. 2003 22(56):8961.

Martensson IL, A Rolink, F Melchers, C Mundt, S Licence, T Shimizu. 2002. The pre-B cell receptor and its role in proliferation and Ig heavy chain allelic exclusion. Semin Immunol 14(5):335.

Medzhitov, R. 2001. Toll-like receptors and innate immunity. Nature Rev Immunol 1: 135.

Nagashima, K, V Sasseville, J Deeds, A McDonald, K Kishimoto, JC GutierrezRamos, Y Xu, C Simpson, CC Fraser. 2004. Selective rapid B cell depletion in vivo by pharmacologic IKK2 inhibition. $12^{\text {th }}$ Internal Congress Immunol July 18. Montreal, CA. 
Office of Pesticide Programs. 1995. Internal Pesticide Notice. US Environmental Protection Agency.

Paige, CJ, PW Kincade, and P Ralph. 1978. Murine B cell leukemia with inducible surface immunoglobulin expression. J Immunol 121(2):641.

Rolink AG, C Schaniel, M Busslinger, SL Nutt, F Melchers. 2000. Fidelity and infidelity in commitment to B-lymphocyte lineage development. Immunol Rev 175:104.

Sen, R, D Baltimore. 1986a. Inducibility of kappa immunoglobulin enhancer-binding protein NF-kB by a posttranslational mechanism. Cell 47:921.

Sen R, D Baltimore.1986b. Multiple nuclear factors interact with the immunoglobulin enhancer sequences. Cell 46(5):705.

Sen R, D Baltimore. 1987. In vitro transcription of immunoglobulin genes in a B-cell extract: effects of enhancer and promoter sequences. Mol Cell Biol 7(5):1989.

Singh $H$, Sen R, Baltimore D, Sharp PA. 1986. A nuclear factor that binds to a conserved sequence motif in transcriptional control elements of immunoglobulin genes. Nature 319(6049):154.

Singh S, K Natarajan, BB Aggarwal, 1996. Capsaicin (8-methyl-N-vanillyl-6nonenamide) is a potent inhibitor of nuclear transcription factor-kappa $B$ activation by diverse agents. J Immunol 157(10):4412. 
Staudt LM, H Singh, R Sen, T Wirth, PA Sharp, D Baltimore. 1986. A lymphoidspecific protein binding to the octamer motif of immunoglobulin genes. Nature 323(6089):640.

Turco MC, MF Romano, A Petrella, R Bisogni, P Tassone, and S Venuta. 2004. NF$\kappa \mathrm{B} /$ Rel-mediated regulation of apoptosis in hematologic malignancies and normal hematopoietic progenitors. Leukemia 18:11. 
CHAPTER 4: In Vitro Heptachlor Exposure Alters NF-kB in Pro-B Cells 


\begin{abstract}
Human exposure to organochlorine pesticides has been correlated with hematotoxicity resulting in megaloblastic anemia and leukemia. Our laboratory previously found that in utero heptachlor exposure resulted in increased lymphoid progenitor cells with no alterations in myeloid progenitor cells. Because of this differential effect on lymphoid cell development, we examined effects of in vitro heptachlor exposure on pro-B cells. Exposure of the pro-B cell line $\mathrm{C} 1.92$ to heptachlor resulted in failure to proliferate and accelerated onset of apoptosis. Pro-B cells require stromal cell contact and cytokines produced by stromal cells for normal development. In our experiments, pro-B cells cultured with stromal cells were more resistant to the effects of heptachlor. Because the transcriptional regulator NF-kB is one of the signaling molecules involved in cell survival, we examined nuclear protein levels following heptachlor exposure. Both in the presence and absence of stromal cells, NF-kB was decreased in nuclei of pro-B cells after treatment with heptachlor. Decreased phosphorylation of I-אB following heptachlor exposure correlated with decreased nuclear shuttling of NF-kB. Taken together, these data suggested heptachlor exposure resulted in decreased survival and expansion of pro-B cells through altered NF-kB signaling.
\end{abstract}




\section{Introduction}

The organochlorine pesticides chlordane and heptachlor have been used abundantly and worldwide for insect control (IARC monographs, 1991; Agency for Toxic Substances and Disease Registry, 1992). Although the use of heptachlor has been banned in the United States, this pesticide can be detected at potentially toxic concentrations in the soil as a result of copious heptachlor use (Dewailly et al, 1999; Guruge et al, 2001; Senthilkumar et al, 2001; Stuetz et al, 2001). Because the halflife of heptachlor in soil ranges from 20 to 30 years, human exposure is a significant

concern. Humans and animals are exposed to heptachlor through ingestion of contaminated foods, absorption of the pesticide directly through the skin, or inhalation when in proximity to pesticide-treated areas (Office of Pesticide Programs, 1995; IARC, 1991, Dietert et al, 2000). Heptachlor is a lipiphilic molecule that can be metabolized to heptachlor epoxide or stored in adipose tissue following human or animal exposure (Fendick et al, 1990). For that reason, heptachlor stored in body fat has resulted in long-term exposure.

Exposure to organochlorine pesticides is associated with development of megaloblastic anemia, neuroblastoma, and leukemia in humans, and exposure to chlordane in utero has shown to be immunotoxic (Furie et al, 1976; Marchand et al, 1986; Barnett et al, 1990a; Barnett et al, 1990b). In utero exposure to chlordane resulted in hematopoietic stem cell deficiencies and alterations of leukocyte function in mice (Barnett et al, 1985; Barnett et al, 1990a). Macrophage tumoricidial function 
was also delayed in postnatal mice exposed to chlordane in utero (Theus et al, 1992). Heptachlor, which is structurally similar to chlordane, has also been determined to have effects on immune cell function (Barnett, 1997). Prenatal or postnatal exposure of rats to heptachlor resulted in suppressed primary IgM and secondary IgG antibody responses (Smialowicz et al, 2001). In vitro exposure of a hybrid $B$ and $T$ cell line to heptachlor resulted in decreased cell proliferation, cell cycle progression, and IL-2 production (Chuang et al, 1992; Chuang et al, 1999; Rought et al, 1999; Rought et al, 2000).

We investigated direct effects of heptachlor on hematopoiesis. Hematopoietic stem cells self-renew and differentiate into committed stem cells that progress to either myeloid or lymphoid cell lineages. Lineage-committed lymphoid and myeloid progenitors differentiate and mature to form cells of the adaptive and innate immune systems, respectively (Lichtman, 1984; Dorshkind, 1990; Landreth and Dodson, 2004 in press). Development of lymphoid progenitor cells requires interaction with supporting stromal cells (Collins et al, 1987; Landreth et al, 1988; Kierney et al, 1987; Billips et al, 1992; Dorshkind and Landreth, 1992; Namen et al, 1998; Akashi et al, 1998). A major goal of this study was to determine whether prenatal immunotoxicity of heptachlor was in part due to underlying hematotoxicty. Our initial studies involved in utero heptachlor exposure and resulted in increased numbers of lymphoid progenitor cells compared to controls (Chapter 2). However, in these same mice, no differences were noted in myeloid progenitor cells. 
In the present study, we examined the direct effects of heptachlor on lymphoid cells using an established hematopoietic pro-B cell line C1.92. C1.92 cells were derived from 14 day murine fetal liver and require direct contact with stromal cells and interleukin-7 (Gibson et al, 1993; Gibson et al, 1996). In the absence of stromal cells, pro-B cells were exquisitely sensitive to heptachlor with significantly decreased proliferation and cell survival. However, in cultures containing both pro-B and stromal cells, stromal cells provided protection from heptachlor-induced hematotoxicity. Because nuclear factor-kappa $B(N F-\kappa B)$ signaling is required for cell survival, we examined nuclear NF-kB protein levels in pro-B cells following heptachlor exposure (Gerondakis and Strasser, 2003; Kucharczak et al 2003; Turco et al, 2004). NF-kB was decreased in nuclei of pro-B cells after treatment with heptachlor. These data suggest that heptachlor exposure resulted in altered nuclear abundance of NF-kB which affects survival of pro-B cell.

\section{Materials and Methods}

Cell lines and cell culture conditions: $\mathrm{C} 1.92$ pro-B cells were isolated from a BALB/c embryonic day 14 liver and characterized previously (Gibson et al, 1993; Gibson et al, 1996). Standard cell culture medium was $\alpha$-modification of Eagle's medium (Cell Gro, MediaTech, Herndon, VA) with 5\% fetal bovine serum (FBS) (Hyclone, Logan, UT), 1\% penicillin/ streptomycin, 1\% I-glutamine, and $0.1 \% 2$ mercaptoethanol. Cultures were incubated at $37^{\circ} \mathrm{C}$ in a humidified incubator with $6 \%$ 
$\mathrm{CO}_{2}$. C1.92 required co-culture with $\mathrm{S} 10$ stromal cells and $20 \mathrm{ng}$ of recombinant interleukin-7 (IL-7) per ml of cell culture medium. S10 adherent stromal cells were cloned from BALB/c bone marrow and previously characterized (Collins LS and Dorshkind K, 1987; Landreth and Dorshkind, 1988; Henderson et al, 1990). Unless otherwise indicated, S10 cells were disassociated from tissue culture plates after 5 minute incubation with $0.05 \%$ trypsin-EDTA followed by FBS inactivation. $\mathrm{S} 10$ cells were allowed to adhere to tissue culture dishes before C1.92 cells were introduced into these cultures. In stromal cell experiments, S10 cultures were approximately at $95 \%$ confluence.

Heptachlor exposure: Stock heptachlor solution (Chem Service, West Chester, PA) was prepared at $10 \mu \mathrm{gs} / \mu \mathrm{l}$ in $95 \%$ ethanol. Cells were exposed to 0 to $25 \mu \mathrm{M}$ heptachlor in standard cell culture medium for 24 hours. Cell apoptosis was assessed by annexin $\mathrm{V}$ staining, and live cells were enumerated using trypan blue dye exclusion.

Antibodies: Annexin $V$ was utilized in detection of apoptotic cells (BD PharMingen, Los Angeles, CA). Antibodies utilized for immunoblotting were rabbit IgG (Southern Biotechnology, Birmingham, AL), rabbit anti-mouse p65 (Santa Cruz, Santa Cruz, CA), rabbit anti-mouse sin3A (Santa Cruz, Santa Cruz, CA), mouse anti-human actin (Santa Cruz, Santa Cruz, CA), rabbit anti-mouse IкB- $\alpha$ (C-21) (Santa Cruz, Santa Cruz, CA), rabbit anti-mouse phospho-IкB-a (B-9) (Santa Cruz, Santa Cruz, CA), 
goat anti-mouse IgG-HRP (Santa Cruz, Santa Cruz, CA), and goat anti-rabbit IgGHRP (Upstate Biotechnology, Lake Placid, NY).

Nuclear protein extraction: Nuclear protein extracts were prepared by hypotonic lysis of cytoplasmic membranes, followed by centrifugation $(14,000 \mathrm{rpm})$ at $4^{\circ} \mathrm{C}$ for 10 minutes and removal of cytoplasmic fractions. The remaining pellets were treated with a high salt lysis buffer to disrupt the nuclear membranes, and following similar centrifugation, nuclear proteins were subsequently collected (Andrews and Faller, 1991). Briefly, the hypotonic lysis buffer contained $10 \mathrm{mM}$ HEPES-KOH (pH 7.9), $1.5 \mathrm{mM} \mathrm{Mg} \mathrm{Cl}_{2}, 10 \mu \mathrm{M} \mathrm{KCl}, 0.5 \mu \mathrm{M}$ DTT , $0.2 \mu \mathrm{M}$ PMSF, $100 \mu \mathrm{M}$ pepstatin A, $100 \mu \mathrm{M}$ leupeptin, $100 \mu \mathrm{M}$ aprotinin, $0.2 \mu \mathrm{M}$ EGTA, and $0.2 \mu \mathrm{M}$ EDTA (pH 8). The high salt lysis buffer contained $20 \mu \mathrm{M}$ HEPES-KOH (pH 7.9), $25 \%$ glycerol (v/v), $420 \mu \mathrm{M} \mathrm{NaCl}$, $1.5 \mu \mathrm{M} \mathrm{MgCl}_{2}, 0.2 \mu \mathrm{M}$ EDTA (pH 8), $0.2 \mu \mathrm{M}$ EGTA, $0.5 \mu \mathrm{M}$ DTT, $0.2 \mu \mathrm{M}$ PMSF, 100 $\mu \mathrm{M}$ pepstatin $\mathrm{A}, 100 \mu \mathrm{M}$ leupeptin, and $100 \mu \mathrm{M}$ aprotinin. Protein extracts were quantitated using BioRad Protein Assay (Hercules, CA).

Proliferation Assay: C1.92 pro-B cells $\left(7.5 \times 10^{5} / \mathrm{ml}\right)$ were cultured with heptachlor, pulsed with $10 \mu \mathrm{Ci}$ of ${ }^{3} \mathrm{H}-\mathrm{TdR}$ after 18 hours in culture, and harvested 6 hours later. Cells were lysed, and DNA collected on glass filter strips by means of a PHD cell harvester (Cambridge Technology, Inc, Cambridge, MA.). Presence of radioactivity was evaluated by a Wallac 1410 liquid scintillation counter (Perkin Elmer, Downers Grove, IL). Experiments included at least three replicate wells for each treatment group. 
Immunoblotting: Protein samples (15 $\mu \mathrm{gs})$ were separated on $10 \%$ SDS-PAGE gels. Protein was transferred to $0.45 \mu \mathrm{M}$ nitrocellulose membranes (Schleicher and Schuell, Keene, $\mathrm{NH}$ ) and probed with specific antibodies in TBS with $0.1 \%$ tween-20 and $5 \%$ dry milk. Protein-bound membranes were incubated with specific primary antibody, followed by HRP-conjugated antibody, and protein detected using chemiluminescene (Amersham Biosciences, Piscataway, NJ). Following exposure of membranes to film (Kodak, Rochester, NY), densitometries of protein bands were evaluated using Eagle Eye II software (Stratagene, La Jolla, CA). Sin3A, a protein component of the deacetylation complex involved in DNA accession, was the internal loading control for all immunoblots. Densitometry values for p65 were normalized to Sin3A for each sample.

NF-kB immunoasay: C1.92 nuclear extracts were assayed for p65 levels using the TransAM ELISA (Active Motif, Carlsbad, CA). Briefly, oligonucletides specific for the Rel homology domain of the p65 subunit were immobilized on ELISA plates. The NF-kB-specific oligonucleotides were incubated with nuclear extracts from medium controls before sample proteins were allowed to bind plates. Scrambled oligonucleotides were used as negative controls for blocking p65 detection. T cell lysates were incorporated in the assays as positive controls in p65 detection.

Statistics: Data were analyzed using Instat statistical software (GraphPad Software, Inc., San Diego, CA). Data are presented as means \pm standard errors of the means 
(SEMs). Statistical differences were assessed using ANOVA to compare treatment groups. Dunnett's test was utilized to compare means, and $p$ values less than 0.05 indicated statistical significance.

\section{Results}

\section{Direct exposure to heptachlor in vitro resulted in decreased pro-B cell} proliferation.

In order to investigate exposure of early lymphoid cells to heptachlor, we evaluated effects of this pesticide on an established fetal liver pro-B cell line, C1.92. C1.92 proB cells are a non-transformed cell line that requires culture with $\mathrm{S} 10$ bone marrow stromal cells to maintain survival and proliferation. In the absence of stromal cells, pro-B cells exposed to low concentrations of heptachlor $(0.25 \mu \mathrm{M})$ decreased pro-B cell proliferation by $17 \%$ (Figure 1). C1.92 cells exposed to $1.25 \mu \mathrm{M}$ heptachlor demonstrated $84 \%$ reduction in proliferation. Replication was ablated in pro-B cells cultured in the absence of S10 cells and exposed to concentrations of heptachlor above $12.5 \mu \mathrm{M}$. These data suggested that pro-B cells were exquisitely sensitive to heptachlor treatment and exposure resulted in failure of pro-B cells to proliferate normally. 
Figure 1: Direct heptachlor exposure resulted in decreased pro-B cell proliferation.

Proliferation of C1.92 cells was determined following exposure to heptachlor $(-\square)$ or vehicle controls ( -- $\square--$ ) for 24 hours. Increasing concentrations of heptachlor $(0.25,1.25,2.512 .5$, and $25 \mu \mathrm{M})$ were added to pro-B cell cultures and proliferation

evaluated by ${ }^{3} \mathrm{H}-\mathrm{TdR}$ incorporation. Data presented here are representative of three experiments. Significant differences are indicated by $\left({ }^{*}\right)=p<0.05$ and $\left({ }^{* *}\right)=p<0.005$. 


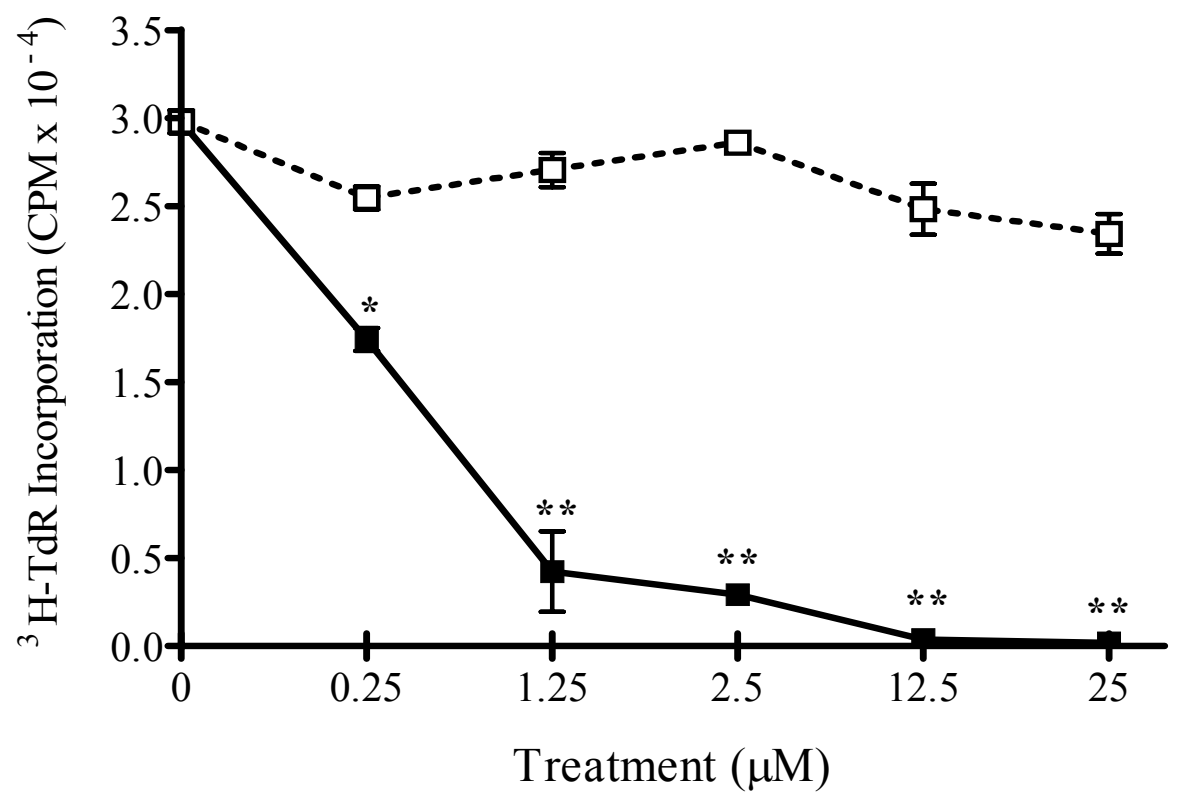

Figure 1: Direct heptachlor exposure resulted in decreased pro-B cell proliferation 


\section{Negative heptachlor effects on pro-B cell proliferation were diminished in the presence of stromal cells.}

Because stromal cells were important for pro-B cell proliferation, we examined effects of heptachlor on C1.92 cells cultured in the presence of S10 stromal cells. When pro-B cells were cultured with stromal cells, higher heptachlor exposure levels (12.5 and $25 \mu \mathrm{M}$ ) were required to observe heptachlor-induced decreased proliferation (Figure 2). Compared to pro-B cultures without stromal cells, 100-fold more (25 $\mu \mathrm{M})$ heptachlor was required to abrogate proliferation when S10 cells were present in C1.92 cultures. C1.92 cells cultured with S10 stromal cells proliferated at levels comparable to controls when exposed to heptachlor concentrations of $2.5 \mu \mathrm{M}$ and below. This suggested that at lower heptachlor concentrations, stromal cells protected C1.92 cells from decreased pro-B cell proliferation in assays. S10 cells cultured without pro-B cells were included to account for contribution of stromal cell

proliferation. S10 cells exhibit replication inhibition upon cell-cell contact (Collins and Dorshkind, 1987), and stromal cell cultures were utilized at $95-100 \%$ confluence. Background S10 proliferation levels were negligible, ranging from 400 to 1000 CPMs in experiments (data not shown).

\section{Heptachlor exposure accelerated pro-B cell apoptosis.}

In order to further investigate the effect of heptachlor on decreased pro-B cell proliferation, numbers of live pro-B cells were enumerated in these cultures. We determined that numbers of viable pro-B cells decreased with increasing concentrations of heptachlor (Figure 3 ). We also evaluated viability of C1.92 cells 
Figure 2: Negative heptachlor effects on pro-B cell proliferation were decreased in the presence of stromal cells.

Pro-B proliferation was assayed following increasing concentrations of heptachlor with S10 cells present in cultures. Proliferation was measured for vehicle-treated ( - - $\square--)$ and heptachlor-treated ( $-\square$ ) C1.92 cells cultured with S10 stromal cells. Cultures were pulsed with radioactively-labeled tritium at 18 hours and cells collected after 24 hours. Significant differences in pro-B cell proliferation are indicated between vehicle control and heptachlor-treated cultures. $\quad\left(^{*}\right)=p<0.05$ and $\left(^{* *}\right)=$ $p<0.005$ 


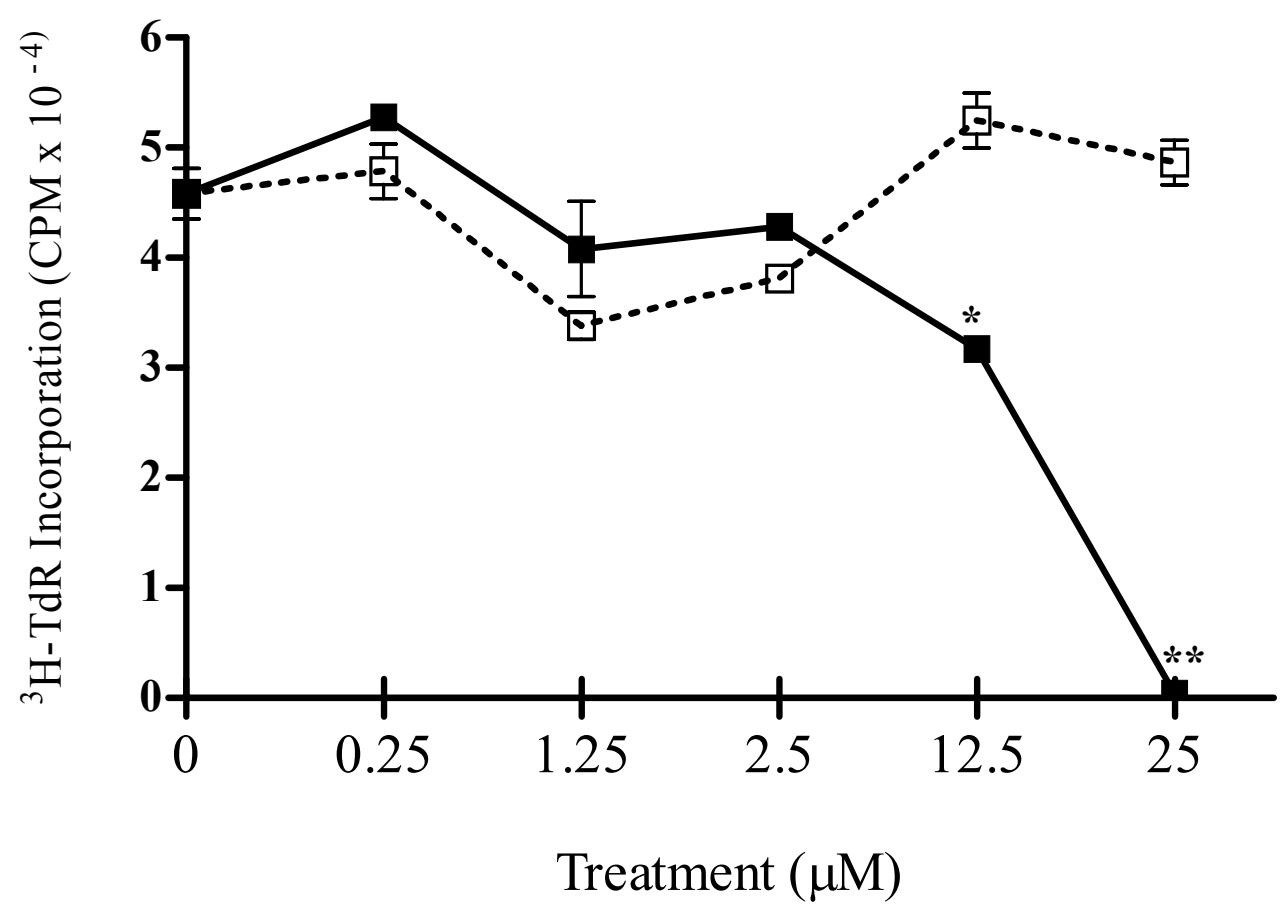

Figure 2: Negative heptachlor effects on pro-B cell proliferation were decreased in the presence of stromal cells 
Figure 3: Heptachlor exposure resulted in decreased numbers of pro-B cells in culture.

Viable pro-B cells were counted after 6,12 , and 24 hours following exposure to heptachlor or vehicle. Concentrations of heptachlor (shaded shapes) or equivalent volumes of ethanol (open shapes) added to cultures were $0.25 \mu \mathrm{M}(\Delta / \mathbf{\Delta}), \quad 2.5 \mu \mathrm{M}$ ( $\bigcirc / \bigcirc), 12.5 \mu \mathrm{M}(\nabla / \nabla)$, and $25 \mu \mathrm{M} \quad(\square / \boldsymbol{\square})$. Medium controls are indicated by stars. (A) C1.92 cells were exposed to heptachlor or the vehicle without S10 stromal cells present in cultures. (B) C1.92 cells were exposed to treatments with S10 cells in the cultures. Statistically significant differences in $\mathrm{C} 1.92$ cell viability between vehicle and heptachlor treatment groups are indicated by $\left(^{*}\right)=p<0.05$ and $\left(^{* *}\right)=$ $p<0.01$. 

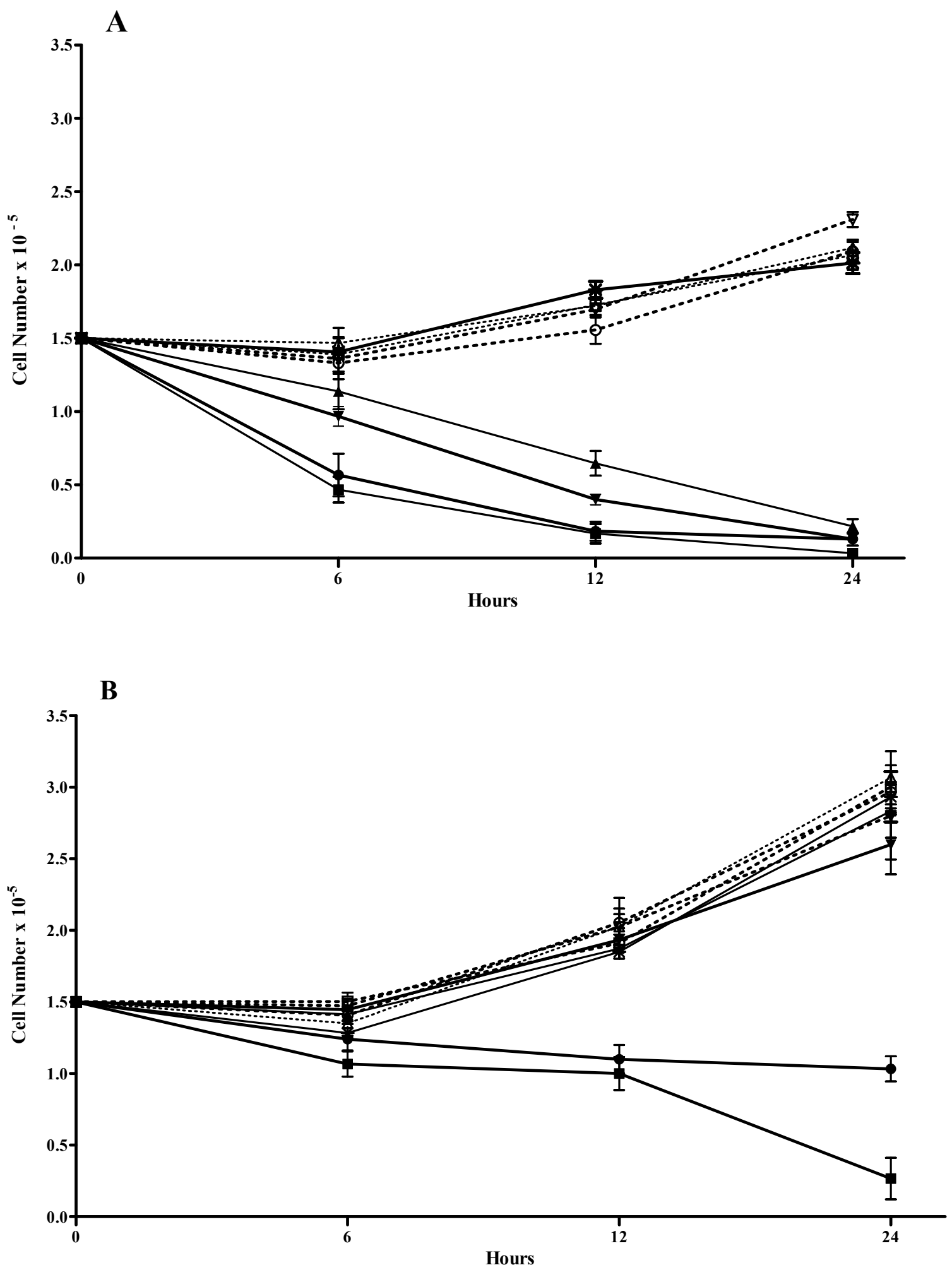

Figure 3: Heptachlor exposure resulted in decreased numbers of pro-B cells in culture 
Figure 4: Heptachlor exposure resulted in apoptosis of pro-B cells.

Numbered histograms correspond with agarose gel lanes examining DNA from medium (1) and vehicle (2) controls, C1.92 +S10 cultures exposed to $12.5 \mu \mathrm{M}$ heptachlor (3), and C1.92 removed from S10 for 24 hours (4). A.) C1.92 pro-B cells were stained with Annexin V. B.) DNA from $\mathrm{C} 1.92$ cells in the same treatment groups were electrophoresed through $1 \%$ agarose gels. DNA laddering present in lanes 3 and 4 . 
A
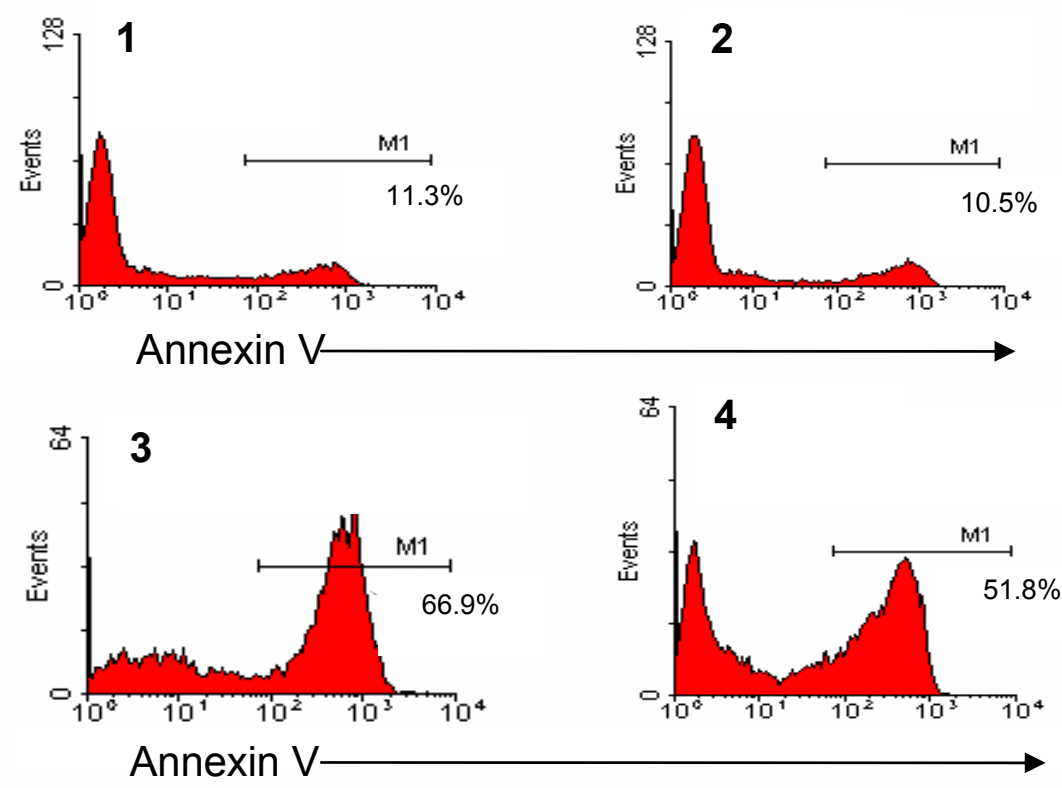

B

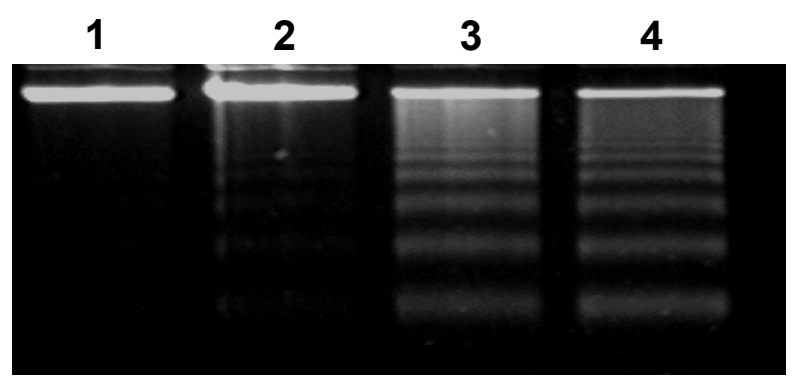

Figure 4: Heptachlor exposure resulted in apoptosis of pro-B cells 
following heptachlor exposure. The number of apoptotic cells increased from $11.3 \%$ in control cultures to $66.9 \%$ in cultures treated with $25 \mu \mathrm{M}$ heptachlor (Figure 4A). Data were confirmed by evaluating DNA from pro-B cells. DNA laddering present on agarose gels (Figure 4B) indicated apoptosis in pro-B cells exposed to heptachlorThese data suggested that heptachlor exposure altered mechanisms of pro-B cell survival.

\section{Heptachlor exposure altered NF-kB signaling in pro-B cells.}

Based on involvement of NF-кB signaling in apoptosis, we examined nuclear levels of NF-kB in C1.92 pro-B cells following exposure to heptachlor. Exposure of pro-B cells to $25 \mu \mathrm{M}$ heptachlor for 15 minutes resulted in dramatically decreased levels of nuclear NF-кB protein (Figures 5A and 5B). Exposure of pro-B cells to 5, 12.5 and $25 \mu \mathrm{M}$ concentrations of heptachlor resulted in dose-dependent-reductions of p65 protein $(43 \%, 65 \%$, and $89 \%$, respectively). Following 2 hours of $5 \mu \mathrm{M}$ heptachlor exposure, nuclear levels of NF-kB were virtually undetectable. These data were confirmed using NF-kB ELISA. Using this method, we additionally demonstrated decreased p65 protein in nuclei of pro-B cells exposed to heptachlor (Figure 6). We confirmed specificity of these assays using NF-kB DNA recognition sequences which blocked detection. These data suggested that exposure of pro-B cells to heptachlor resulted in dose-dependant alterations in nuclear shuttling of NF-kB. 
Figure 5: Heptachlor exposure diminished nuclear levels of NF-KB in pro-B cells.

A.) Nuclear protein levels of p65 were detected in pro-B cells at 15 minutes and 2 hours after heptachlor exposure by immunoblotting. B.) Densitometry of p65 protein bands was analyzed and values normalized to $\sin 3 \mathrm{~A}$ for all samples. Statistically significant differences in p65 protein levels were consistently found between control and heptachlor treatment groups. Results from one representative experiment are shown. 


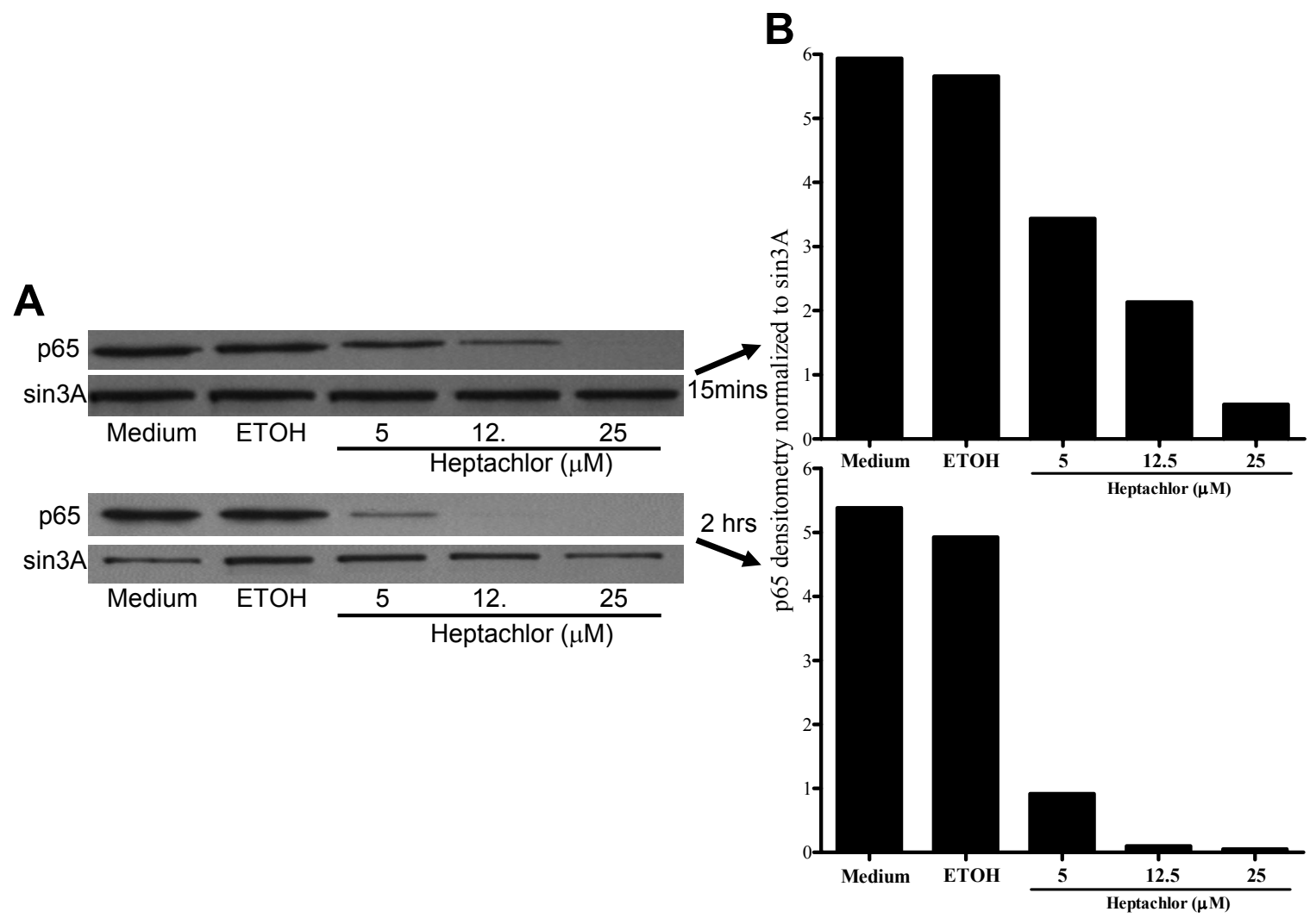

Figure 5: Heptachlor exposure diminished nuclear levels of NF-kB in pro-B cells 
Figure 6: ELISA confirmed that heptachlor exposure decreased nuclear NF-kB levels in pro-B cells.

NF-kB-specific ELISAs were used to confirm nuclear levels of p65 in C1.92 cells exposed to increasing concentrations of heptachlor for 15 minutes. Nuclear protein samples from medium control groups were incubated with blocking or scrambled oligonucleotides to demonstrate assay specificity. Statistically significant differences in p65 protein levels between control and heptachlor treatment groups are indicated by $\left({ }^{*}\right)=p<0.05$ and $\left({ }^{* *}\right)=p<0.01$. 


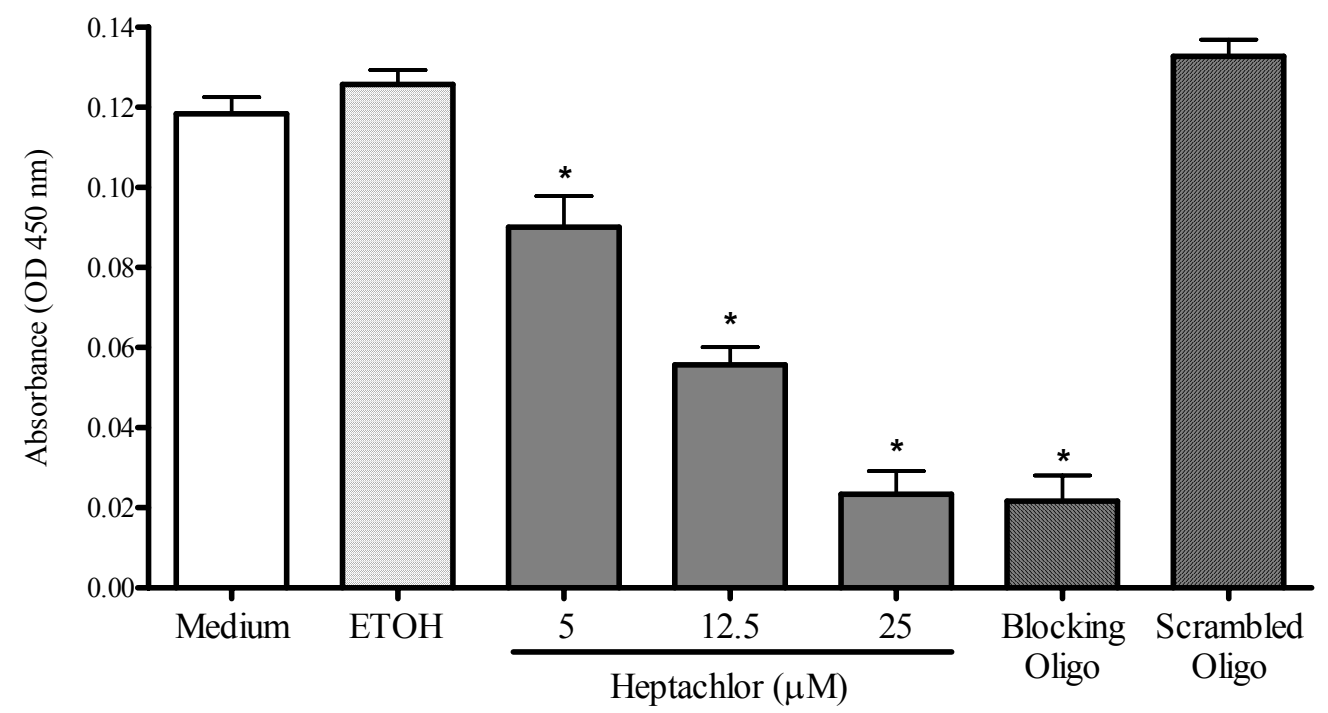

Figure 6: ELISA confirmed that heptachlor exposure decreased nuclear NF-kB levels in pro-B cells 


\section{Inhibitor of kappa B decreases nuclear shuttling of NF-kB.}

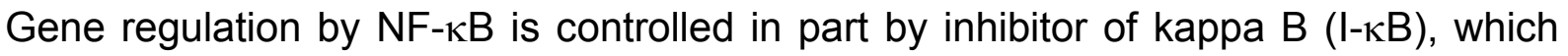
binds p65, and masks nuclear localization signals to retain NF-kB in the cytoplasm. Following cell stimulation, I-KB is phosphorylated by I-kappa kinase (IKK), targeting this inhibitor for degradation, and allowing NF-kB to translocate into the nucleus. We determined abundance of phosphorylated $\mathrm{I}-\mathrm{\kappa B}$ protein $(\mathrm{P}-\mathrm{I}-\mathrm{\kappa B})$ in relation to total $\mathrm{I}-\mathrm{\kappa B}$ protein. $\mathrm{P}-\mathrm{I}-\mathrm{kB}$ levels were examined in pro-B cells following heptachlor exposure for 15 minutes. P-I-kB protein was significantly diminished after 15 minutes exposure to $5 \mu \mathrm{M}$ heptachlor (Figure 7A). When stromal cells were present in cultures, $\mathrm{P}-\mathrm{I}-\mathrm{kB}$ in pro-B cells was significantly decreased at concentrations greater than $2.5 \mu \mathrm{M}$ heptachlor (Figure 7B). In cultures without stromal cells, P-I-kB also decreased in pro-B cells exposed to heptachlor (Figure 7C). However, in the absence of stromal cells, P-I-кB was significantly decreased at much lower heptachlor concentrations than when stromal cells were present in pro-B cell cultures. These data suggested that heptachlor exposure of pro-B cells resulted in a concentration-dependent decrease in phosphorylated I-אB protein.

\section{Discussion}

The overall goal of this study was to determine whether immunotoxicity following heptachlor exposure resulted from altered hematopoietic development of lymphocytes. Initial studies examining in utero heptachlor exposure resulted in 
Figure 7: Heptachlor exposure dose-dependently decreased phosphorylated I$\kappa B$ protein.

Cytoplasmic protein levels of phospho-I-KB were detected in pro-B cells by immunoblotting. Densitometries of phosphor-I-KB protein bands were analyzed and

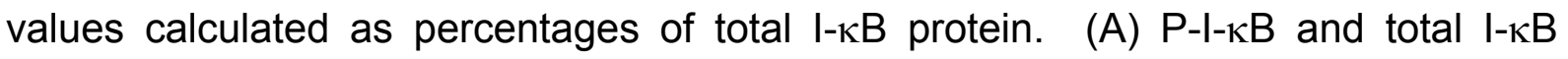
protein were detected after $0,5,10,15,30$, and 45 minutes following exposure to 5 אM heptachlor. (B) Pro-B cells in culture with stromal cells were treated with increasing concentrations of heptachlor for 15 minutes. (C) Pro-B cells without stromal cells in cultures were exposed to heptachlor for 15 minutes, and cytoplasmic P-I-KB was detected. Statistically significant differences in $\mathrm{I}-\kappa \mathrm{B}$ protein levels between control and heptachlor treatment groups are indicated by $\left({ }^{*}\right)=p<0.05,\left({ }^{* *}\right)=$ $p<0.01$, or $\left(^{* * *}\right)=p<0.005$ 
A

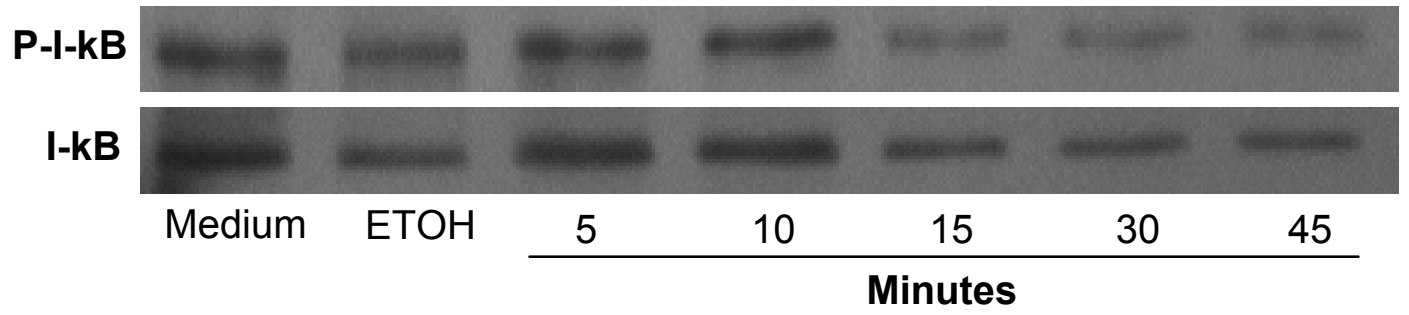

B

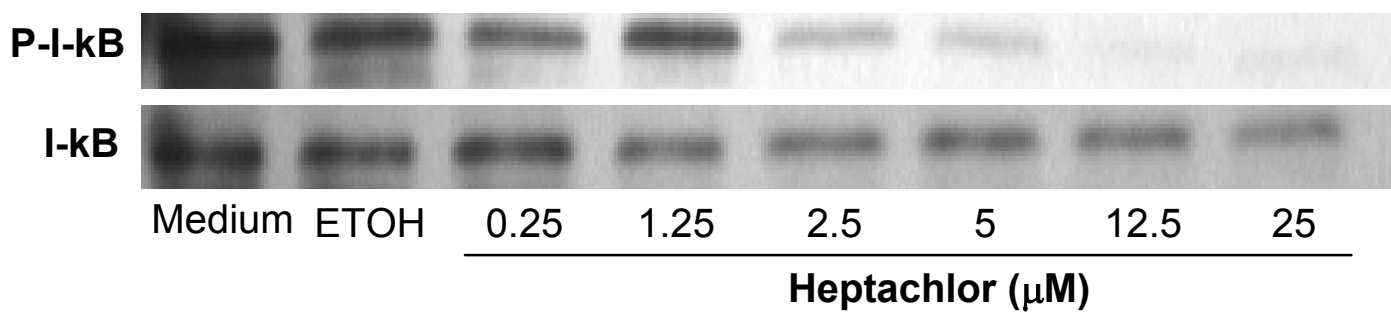

C

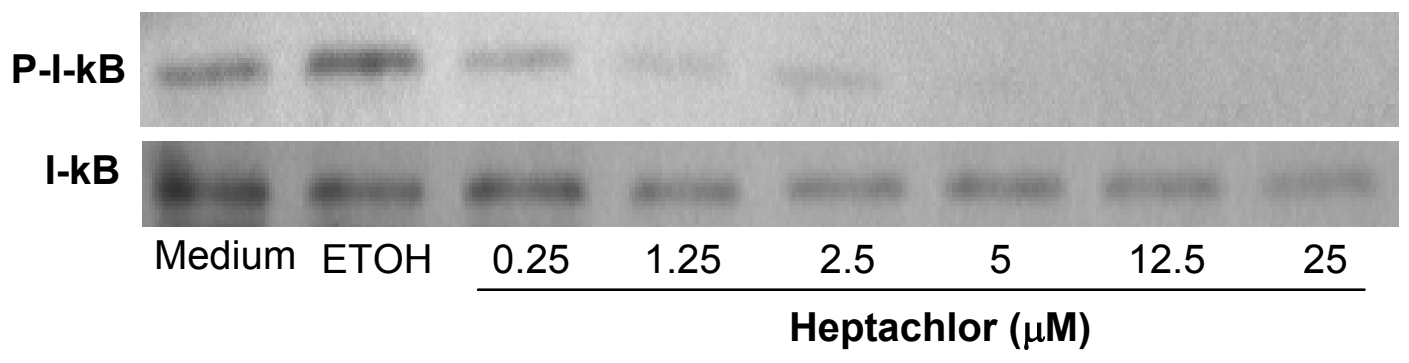

Figure 7: Heptachlor exposure dose-dependently decreased phosphorylated I-אB protein 
increased lymphoid progenitor cells compared to controls (Chapter 2). In these same embryos, no differences were noted in myeloid progenitor cells. Because of this effect of heptachlor on lymphoid cells, we evaluated heptachlor exposure on early lymphoid cells using C1.92 pro-B cells. Direct exposure of pro-B cells to heptachlor in vitro resulted in dramatic and significant decreases in both proliferation and numbers of viable cells. We also determined that NF-kB nuclear shuttling was decreased in pro-B cells following heptachlor exposure. A number of gene families involved in cell survival and programmed cell death are regulated in part by nuclear factor-kappa B. NF-kB is comprised of several proteins of the NF-kB family, which dimerize to form signaling complexes (Gerondakis and Strasser, 2003). The p65 and

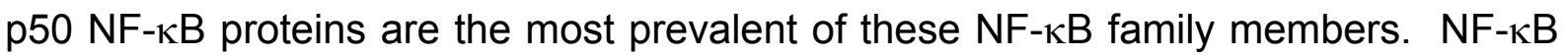
is held in the cytoplasm by unphosphorylated $\mathrm{I}-\kappa \mathrm{B}$ which binds to NF-kB and obstructs the nuclear localization signal (NLS). I-kB phosphorylation occurs by action of the inhibitor of kappa kinase (IKK). After phosphorylation, this kinase identifies I$\kappa \mathrm{B}$ for degradation through ubiquination and protesomal degredation (Turco et al,

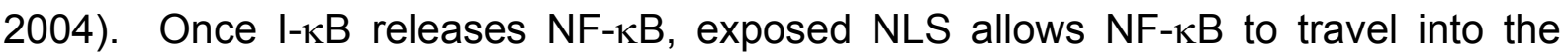
nucleus. Once in the nucleus, NF-kB specifically binds DNA recognition sites and promotes gene transcription.

In these studies, we determined nuclear NF-kB protein signaling was altered in pro-B cells, as indicated by decreased nuclear p65 protein following heptachlor exposure. NF-кB protein levels decreased in nuclei of pro-B cells after heptachlor treatment. We further determined that $\mathrm{P}-\mathrm{I}-\mathrm{\kappa} \mathrm{B} \alpha$ was decreased in pro-B cells 
exposed to heptachlor. This correlated with literature describing that

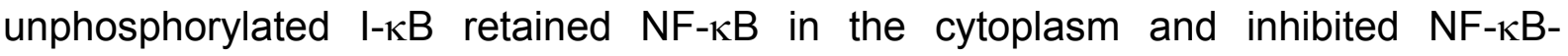
promoted gene transcription (Arenzana-Seisdedos et al, 1997). Taken together, these data suggested that heptachlor exposure resulted in altered nuclear abundance of NF-kB, which dramatically affected pro-B cell survival, essential to lymphopoiesis.

These data suggested that heptachlor exposure damaged lymphoid cell development by accelerated and premature apoptosis of pro-B cells. Events leading from heptachlor exposure to pro-B cell death are most likely mediated through mechanisms involving abrogation of NF-kB signaling. Interestingly, recent information from Nagashima et al (2004) described a surprising outcome when IKK was chemically blocked in mice. Similar to our results describing selective alteration of lymphoid cells after in vivo heptachlor exposure, lymphoid-committed cells, but not myeloid cells, were depleted from bone marrow and spleen of these mice (Nagashima et al, 2004). Additionally, other laboratories have documented that NF$\kappa \mathrm{B}$ inhibition results in a developmental block in progression from pro-B cells to pre-B cells (Feng et al, 2004). These studies correlate with data generated in our laboratory to paint a picture of heptachlor-induced toxicity, driven by alterations in NF- $\kappa B$ signaling.

These data can be used to develop a working hypothesis of the effect of heptachlor on vertebrate cells. In the current study, exposure of pro-B cells to 
heptachlor resulted in decreased NF-kB, ablated cell proliferation, and initiation of apoptosis of these treated pro-B cells. NF-kB regulates gene transcription in many kinds of cells, but it is unknown whether heptachlor toxicity involves alterations in NF$\kappa \mathrm{B}$ signaling in other types of cells. Because NF- $\mathrm{NB}$ is integral to ubiquitous cell signaling cascades, exposure to heptachlor could result in differing sequela in different cells. This complexity may account for the variety of defects reported following in vivo exposure to heptachlor and other related pesticides.

\section{Acknowledgements}

This research was supported by the National Institute of Environmental Health Sciences Training Grant ES010953. 


\section{References}

Agency for Toxic Substances and Disease Registry. 1992. Toxicological Profile for Heptachlor. US Public Health Service, US Department of Health and Human Services, Atlanta, Georgia.

Akashi, K, K Motonari, I Weissman. 1998. Role of interleukin-7 in T-cell development from hematopoietic stem cells. Immunol Rev 165:13.

Andrews, NC, DV Faller. 1991. A rapid micropreparation technique for extraction of DNA-binding proteins from limiting numbers of mammalian cells. Nucleic Acids Res 19(9):2499.

Arenzana-Seisdedos, F, P Turpin, M Rodriguez, D Thomas, RT Hay, JL Virelizier, C Dargemont. 1997. Nuclear localization of $\mathrm{I} K \mathrm{~B} \alpha$ promotes active transport of NF- B from the nucleus to the cytoplasm. J Cell Sci 110:369.

Barnett, J, L Soderberg, J Menna. 1985. The effect of prenatal chlordane exposure on the delayed hypersensitivity response of BALB/c mice. Toxicol Lett 25:173.

Barnett, J, B Blaylock, J Gandy, J Menna, R Denton, L Soderberg. 1990a. Long-term alteration of adult bone marrow colony formation by prenatal chlordane exposure. Fund Appl Toxicol 14:688.

Barnett, J, B Blaylock, J Gandy, J Menna, R Denton, L Soderberg. 1990b. Short Communication: Alteration of fetal liver colony formation by prenatal chlordane exposure. Fund Appli Toxicol 15:820. 
Barnett, J. 1997. Age-related susceptibility to immunotoxicants: animal data and human parallels. Environ Toxicol Pharm. 4:315.

Billips, L, D Petitte, K Dorshkind, R Narayanan, C Chiu, K Landreth. 1992. Differential roles of stromal cells, interleukin-7, and kit-ligand in the regulation of $B$ lymphopoiesis. Blood 79(5):1185.

Chuang, L, Y Liu, K Killam Jr, R Chuang. 1992. Modulation by the insecticides heptachlor and chlordane of the cell-mediated immune proliferative responses of Rhesus monkeys. In vivo 6:29.

Chuang, L, S Rought, R Chuang. 1999. Differential regulation of the major cyclindependent kinases, cdk2 and cdc2 during cell cycle progression in human lymphocytes exposed to heptachlor. In vivo 13:455.

Collins, L, K Dorshkind. 1987. A stromal cell line from myeloid long-term bone marrow cultures can support myelopoiesis and B lymphopoiesis. J Immunol 138(4):1982.

Dewailly, E, G Mulvad, H Pedersen, P Ayotte, A Demers, J Weber, J Hansen. 1999. Concentration of organochlorines in human brain, liver, and adipose tissue autopsy samples from Greenland. 107(10):823.

Dietert, R, R Etzel, D Chen, M Halonen, S Holladay, A Jarabek, K Landreth, D Peden, K Pinkerton, R Smialowicz, T Zoetis. 2000. Workshop to identify critical windows of exposure for children's health: Immune and respiratory systems work group summary. Environ Health Perspect 108(3):483.

Dorshkind, K. 1990. Regulation of hemopoiesis by bone marrow stromal cells and their products. Annual Rev Immunol 8:111. 
Dorshkind, K, K Landreth. 1992. Regulation of B cell differentiation by bone marrow stromal cells. Internat J Cell Clon 10:12.

Fendick, EA, E Mather-Mihaich, KA Houck, MB St Clair, JB Faust, CH Rockwell, M Owens. 1990. Ecological toxicology and human health effects of heptachlor. Rev Environ Contam Toxicol 111:61.

Feng, B, S Cheng, WS Pear, HC Liou. 2004. NF-kB inhibitor blocks B cell development at two checkpoints. Medical Immunol 3(1):1.

Furie, B, S Trubwitz. 1976. Insecticides and blood dyscrasias: Chlordane exposure and self-limited refractory megaloblastic anemia. JAMA 235:1720.

Gerondakis, S, A Strasser. 2003. The role of Rel/NF-kappaB transcription factors in B lymphocyte survival. Semin Immunol 15(3):159.

Gibson, L, D Piktel, R Narayanan, G Nunez, K Landreth. 1996. Stromal cells regulate bcl-2 and bax expression in pro-B cells. Exp Hematol 24:628.

Gibson, LF, D Piktel, KS Landreth. 1993. Insulin-like growth factor-1 potentiates expansion of interleukin-7-dependent pro-B cells. Blood 82(10):3005.

Guruge, K, S Tanabe. 2001. Contamination by persistent organochlorines and butyltin compounds in the West Coast of Sri Lanka. Marine Poll Bull 42:179.

Henderson, AJ, A Johnson, K Dorshkind. 1990. Functional characterization of two stromal cell lines that support B lymphopoiesis. J Immunol 145(2):423.

IARC Monographs Evaluating Carcinogenic Risks in Humans. 1991. Chlordane and heptachlor. 53:115. 
Kierney, P, K Dorshkind. 1987. B lymphocyte precursors survive in diffusion chamber cultures but $B$ cell differentiation requires close association with stromal cells. Blood $70: 1418$.

Kucharczak, J, MJ Simmons, Y Fan, C Gelinas. 2003. To be, or not to be: NFkappaB is the answer--role of Rel/NF-kappaB in the regulation of apoptosis. Oncogene. 2003 22(56):8961.

Landreth, K, K Dorshkind. 1988. Pre-B cell generation potentiated by soluble factors from a bone marrow stromal cell line. J Immunol 140(3):845.

Landreth, KS, SVM Dodson. 2004. Development of the rodent immune system. In: S Holladay (ed) Developmental Immunotoxicology. CRC Press.

Lichtman, M. 1984. The relationship of stromal cells to hemopoietic cells in marrow. Kroc Found Ser 18:3.

Marchand, L, L Kolonel, B Siegel, W Dendle III. 1986. Trends in birth defects for a Hawaiian population exposed to heptachlor and for the United States. Arch Environ Health 41(3):145.

Nagashima, K, V Sasseville, J Deeds, A McDonald, K Kishimoto, JC GutierrezRamos, Y Xu, C Simpson, CC Fraser. 2004. Selective rapid B cell depletion in vivo by pharmacologic IKK2 inhibition. $12^{\text {th }}$ Internal Congress Immunol July 18. Montreal, CA.

Namen, A, S Lupton, K Hjerrild, J Wignall, D Mochizuki, A Schmierer, B Mosley, C March, D Urdal, S Gullis, D Cosman, R Goodwin. 1998. Stimulation of B-cell progenitors by cloned murine interleukin-7. Nature 333(9):571. 
Office of Pesticide Programs. 1995. Internal Pesticide Notice. US Environmental Protection Agency.

Rought, S, P Yau, L Chuang, R Doi, R Chuang. 1999. Effect of the chlorinated hydrocarbons heptachlor, chlordane, and toxaphene on retinoblastoma tumor suppressor in human lymphocytes. Toxicol Lett 104:127.

Rought, S, P Yau, X Guo, L Chuang R Doi, R Chuang. 2000. Modulation of CPP32 activity and induction of apoptosis in human CEM x 174 lymphocytes by heptachlor, a chlorinated hydrocarbon insecticide. J Biochem Molecul Toxicol 14(1):42.

Senthilkumar, K, K Kannan, A Subramanian, S Tanabe. 2001. Accumulation of organochlorine pesticides and polychlorinated biphenyls in sediments, aquatic organisms, birds, bird eggs, and bats collected from South India. Environ Sci Pollut Res 8:1.

Smialowicz, R, W Williams, C Copeland, M Harris, D Overstreet, B Davis, R Chapin. 2001. The effects of perinatal/juvenile heptachlor exposure on adult immune and reproductive system function in rats. Toxicol Sci 61:164.

Stuetz, W, T Prapamontol, J Erhardt, H Classen. 2001. Organochlorine pesticide residues in human milk of a Hmong hill tribe living in Northern Thialand. Sci Total Environ 273:53.

Theus, SD, L Tabor. Soderberg, J. Barnett. 1992. Macrophage tumoricidal mechanisms are selectively altered by prenatal chlordane exposure. Agents Actions $37: 140$.

Turco, MC, MF Romano, A Petrella, R Bisogni, P Tassone, S Venuta. 2004. NF$\kappa \mathrm{B} /$ Rel-mediated regulation of apoptosis in hematologic malignancies and normal hematopoietic progenitors. Leukemia 18:11. 


\section{CHAPTER 5: In Vitro Heptachlor Exposure Alters Stromal \\ Cell Function}




\begin{abstract}
\end{abstract}
Human exposure to chlorinated pesticides such as heptachlor and chlordane has been correlated with hematotoxicity resulting in megaloblastic anemia and leukemia. Our laboratory determined that in utero heptachlor exposure resulted in increased lymphoid progenitor cells without altered numbers of myeloid progenitor cells. These results demonstrated a differential effect of heptachlor on lymphoid cell development and led to in vitro examination of heptachlor exposure on lymphoid pro-B cells. Exposure of C1.92 pro-B cells to heptachlor resulted in failure of cells to proliferate and accelerated onset of apoptosis. Pro-B cells require stromal cell contact and cytokines produced by stromal cells for normal development. In previous studies, C1.92 pro cells cultured with $\mathrm{S} 10$ stromal cells were more resistant to the effects of heptachlor. We also noted in previous experiments that the functional capacity of stromal cells to support pro-B cells diminished after exposure of S10 stromal cells to heptachlor. Evidence presented here demonstrates that heptachlor exposure altered stromal cell function in addition to previously described direct effects on pro-B cells. Exposure of stromal cells to heptachlor resulted in increased expression of stem cell factor (SCF) mRNA following treatment with low heptachlor concentrations and decreased SCF mRNA abundance at higher heptachlor concentrations. SCF protein levels corresponded with mRNA alterations following heptachlor exposure. IGF-1 and IL-7 mRNA abundance was not changed after heptachlor exposure. S10 cells also had decreased VCAM-1 surface expression after exposure to $25 \mu \mathrm{M}$ heptachlor. Stromal cells exposed to heptachlor had decreased nuclear levels of NF-kB. Taken 
together, these data suggest heptachlor exposure resulted in altered stromal cell function at least in part through altered NF-kB signaling.

\section{Introduction}

Stromal cells comprise a crucial component of the bone marrow microenvironment (Lichtman, 1984). It is within this microenvironment, made up of endothelial cells, adipocytes, and fibroblasts, that hematopoietic cells interact closely with stromal cells (Chen and Weiss, 1975). Hematopoietic stem cells self-renew and differentiate into cells committed to either the myeloid or lymphoid lineage (Potten and Loeffler, 1990; Jordan and Lemischka, 1990). Lineage-committed lymphoid and myeloid progenitors differentiate and mature to form cells of the adaptive and innate immune systems, respectively (Akashi et al, 1998). Adhesion molecules expressed on the surface of stromal cells, along with cytokines produced by these cells, regulate survival, proliferation, and differentiation of lymphoid and myeloid cells (Kierney et al, 1987; Landreth et al, 1988; Dorshkind, 1990; Dorshkind et al, 1992; Billips et al, 1992; Namen et al, 1998; Landreth et al, 1992; Schatz and Malissen, 2002; Borowski et al, 2002; Nutt et al, 199). These mature effector cells, which have a finite lifespan, are continuously repopulated from committed progenitor cells to maintain hematopoietic homeostasis. 
Our laboratory is interested in hematopoiesis, and specially, the effect that the organochlorine pesticides chlordane and heptachlor have on blood cell production. It is documented that exposure to heptachlor and chlordane is correlated with development of megaloblastic anemia, neuroblastoma, and leukemia in humans (Furie et al, 1976; Marchand et al, 1986; Barnett et al, 1990a; Barnett et al, 1990b). Several studies have established a link between in utero chlordane exposure and immunotoxicity. In utero exposure of mice to chlordane resulted in hematopoietic stem cell deficiencies and alterations of leukocyte function (Barnett et al, 1985; Barnett et al, 1990a). Macrophage tumoricidial capacity was also delayed in postnatal mice exposed to chlordane in utero (Theus et al, 1992). Heptachlor has also been determined to have similar effects on immune cell function. Prenatal or postnatal exposure of rats to heptachlor resulted in suppressed primary IgM and secondary IgG antibody responses (Smialowicz et al, 2001). Previous studies in our lab determined that prenatal administration of heptachlor resulted in increased numbers of early lymphoid progenitor cells in the fetal liver of gestational day 17 BALB/c mice (Chapter 2). When compared to controls, in utero heptachlor exposure did not alter myeloid progenitor cells in these same animals.

For several decades, the insecticide heptachlor was abundantly applied to buildings to prevent termite damage and also to crops to protect from insect destruction (Agency for Toxic Substances, 1992). Heptachlor can be found at potentially toxic concentrations in soil as a result of profuse pesticide application combined with long-term environmental stability of this pesticide (Dewailly et al, 1999; 
Guruge et al, 2001; Senthilkumar et al, 2001; Stuetz et al, 2001). Humans and animals are exposed to heptachlor through ingestion of contaminated foods, dermal absorption of the pesticide, or inhalation when in proximity to pesticide-treated areas (Fendick et al, 1990; IARC, 1991; Office of Pesticide Programs, 1995; Dietert et al, 2000). Heptachlor accumulates in adipose tissue due to the lipophilic nature of the molecule, and for that reason, heptachlor stored in body fat has resulted in continual pesticide exposure. Heptachlor is toxic to humans, causing acute symptoms of vomiting, gastrointestinal distress, and chronic episodes of seizures and sinusitis (Agency for Toxic Substances, 1992).

We currently have investigated direct effects of heptachlor on hematopoiesis. Previous studies in our lab examined direct effects of heptachlor on lymphoid cells using an established hematopoietic pro-B cell line C1.92 (Gibson et al, 1993; Gibson et al, 1996). In the absence of stromal cells, pro-B cells were exquisitely sensitive to heptachlor and had significantly decreased proliferation and cell survival. However, in cultures containing both pro-B and stromal cells, S10 stromal cells provided protection from heptachlor-induced pro-B cell hematotoxicity.

Because stromal cell capacity to support pro-B cell proliferation diminished after exposure to higher heptachlor concentrations, we have recently examined effects of heptachlor exposure on S10 stromal cells. Evidence is provided to support the hypothesis that heptachlor exposure altered not only lymphoid cells but also stromal cell function. Evaluation of cytokine production by $\mathrm{S} 10$ cells exposed to 
heptachlor revealed that stem cell factor (SCF) mRNA abundance and protein levels increased at low concentrations of heptachlor but both SCF mRNA and protein were decreased following exposure to higher heptachlor concentrations. S10 cells also had decreased VCAM-1 surface expression after exposure to $25 \mu \mathrm{M}$ concentrations of heptachlor. Previous results from our laboratory indicated that heptachlor altered NF-kB shuttling in both pro-B and pre-B cells, so we also examined S10 cells for changes in NF-kB signaling. In $\mathrm{S} 10$ cells, nuclear levels of NF-kB were decreased following heptachlor exposure. Taken together, these data suggested that heptachlor exposure resulted in altered nuclear abundance of NF-кB which affected the ability of stromal cells to support lymphopoiesis.

\section{Materials and Methods}

Cell lines and cell culture conditions: S10 adherent stromal cells were cloned from BALB/c bone marrow and previously characterized (Collins and Dorshkind, 1987; Landreth and Dorshkind, 1988; Henderson et al, 1990). Standard cell culture medium was $\alpha$-modification of Eagle's medium (Cell Gro, MediaTech, Herndon, VA) with $5 \%$ fetal bovine serum (FBS) (Hyclone, Logan, UT), 1\% penicillin/ streptomycin, $1 \%$ I-glutamine, and $0.1 \% 2$-mercaptoethanol. Cultures were incubated at $37^{\circ} \mathrm{C}$ in a humidified incubator with $6 \% \mathrm{CO}_{2}$. Unless otherwise indicated, $\mathrm{S} 10$ cells were disassociated from tissue culture plates after 5 minute incubation with $0.05 \%$ trypsinEDTA followed by FBS inactivation. In experiments, S10 cell cultures were 
approximately at $95 \%$ confluence. C1.92 pro-B cells were isolated from a BALB/C embryonic day 14 liver and characterized previously (Gibson et al, 1993; Gibson et al, 1996). C1.92 required co-culture with S10 stromal cells and $20 \mathrm{ng}$ of recombinant interleukin-7 (IL-7) per milliliter (ml) of standard cell culture medium.

Heptachlor exposure: Stock heptachlor solution (Chem Service, West Chester, PA) was prepared at $10 \mu \mathrm{gs} / \mu \mathrm{l}$ in $95 \%$ ethanol. Cells were exposed to 0 to $25 \mu \mathrm{M}$ heptachlor in standard cell culture medium for 24 hours. Cell apoptosis was assessed by annexin $\mathrm{V}$ staining, and live cells were enumerated using trypan blue dye exclusion.

Proliferation Assay: C1.92 pro-B cells $\left(7.5 \times 10^{5} / \mathrm{ml}\right)$ were cultured with heptachlor, pulsed with $10 \mu \mathrm{Ci}$ of ${ }^{3} \mathrm{H}-\mathrm{TdR}$ after 18 hours in culture, and harvested 6 hours later. Cells were lysed, and DNA collected on glass filter strips by means of a PHD cell harvester (Cambridge Technology, Inc, Cambridge, MA.). Presence of radioactivity was evaluated by a Wallac 1410 liquid scintillation counter (Perkin Elmer, Downers Grove, IL). Experiments included at least three replicate wells for each treatment group.

Antibodies: Antibodies used in flow cytometric analysis of surface staining were rat anti-mouse VCAM-1 in conjunction with FITC-labeled goat anti-rat antibody to detect anti-VCAM-1 antibody (BD PharMingen, Los Angeles, CA). Antibodies utilized for immunoblotting were rabbit IgG (Southern Biotechnology, Birmingham, $A L$ ), rabbit 
anti-mouse p65 (Santa Cruz, Santa Cruz, CA), rabbit anti-mouse sin3A (Santa Cruz, Santa Cruz, CA), and goat anti-rabbit IgG-HRP (Upstate Biotechnology, Lake Placid, NY).

Cell surface staining: For immunofluorescent cell surface staining, $10^{6}$ cells were pelleted (1,200 RPM centrifugation at $4^{\circ} \mathrm{C}$ for 7 minutes) and washed with cold PBS with $0.1 \%$ FBS. After centrifugation, cell pellets were resuspended in $200 \mu \mathrm{ls}$ of PBS with $1 \mu \mathrm{g}$ of antibody and placed on ice for 1 hour. Excess antibody was removed by washing with cold PBS followed by centrifugation. Cells were fixed in $2 \%$ paraformaldehyde and analyzed for cell surface staining on FACScan (Becton Dickinson, San Jose CA).

Nuclear protein extraction: Nuclear protein extracts were prepared by hypotonic lysis of cytoplasmic membranes, followed by centrifugation $(14,000 \mathrm{rpm})$ at $4^{\circ} \mathrm{C}$ for 10 minutes and removal of cytoplasmic fractions. The remaining pellets were treated with a high salt lysis buffer to disrupt the nuclear membranes, and following similar centrifugation, nuclear proteins were subsequently collected (Andrews and Faller, 1991). Briefly, the hypotonic lysis buffer contained $10 \mu \mathrm{M}$ HEPES-KOH (pH 7.9), 1.5 $\mu \mathrm{M} \mathrm{Mg} \mathrm{Cl} 2,10 \mu \mathrm{M} \mathrm{KCl}, 0.5$ mM DTT , $0.2 \mu \mathrm{M}$ PMSF, $100 \mu \mathrm{M}$ pepstatin A, $100 \mu \mathrm{M}$ leupeptin, $100 \mu \mathrm{M}$ aprotinin, $0.2 \mu \mathrm{M}$ EGTA, and $0.2 \mu \mathrm{M}$ EDTA (pH 8). The high salt lysis buffer contained $20 \mu \mathrm{M}$ HEPES-KOH $(\mathrm{pH} 7.9), 25 \%$ glycerol (v/v), $420 \mu \mathrm{M}$ $\mathrm{NaCl}, 1.5 \mu \mathrm{M} \mathrm{MgCl}, 0.2 \mu \mathrm{M}$ EDTA $(\mathrm{pH}$ 8), $0.2 \mu \mathrm{M}$ EGTA, $0.5 \mu \mathrm{M}$ DTT, $0.2 \mu \mathrm{M}$ 
PMSF, $100 \mu \mathrm{M}$ pepstatin A, $100 \mu \mathrm{M}$ leupeptin, and $100 \mu \mathrm{M}$ aprotinin. Protein extracts were quantitated using BioRad Protein Assay (Hercules, CA).

Immunoblotting: Protein samples (15 $\mu \mathrm{gs})$ were separated on $10 \%$ SDS-PAGE gels. Protein was transferred to $0.45 \mathrm{mM}$ nitrocellulose membranes (Schleicher and Schuell, Keene, $\mathrm{NH}$ ) and probed with specific antibodies in TBS with $0.1 \%$ tween-20 and $5 \%$ dry milk. Protein-bound membranes were incubated with specific primary antibody, followed by HRP-conjugated antibody, and protein detected using chemiluminescene (Amersham Biosciences, Piscataway, NJ). Following exposure of membranes to film (Kodak, Rochester, NY), densitometries of protein bands were evaluated using Eagle Eye II software (Stratagene, La Jolla, CA). Sin3A, a protein component of the deacetylation complex involved in DNA accession, was the internal loading control for all immunoblots. Densitometry values for p65 were normalized to Sin3A for each sample.

RNA isolation and RT-PCR: $\mathrm{S} 10$ stromal cells were cultured to $95-100 \%$ confluence and RNA extracted using SNAP total RNA isolation kit (Invitrogen, Carlsbad, CA). mRNA samples were amplified using One-Step RT-PCR reaction kit (Qiagen, Valencia, CA). All primer sets were specific for amplification of murine mRNA and synthesized by Biosource International (Camarillo, CA). Primers were utilized to amplify murine IL-7, IGF-1, SCF, $\beta$-actin, and GAPDH DNA (Billips et al, 1992; Landreth et al, 1992) (Table 1). GAPDH and $\beta$-actin were gel loading and amplification positive controls. The RT-PCR program began with a hot-start of $50^{\circ} \mathrm{C}$ 
Table 1: Cytokine and housekeeping gene primers sets.

IL-7, IGF-1, SCF, $\beta$-actin, and GAPDH primers were used to amplify murine cDNA synthesized from stromal cell mRNA. Primer sequences were reported $5^{\prime} \rightarrow 3$ '. 


\begin{tabular}{|c|c|c|}
\hline Cytokine & Sense Primer & Antisense Primer \\
\hline IL-7 & GCCTGTCACATCATCTGAGTGCC & CAGGAGGCATCCAGGAACTTCTG \\
\hline IGF-1 & GACCCTTTGCGGGGCTGAGCTGGT & CTTCTGAGTCTTGGGCATGTCAGT \\
\hline SCF & CGTACTGCAGCCTTTCCTTAT & GGCTTTCCTATTACTGCTACT \\
\hline p-ACtin & AAGCGCCCCATGAATGCATT & TCCCAGCTGCTTGCTGATCT \\
\hline GAPDH & TGAAGGTCGGTGTGAACGGATTTGG & ACGACATACTCAGCACCGGCCTCAC \\
\hline
\end{tabular}

Table 1: Cytokine and housekeeping gene primers sets 
for 30 minutes and $95^{\circ} \mathrm{C}$ for 15 minutes. This was followed by heating and cooling cycles of $94^{\circ} \mathrm{C}$ for 30 seconds, $60^{\circ} \mathrm{C}$ for 1 minute, $72^{\circ} \mathrm{C}$ for 10 seconds. The entire replication cycle was repeated for approximately 32 cycles. Product amplification was within increasing linear ranges of replication. PCR products were run on $1 \%$ agarose gels. Densitometry of PCR products was analyzed using the EagleSight software (Stratagene, La Jolla, CA). Densitometry readings for cytokine amplified products were normalized to either GAPDH or actin RT-PCR products.

SCF protein immunoassay: S10 cells were cultured to $95 \%$ confluence before exposed to heptachlor for 24 hours. Cultures were treated with GolgiStop (BD PharMingen, Los Angeles, CA) 12 hours before collection to retain SCF protein within the cells. These adherent stromal cells were removed from culture dishes using 10 minute incubation with cell dissociation solution (Sigma Aldrich, St. Louis, MO). Protein was collected using lysis reagent (Endogen, Woburn, MA) followed by centrifugation to remove cell debris. SCF protein was detected in S10 lysates by use of murine SCF Quantikine ELISAs ( $R$ \& D Systems, Minneapolis, MN). Standard curves of SCF protein conducted in parallel with cell lysates allowed calculation of SCF protein in samples.

Statistics: Data were analyzed using Instat statistical software (GraphPad Software, Inc., San Diego, CA). Data are presented as means \pm standard errors of the means (SEMs). Statistical differences were assessed using ANOVA to compare multiple treatment groups, and Dunnett's test was utilized to evaluate these means. Student's 
T-test was used to determine statistical significance between individual groups. Statistical significance was indicated by $p$ values less than 0.05 .

\section{Results}

\section{Heptachlor exposure did not affect stromal cell viability.}

We evaluated whether heptachlor exposure altered survival or proliferation of S10 stromal cells. Heptachlor did not affect the ability of S10 to adhere to tissue culture plates or alter the morphology of S10 cells (data not shown). S10 cell viability, measured by trypan blue dye exclusion (data not shown) and annexin $\mathrm{V}$ staining (Figure $1 \mathrm{~A}$ ), was not reduced following treatment with $25 \mu \mathrm{M}$ heptachlor. $\mathrm{S} 10$ cells were able to repopulate new culture plates when these stromal cells were passaged following treated with $25 \mu \mathrm{M}$ heptachlor. Additionally, DNA isolated from heptachlortreated S10 cells was examined on agarose gels, and no DNA laddering, indicative of cell apoptosis, was observed (Figure 1B).

Heptachlor exposure decreased the ability of stromal cells to support pro-B proliferation.

Our previous studies concluded that the ability of stromal cells to protect pro-B cells from accelerated apoptosis was diminished at heptachlor concentrations above 12.5 $\mu \mathrm{M}$ (Chapter 4). Because of the observed loss of pro-B cell protection from apoptosis in co-cultures at $25 \mu \mathrm{M}$ heptachlor, S10 cells were examined for ability to 
Figure 1: Heptachlor exposure did not decrease viability of stromal cells.

(A) Annexin V staining of stromal cells following heptachlor exposure did not reveal apoptosis of these cells. (B) Absence of DNA laddering on agarose gels indicated that $\mathrm{S} 10$ cells were not apoptosing after heptachlor exposure. 
A
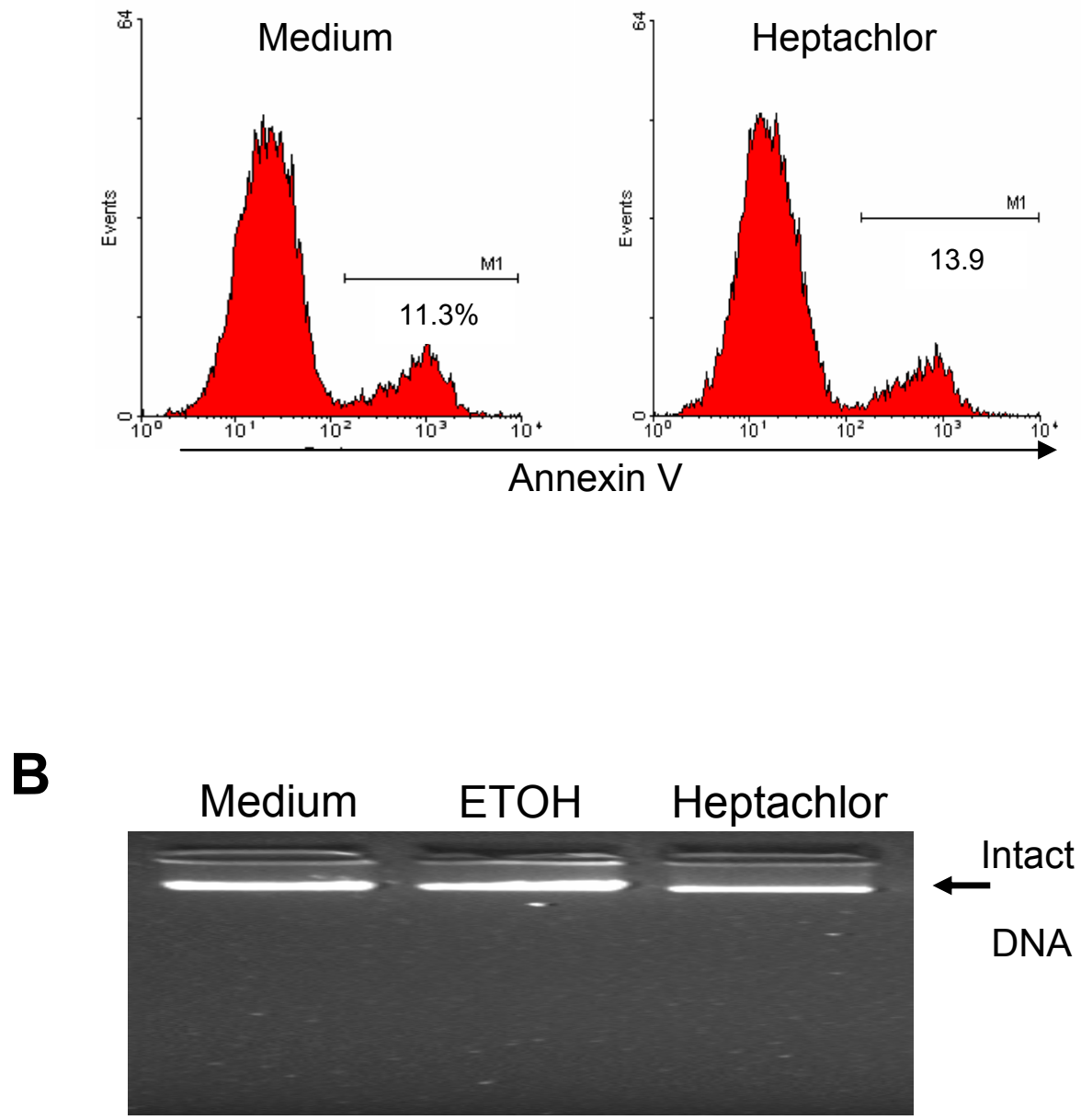

Figure 1: Heptachlor exposure did not decrease viability of stromal cells 
support pro-B cell proliferation following heptachlor treatment. Heptachlor pretreatment of stromal cells resulted in decreased pro-B cell proliferation at $25 \mu \mathrm{M}$ concentrations (Figure 2). Proliferation of pro-B cells was diminished by $61 \%$ when stromal cells were pretreated with $25 \mu \mathrm{M}$ heptachlor. Reductions in pro-B proliferation following stromal cell exposure suggested that stromal cell function, but not viability of these stromal cells, was altered following heptachlor treatment.

\section{Heptachlor exposure altered SCF mRNA abundance in stromal cells.}

SCF, IL-7, and IGF-1 produced by stromal cells are necessary for normal proliferation and development of pro-B cells (Billips et al, 1992; Dorshkind, 1990; Dorshkind et al, 1992). There are two different SCF mRNA products that result from alternative splicing (Andrews et al, 1994). Exposure of stromal cells to $5 \mu \mathrm{M}$ heptachlor resulted in increased SCF1 and SCF2 mRNA transcript abundance compared to medium and vehicle controls (Figure 3A). At $25 \mu \mathrm{M}$ heptachlor, SCF1 mRNA decreased $42 \%$ and SCF2 mRNA decreased $35 \%$ below control levels. There were no differences in abundance of IGF-1 or IL-7 mRNA from stromal cells exposed to heptachlor, vehicle, or medium controls (Figure 3B). These data suggest that heptachlor exposure affects SCF mRNA abundance in stromal cells. 
Figure 2: Heptachlor exposure diminished the capacity of stromal cells to support pro-B proliferation.

A.) S10 and C1.92 were both exposed to increasing concentrations of heptachlor ( - ) or vehicle control (-- $\square--)$. B.) Only S10 stromal cells were pretreated with heptachlor ( - ) ) or the vehicle $\left(-\triangle_{--}\right)$before co-cultured with $\mathrm{C} 1.92$ pro-B cells. Significant differences in pro-B cell proliferation are indicated between vehicle control and heptachlor-treated cultures, where $\left(^{*}\right)=p<0.05$ and $\left(^{* *}\right)=p<0.005$. 

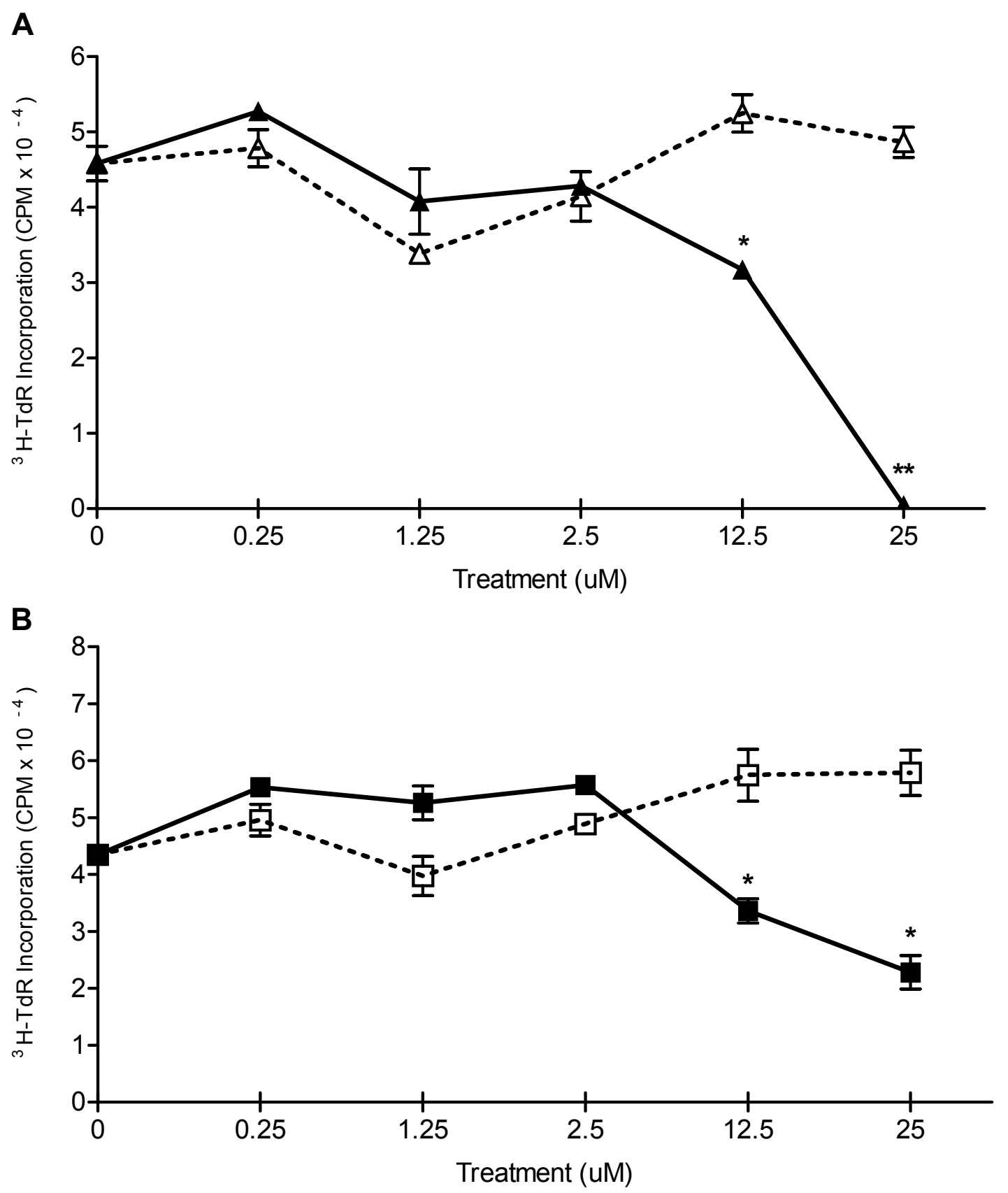

Figure 2: Heptachlor exposure diminished the capacity of stromal cells to support pro-B proliferation 
Figure 3: Heptachlor exposure affected SCF mRNA abundance in stromal cells. S10 cells were cultured with medium, vehicle (ethanol), or increasing concentrations of heptachlor for 24 hours. A.) RT-PCR was used to examine mRNA abundance of SCF, IGF-1, and IL-7 cytokines by stromal cells after heptachlor exposure. B.) SCF mRNA abundance was normalized to the housekeeping gene GAPDH. IGF-1 and IL7 mRNAs was normalized to $\beta$-actin. Data from one representative experiment is shown. 


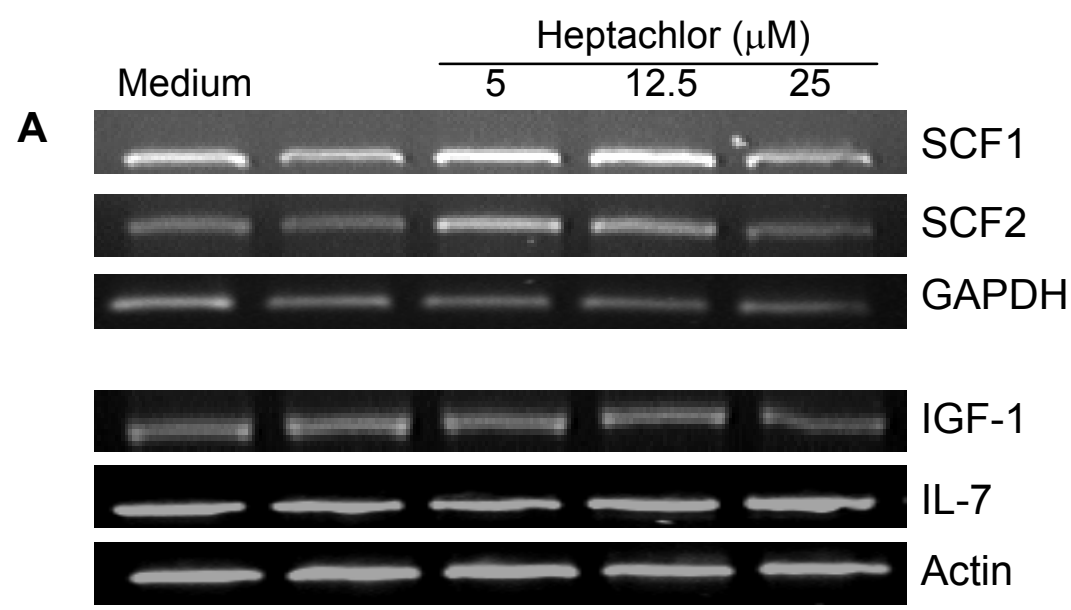

B
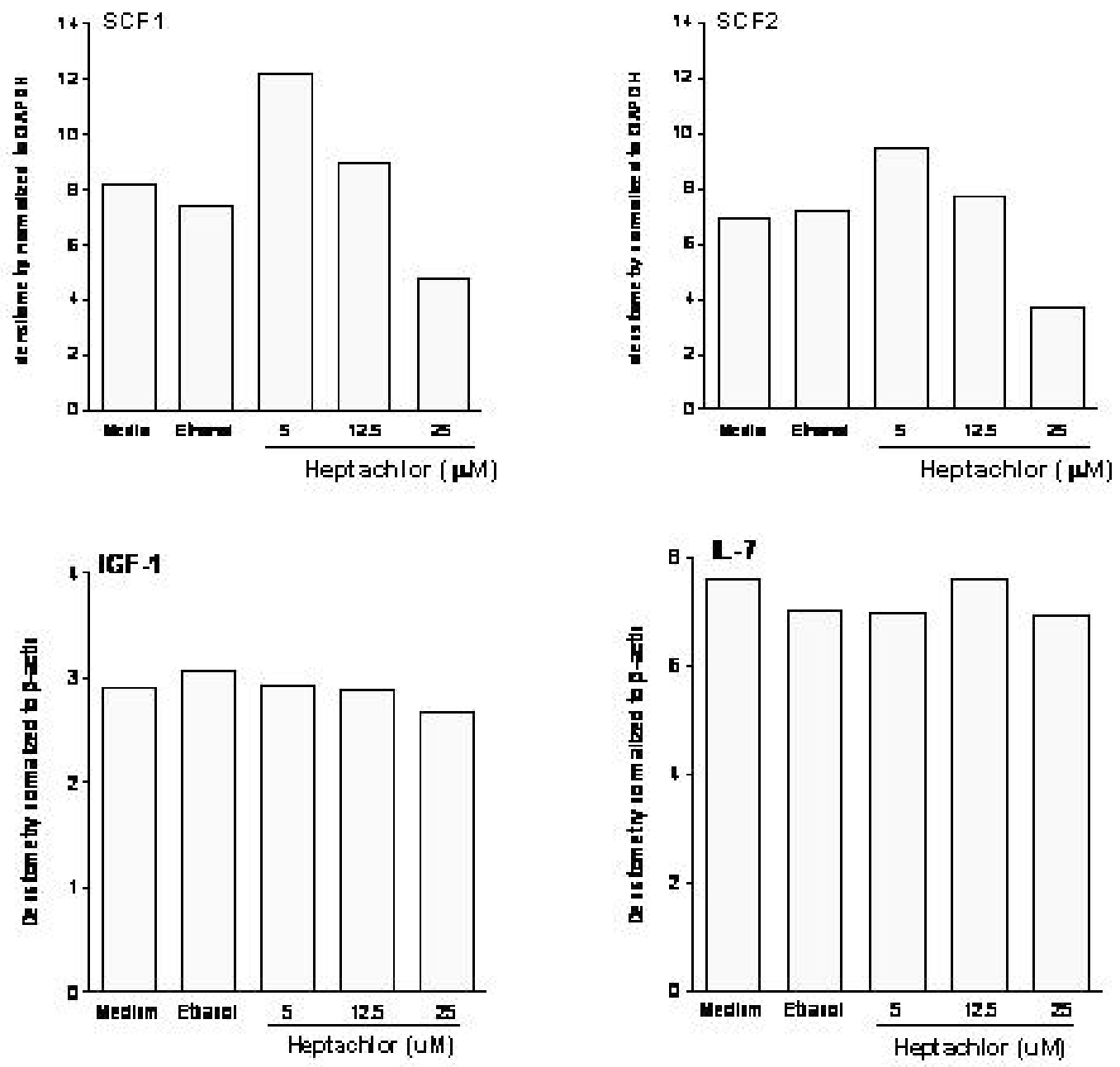

Figure 3: Heptachlor exposure affected SCF mRNA abundance in stromal cells 


\section{Heptachlor exposure altered SCF protein production by stromal cells.}

We further examined the effect of heptachlor on SCF protein levels in stromal cells. Using ELISA, we determined that SCF protein in S10 cells was altered following exposure to heptachlor (Figure 4). After exposure to $5 \mu \mathrm{M}$ heptachlor, the amount of SCF protein increased compared to levels detected in S10 medium and vehicletreated controls. There was no difference in SCF protein in stromal cells exposed to $12.5 \mu \mathrm{M}$ heptachlor. However, a decrease in SCF protein was observed in cells treated with the highest dose $(25 \mu \mathrm{M})$ of heptachlor. These SCF protein data correlated with changes in SCF mRNA detected in stromal cells following heptachlor exposure.

\section{Heptachlor decreased stromal cell VCAM-1 adhesion molecule expression.}

Because our data suggested that heptachlor treatment disrupted the ability of stromal cells to interact with pro-B cells, we examined surface expression of VCAM-1. VCAM-1, also known as CD106, is an essential vascular adhesion molecule involved in homing of hematopoietic cells to bone marrow and also attachment of these cells to the supporting stromal cells (Miyake et al, 1991; Kina et al, 1991; Schweitzer et al, 1996; Frenette et al, 1998). We determined that treatment of stromal cells exposed to $25 \mu \mathrm{M}$ heptachlor resulted in decreased numbers of VCAM-1+ cells from $90 \%$ in the medium control group to $57 \%$ positive VCAM-1 stromal cells in heptachlorexposed cultures (Figures 5A and 5B). Reduced VCAM-1 expression was not observed for stromal cells exposed to $12.5 \mu \mathrm{M}$ heptachlor. From these data, we 
Figure 4: Heptachlor exposure affected SCF protein in stromal cells.

SCF protein was quantitated by ELISA in S10 stromal cells treated with heptachlor.

Statistically significant differences between control and heptachlor exposure groups are indicated by $\left(^{*}\right)=p<0.05$. 


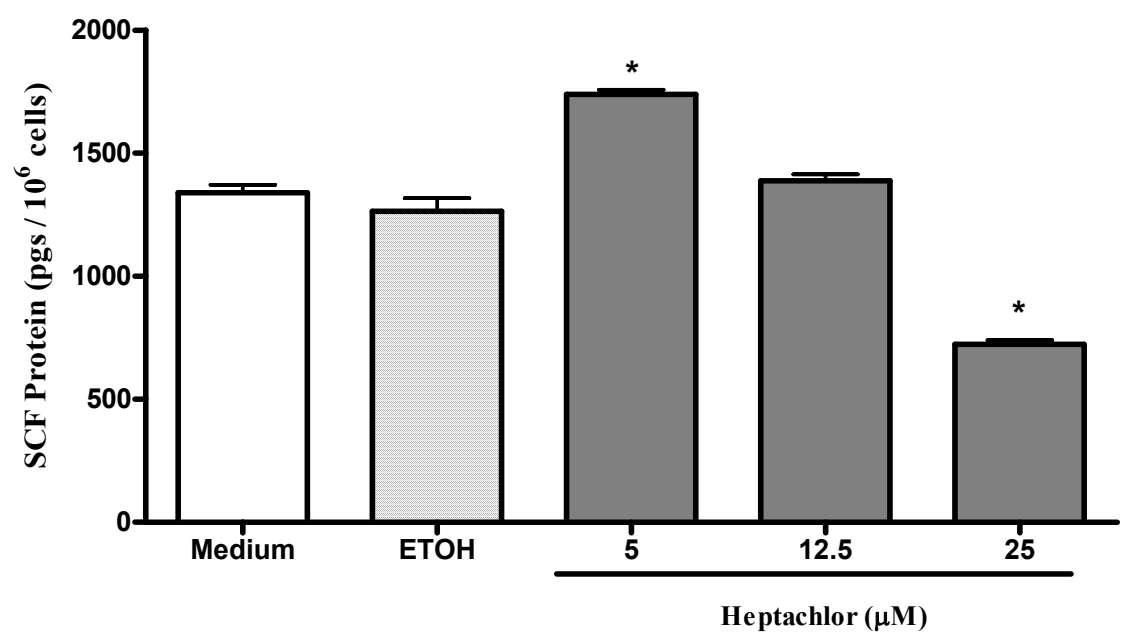

Figure 4: Heptachlor exposure affected SCF protein in stromal cells 
Figure 5: Heptachlor exposure decreased stromal cell VCAM-1 protein expression.

Expression of VCAM-1 protein on S10 stromal cells was determined after heptachlor treatment. A.) Representative histograms depicting VCAM-1 and isotype control staining for $\mathrm{S} 10$ cells are shown. B.) VCAM-1 protein surface expression for three experiments was conducted and analyzed. Statistical difference is indicated in VCAM-1 protein expression between controls and heptachlor-treated on S10 cells where $\left(^{*}\right)=p<0.05$. 

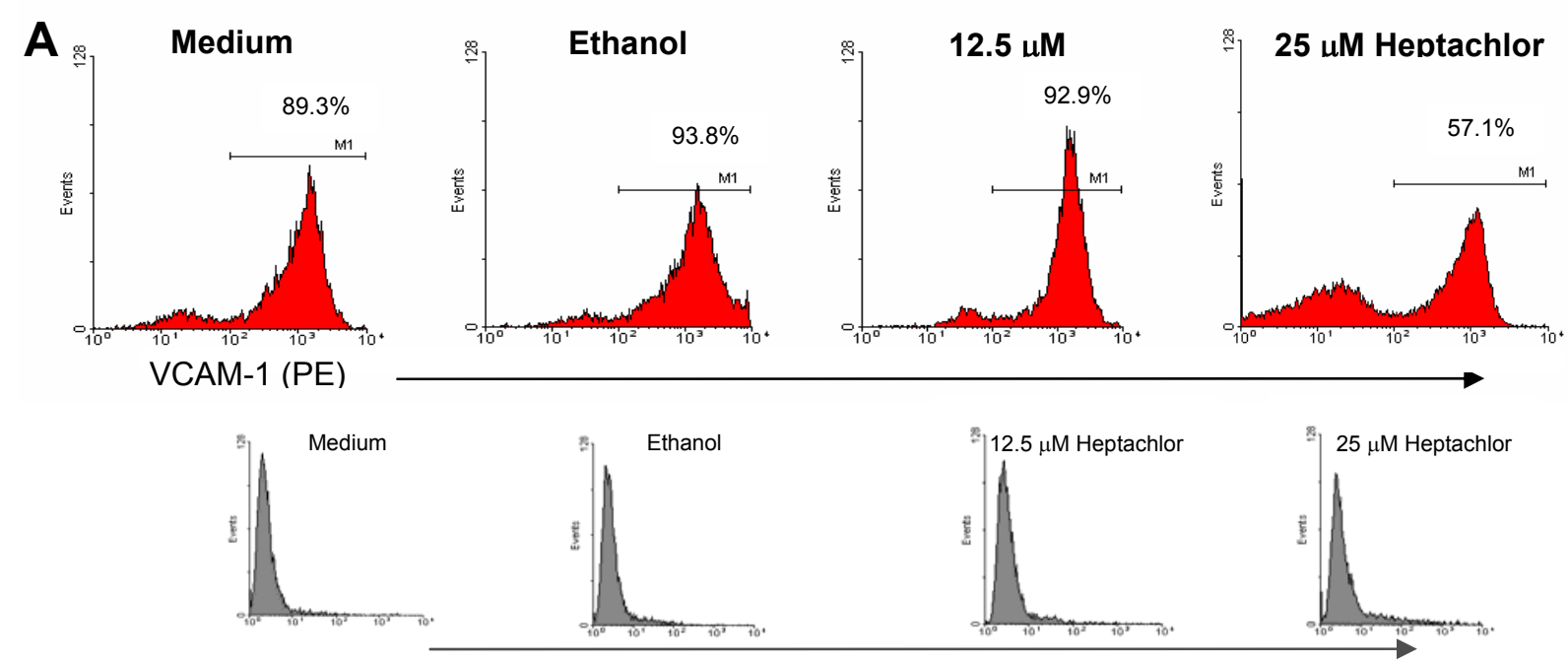

B

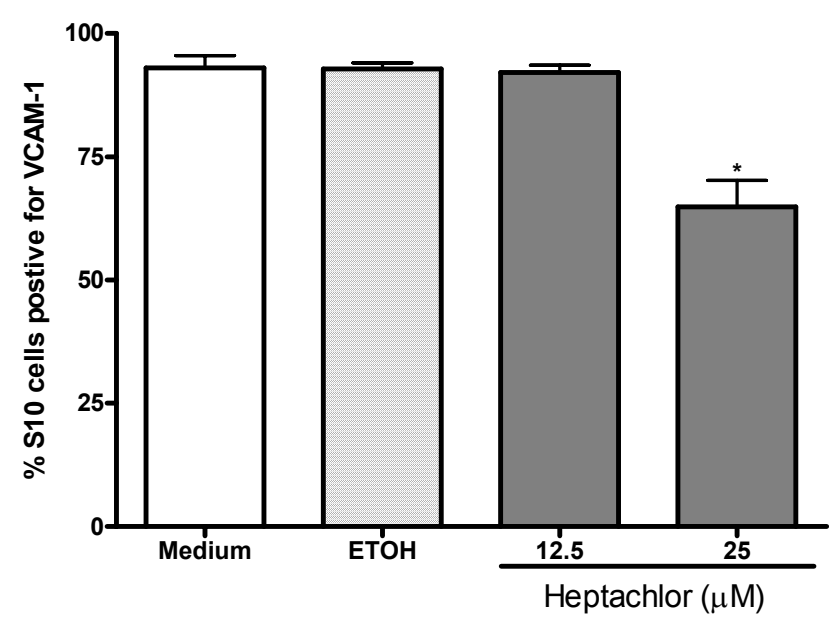

Figure 5: Heptachlor exposure decreased stromal cell VCAM-1 protein expression 
concluded that exposure to $25 \mu \mathrm{M}$ heptachlor decreased cell surface VCAM-1 expression.

\section{Heptachlor decreased nuclear NF-kB in stromal cells.}

Because expression of VCAM-1 is regulated by NF-kB, we examined nuclear levels of NF-kB in S10 stromal cells following heptachlor exposure. Nuclear p65 was decreased in S10 cells exposed to $25 \mu \mathrm{M}$ heptachlor as compared to medium and vehicle controls (Figures $6 \mathrm{~A}$ and $6 \mathrm{~B}$ ). This effect did appear to be concentrationdependent although no significant differences were determined in nuclear levels of $\mathrm{NF}-\mathrm{\kappa B}$ from stromal cells exposed to 5 or $12.5 \mu \mathrm{M}$ heptachlor, there was a trend in decreasing abundance. These data suggest that heptachlor decreased NF-KB nuclear shuttling in stromal cells.

\section{Discussion}

Damage to the developing immune system has been documented in studies evaluating prenatal exposure to organochlorine pesticides such as heptachlor (Barnett et al, 1990a; Barnett et al, 1990b; Barnett 1997). We determined that

prenatal heptachlor exposure altered lymphoid progenitor cell development, but heptachlor did not affect myeloid cells in these same embryos (Chapter 2). Because of this effect of heptachlor on lymphoid cells, we previously determined that direct exposure to C1.92 pro-B cells resulted in dramatic and significant decreased 
Figure 6: Heptachlor exposure decreased nuclear NF-kB protein abundance in stromal cells.
A.) Nuclear protein levels of p65 in S10 cells exposed to heptachlor were examined
by immunoblotting. B.) Densitometry of p65 protein bands were conducted in triplicate and normalized to $\sin 3 \mathrm{~A}$ for comparisons between groups. Statistical significant differences are indicated between controls and heptachlor-treated groups by $\left(^{*}\right)=p<0.05$. 

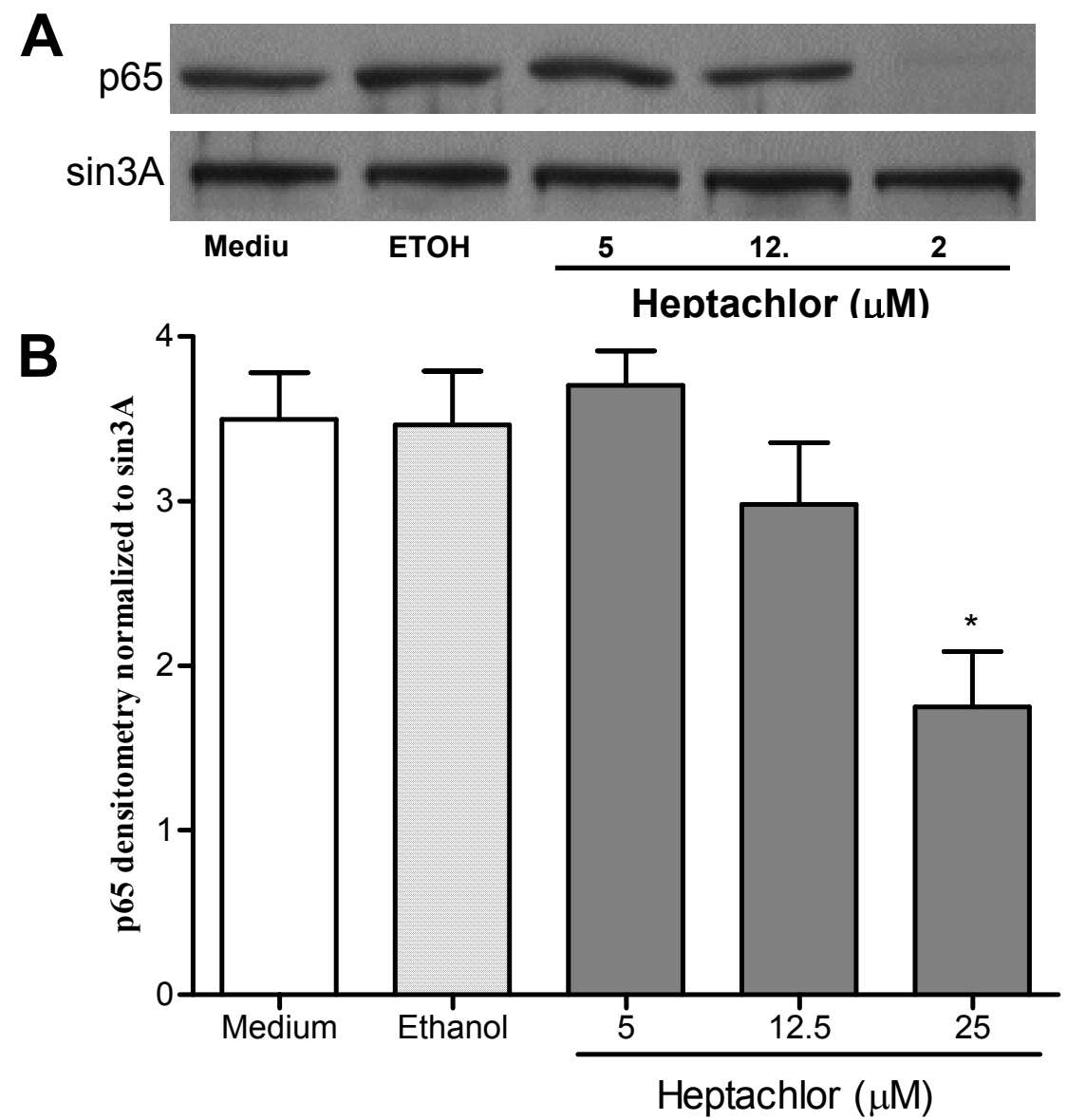

Figure 6: Heptachlor exposure decreased nuclear NF- B protein abundance in stromal cells 
proliferation and cell viability (Chapter 4). S10 cells present in pro-B cell cultures supported $\mathrm{C} 1.92$ cell viability and proliferation against damage incurred following exposure to lower heptachlor concentrations. In the present study, we demonstrated that pretreatment of stromal cells with $25 \mu \mathrm{M}$ heptachlor before pro-B cells are introduced into the cultures also resulted in decreased pro-B cell proliferation. We have examined S10 stromal cells and determined that SCF cytokine mRNA abundance, SCF protein levels, and VCAM-1 surface expression on stromal cells were altered following exposure to the highest concentration of heptachlor $(25 \mu \mathrm{M})$. Similar to previous studies where pro-B cells were examined, S10 stromal cells also had decreased NF-kB nuclear shuttling following $25 \mu \mathrm{M}$ heptachlor exposure. These data suggest that heptachlor exposure could cause damage to development of the immune system by altering the capacity of stromal cells to sustain survival and proliferation of lymphoid cells.

Interactions between emergent lymphoid cells and stromal cells are essential for extended survival of developing hematopoietic cells (Gibson et al, 1996, Mudry et al, 2000). We demonstrated that heptachlor pretreatment of stromal cells and direct exposure of $\mathrm{S} 10$ and pro-B co-cultures to $12.5 \mu \mathrm{M}$ heptachlor resulted in similar decreased pro-B cell proliferation. Pro-B and stromal cell co-cultures both exposed to $25 \mu \mathrm{M}$ heptachlor resulted in total arrest of pro-B cell survival. This demonstrated that stromal cell capacity to support pro-B cell proliferation diminished after exposure to higher heptachlor concentrations. However, when stromal cells alone were exposed prior to $\mathrm{S} 10$ and $\mathrm{C} 1.92$ cells being cultured together, pro-B cell proliferation 
was not as markedly decreased. These data indicated that the ability of stromal cells in supporting lymphoid cells was directly altered following heptachlor exposure.

We sought to explain the decreased capacity of stromal cells to support pro-B cells following exposure to heptachlor. Stromal cell cytokine production and adhesion molecule expression were analyzed following heptachlor exposure. Abundance of mRNA for IGF-1 and IL-7 cytokines was not altered; however, SCF mRNA abundance and protein levels were both changed following heptachlor exposure. SCF mRNA abundance and protein levels increased at low concentrations of heptachlor, however, SCF mRNA and protein were decreased following exposure to higher heptachlor concentrations. SCF is an important mediator, which acts to stimulate proliferation and survival of hematopoietic progenitor cells (Andrews et al, 1994). Deregulation of such an important cytokine has the ability to dramatically alter the hematopoietic repopulating potential. Along with SCF, VCAM-1 expression was significantly decreased in stromal cells exposed to $25 \mu \mathrm{M}$ heptachlor. These data suggested that stromal cells exposed to $25 \mu \mathrm{M}$ heptachlor were deficient in protecting pro-B cells from heptachlor toxicity possibly due to decreased expression of adhesion molecules, such as VCAM-1, along with decreased SCF cytokine production by these stromal cells.

Along with controlling expression of many genes involved in cell survival, numerous adhesion molecules are also regulated by nuclear factor-kappa B. NF-кB is composed of dimerized p65 and p50 proteins (Gerondakis and Strasser, 2003). 
$\mathrm{NF}-\mathrm{kB}$ complexes are retained in the cell cytoplasm when bound by the inhibitor, l-kB (Kucharczak et al, 2003). I-kB conceals the nuclear localization signal preventing translocation into the nucleus. However, following $\mathrm{I}-\mathrm{kB}$ phosphorylation by the inhibitor of kappa kinase (IKK), I-אB is targeted for proteosomal degradation (Turco et al, 2004). When NF-kB is not bound by $\mathrm{l}-\kappa \mathrm{B}, \mathrm{NF}-\kappa \mathrm{B}$ travels to the nucleus, specifically binds to DNA, and promotes gene transcription (Arenzana-Seisdedos et al, 1997). In the current study, we determined that nuclear NF-kB protein shuttling in S10 cells decreased following exposure to $25 \mu \mathrm{M}$ heptachlor. As we determined in two previous studies, heptachlor affected pro-B cells and pre-B cells by altering NF$\kappa \mathrm{B}$ signaling. In the current study, we again offer evidence and revisit the strengthening hypothesis that heptachlor exposure alters multiple cell types through alterations in NF-kB signaling. Stromal cells, which are essential in lymphoid cell survival, proliferation, and differentiation, demonstrated a diminished capability to support pro-B cells following heptachlor exposure. We have focused the majority of our efforts in explaining how heptachlor preferentially affects lymphoid cells and not myeloid cells. We do know from recent information from Nagashima et al (2004) that when IKK is blocked in vivo, lymphoid cells undergo apoptosis and are depleted from bone marrow and spleen (Nagashima et al, 2004).

Taken together, these data demonstrate that heptachlor exposure affects the function of stromal cells. This disruption in function appears to be the result of altered NF-kB intracellular signaling. These data reveal that heptachlor exposure impairs lymphopoiesis by directly affecting pro-B cells (Chapter 4 ) and by damaging 
the function of supporting stromal cells that are obligatory for normal B cell development. The net result of heptachlor affecting both cells types involved in B cell development may give even more explanation as to why B-lineage cells are more susceptible to this compound than myeloid cells.

\section{Acknowledgements}

This research was supported by the National Institute of Environmental Health Sciences Training Grant ES010953. 


\section{References}

Agency for Toxic Substances and Disease Registry. 1992. Toxicological Profile for Heptachlor. US Public Health Service, US Department of Health and Human Services, Atlanta, Georgia.

Akashi, K, K Motonari, I Weissman. 1998. Role of interleukin-7 in T-cell development from hematopoietic stem cells. Immunol Rev 165:13.

Andrews, NC, DV Faller. 1991. A rapid micropreparation technique for extraction of DNA-binding proteins from limiting numbers of mammalian cells. Nucleic Acids Res 19(9):2499.

Andrews RG, Briddell RA, Appelbaum FR, McNiece IK. 1994. Stimulation of hematopoiesis in vivo by stem cell factor. Curr Opin Hematol 1(3):187.

Arenzana-Seisdedos, F, P Turpin, M Rodriguez, D Thomas, RT Hay, JL Virelizier C Dargemont. 1997. Nuclear localization of $\mathrm{I}-\kappa \mathrm{B} \alpha$ promotes active transport of NF-kB from the nucleus to the cytoplasm. J Cell Sci 110:369.

Barnett, J, L Soderberg, J Menna. 1985. The effect of prenatal chlordane exposure on the delayed hypersensitivity response of BALB/c mice. Toxicol Lett 25:173.

Barnett, J, B Blaylock, J Gandy, J Menna, R Denton, L Soderberg. 1990a. Long-term alteration of adult bone marrow colony formation by prenatal chlordane exposure. Fund Appl Toxicol 14:688. 
Barnett, J. B Blaylock, J Gandy, J Menna, R Denton, L Soderberg. 1990b. Short Communication: Alteration of fetal liver colony formation by prenatal chlordane exposure. Fund Appli Toxicol 15:820.

Barnett, J. 1997. Age-related susceptibility to immunotoxicants: animal data and human parallels. Environ Toxicol Pharm. 4:315.

Billips, L, D Petitte, K Dorshkind, R Narayanan, C Chiu, and K Landreth. 1992. Differential roles of stromal cells, interleukin-7, and kit-ligand in the regulation of $B$ lymphopoiesis. Blood 79(5):1185.

Chen LT, L Weiss. 1975. The development of vertebral bone marrow of human fetuses. Blood 46:389.

Collins, L, and K Dorshkind. 1987. A stromal cell line from myeloid long-term bone marrow cultures can support myelopoiesis and B lymphopoiesis. J Immunol 138(4):1982.

Dewailly, E, G Mulvad, H Pedersen, P Ayotte, A Demers, J Weber, J Hansen. 1999. Concentration of organochlorines in human brain, liver, and adipose tissue autopsy samples from Greenland. 107(10):823.

Dietert, R, R Etzel, D Chen, M Halonen, S Holladay, A Jarabek, K Landreth, D Peden, K Pinkerton, R Smialowicz, T Zoetis. 2000. Workshop to identify critical windows of exposure for children's health: Immune and respiratory systems work group summary. Environ Health Perspect 108(3):483.

Dorshkind, K. 1990. Regulation of hemopoiesis by bone marrow stromal cells and their products. Annual Rev Immunol 8:111. 
Dorshkind, K, K Landreth. 1992. Regulation of B cell differentiation by bone marrow stromal cells. Internat J Cell Clon 10:12.

Fendick, EA, E. Mather-Mihaich, KA Houck, MB St Clair, JB Faust, CH Rockwell, M Owens. 1990. Ecological toxicology and human health effects of heptachlor. Rev Environ Contam Toxicol. 111:61.

Frenette, PS, S Subbarao, IB Mazo, UH von Andrian, DD Wagner. 1998. Endothelial selectins and vascular cell adhesion molecule-1 promote hematopoietic progenitor homing to bone marrow. PNSA USA 95:14423.

Furie, B., and S. Trubwitz. 1976. Insecticides and blood dyscrasias: Chlordane exposure and self-limited refractory megaloblastic anemia. JAMA. 235:1720.

Gerondakis S, and A Strasser. 2003. The role of Rel/NF-kappaB transcription factors in B lymphocyte survival. Semin Immunol 15(3):159.

Gibson, L, D Piktel, R Narayanan, G Nunez, K Landreth. 1996. Stromal cells regulate bcl-2 and bax expression in pro-B cells. Exp Hematol 24:628.

Gibson LF, Piktel D, Landreth KS. 1993. Insulin-like growth factor-1 potentiates expansion of interleukin-7-dependent pro-B cells. Blood 82(10):3005.

Guruge, K, S Tanabe. 2001. Contamination by persistent organochlorines and butyltin compounds in the West Coast of Sri Lanka. Marine Poll Bull 42:179.

Henderson, AJ, A Johnson, K Dorshkind. 1990. Functional characterization of two stromal cell lines that support B lymphopoiesis. J Immunol 145(2):423.

IARC Monographs Evaluating Carcinogenic Risks in Humans. 1991. Chlordane and heptachlor.53: 115. 
Jordan CT, IR Lemischka. 1990. Clonal and systemic analysis of long-term hematopoiesis in the mouse. Genes Dev 4(2):220.

Kierney, P, K Dorshkind. 1987. B lymphocyte precursors survive in diffusion chamber cultures but $B$ cell differentiation requires close association with stromal cells. Blood $70: 1418$.

Kina T, AS Majumdar, S Heimfeld, H Kaneshima, B Holzmann, Y Katsura, IL Weissman. 1991. Identification of a 107-kD glycoprotein that mediates adhesion between stromal cells and hematolymphoid cells. J Exp Med 173:373.

Kucharczak J, MJ Simmons, Y Fan, C Gelinas. 2003. To be, or not to be: NF-kappaB is the answer--role of Rel/NF-kappaB in the regulation of apoptosis. Oncogene 22(56):8961.

Landreth, K, K Dorshkind. 1988. Pre-B cell generation potentiated by soluble factors from a bone marrow stromal cell line. J Immunol 140(3):845.

Landreth KS, N Ramaswamy, K Dorshkind. 1992. Insulin-like Growth Factor-I Regulates Pro-B Cell Differentiation. Blood 80(5):1207.

Lichtman, M. 1984. The relationship of stromal cells to hemopoietic cells in marrow. Kroc Found Ser 18:3.

Marchand, L, L Kolonel, B Siegel, W Dendle III. 1986. Trends in birth defects for a Hawaiian population exposed to heptachlor and for the United States. Arch Environ Health 41(3):145.

Miyake K, K Medina, K Ishihara, M Kimota, R Auerbach, PW Kincade. 1991. A VCAM-like adhesion molecule on murine bone marrow stromal cells mediates binding of lymphocyte precursors in culture. J Cell Biol 114:557. 
Mudry, RE, JE Fortney, T York, BM Hall, LF Gibson. 2000. Stromal cells regulate survival of B-lineage leukemic cells during chemotherapy. Blood 96(5):1926.

Nagashima, K, V Sasseville, J Deeds, A McDonald, K Kishimoto, JC GutierrezRamos, Y Xu, C Simpson, CC Fraser. 2004. Selective rapid B cell depletion in vivo by pharmacologic IKK2 inhibition. $12^{\text {th }}$ Internal Congress Immunol July 18 . Montreal, CA.

Namen, A, S Lupton, K Hjerrild, J Wignall, D Mochizuki, A Schmierer, B Mosley, C March, D Urdal, S Gullis, D Cosman, R Goodwin. 1998. Stimulation of B-cell progenitors by cloned murine interleukin-7. Nature 333(9):571.

Office of Pesticide Programs. 1995. Internal Pesticide Notice. US Environmental Protection Agency.

Potten, CS, M Loeffler. 1990. Stem Cells: attributes, cycles, spirals, pitfalls and uncertainties. Lessons for and from the crypt. Development 110(4):1001.

Schweitzer, KM, AM Drager, $\mathrm{P}$ van der Valk, SF Thijsen, A Zevenbergen, AP Theijsmeijer, CE van der Schoot, MM Langenhuijsen. 1996. Constitutive expression of E-selectin and vascular cell adhesion molecule-1 on endothelial cells of hematopoietic tissues. Am J Pathol 148:165.

Senthilkumar, K, K Kannan, A Subramanian, S Tanabe. 2001. Accumulation of organochlorine pesticides and polychlorinated biphenyls in sediments, aquatic organisms, birds, bird eggs, and bats collected from South India. Environ Sci Pollut Res 8:1. 
Smialowicz, R, W Williams, C Copeland, M Harris, D Overstreet, B Davis, and R Chapin. 2001. The effects of perinatal/juvenile heptachlor exposure on adult immune and reproductive system function in rats. Toxicol Sci 61:164.

Stuetz, W, T Prapamontol, J Erhardt, H Classen. 2001. Organochlorine pesticide residues in human milk of a Hmong hill tribe living in Northern Thialand. Sci Total Environ 273:53.

Theus, S., D. Tabor, L. Soderberg and J. Barnett. 1992. Macrophage tumoricidal mechanisms are selectively altered by prenatal chlordane exposure. Agents Actions $37: 140$.

Turco MC, MF Romano, A Petrella, R Bisogni, P Tassone, and S Venuta. 2004. NF$\kappa \mathrm{B} /$ Rel-mediated regulation of apoptosis in hematologic malignancies and normal hematopoietic progenitors. Leukemia 18:11. 
CHAPTER 6: Overall Discussion 
Organochlorine pesticides have been used worldwide for many years to prevent insect damage to buildings, crops, and livestock. This widespread use, and the fact that organochlorine pesticides such as heptachlor and chlordane are environmentally stable with half-lives in excess of 30 years, has resulted in considerable concern that these compounds may cause health effects to humans and animals (Barnett, 1997; Barnett and Rodgers, 1994). Exposure to organochlorine pesticides can occur through ingestion of foods that contain pesticide residue, through dermal adsorption from direct pesticide contact with skin, and through inhalation of pesticide carried in the air. The lipophilic nature of organochlorines, like chlordane and heptachlor, allow accumulation of these pesticides in adipose tissue which increase likelihood that these pesticides are transferred to all levels in the food chain, including humans. Human exposure to chlordane has been correlated with hematotoxicity, a term used to describe alterations of blood cell number and function (Furie et al, 1976). Although immunotoxicity resulting from heptachlor exposure to adult mice was not demonstrated, previous studies evaluating in utero exposure to chlordane resulted in hematotoxicity in murine embryos which continued into postnatal life (Johnson et al, 1986; Barnett et al, 1997). Prenatal in utero exposure to chlordane resulted in stem cell deficiencies (CFU-S) detected both in embryos and postnatal offspring (Barnett et al, 1985; Barnett et al, 1990a; Barnett et al, 1990b; Barnett et al, 1997; Barnett et al, 2004). These studies demonstrated long-lasting hematotoxicity which resulted from in utero exposure to developing murine embryos. 
The overall goal of the work presented in this dissertation was to determine the impact of another widely used organochlorine pesticide, heptachlor, on development of hematopoiesis in mice. The overall working hypothesis of the study was that prenatal exposure to heptachlor would alter development of all hematopoietic cells in embryonic tissues and result in persistent immune defects as observed following in vivo exposure to other organochlorine pesticides.

We initially utilized the same in utero exposure model that was used by Barnett et al. (Barnett et al, 1985; Barnett et al, 1990a; Barnett et al, 1990b) to determine in vivo effects of heptachlor on development of hematopoietic cells. This model was previously used to determine effect of chlordane on development of hematopoiesis in mice (Barnett et al, 1985; Barnett et al, 1990a; Barnett et al, 1990b; Blaylock et al, 1990; Blyer et al, 1994). Following exposure of pregnant dams to heptachlor during specific periods of gestation, embryos were evaluated just before birth to determine cumulative effects of the specific period of heptachlor exposure used (Chapter 2). Although there were differences in our results that related to the timing and period of dosing (see below), we consistently found that lymphoid progenitor cells in the fetal liver were altered by in utero heptachlor exposure, but that no differences were found in myeloid progenitor cells following any exposure regimen used. Reasons for this differential response of myeloid and lymphoid cells to heptachlor exposure will be considered at the end of this discussion. 
Ontogeny of the vertebrate hematopoietic system is characterized by progression of hematopoietic cells through a series of embryonic tissue microenvironments (Ghatpande et al, 2002; Landreth, 2002; Ling and Dzierzak, 2002). This unique developmental process that involves sequential migration of stem cells from tissue to tissue in the embryo appears to be essential for normal postnatal hematopoiesis and immunocompentence. In mice, hematopoietic cells are initially detected by gestational day 7.5 in the paraarotic spanchnopleura/AGM region (Tavassoli, 1991; Godin et al, 1999). These initial hematopoietic cells migrate to the developing fetal liver on gestational day 10 (Cumano et al, 2001a; Cumano et al, 2001b) and the fetal liver remains the primary tissue site of blood cell development, progenitor cell commitment, and massive hematopoietic cell expansion (Godin et al, 1999; Weissman, 2000). Just prior to birth in mammals, hematopoietic cells emigrate from the fetal liver and relocate to other tissues, primarily the bone marrow. Immediately following birth, the mammalian liver ceases hematopoietic function (likely due to a dramatic change in oxygen tension in that tissue), and the bone marrow serves as the primary tissue residence of hematopoiesis throughout postnatal life (Cumano et al, 2001a).

In the initial experiments of this study, we exposed pregnant mice to heptachlor from days 10 to 16 of gestation. Fetal livers from embryos were evaluated on gestational day 17, a developmental age selected to insure that hematopoiesis remained largely in the fetal liver. Day 18 in the mouse embryo marks the beginning of significant migration of hematopoietic cells to bone marrow (Cumano and Godin, 
2001a). Experiments using this heptachlor dosing scheme were equivocal, and in different experiments resulted in either increases, decreases, or no affect to lymphoid progenitor cells. We rationalized that our exposure window was the reason for the equivocal results and subsequent experiments included two different heptachlor dosing regimens (Chapter 2: Figure 1). The first dosing plan (Dosing Regimen A) began on day 6 , one day prior to the emergence of hematopoietic cells in the paraaortic splanchnopleure. The second dosing schedule (Dosing Regimen B) began on day 12 after hematopoiesis was established in fetal liver. The first two days in each dosing regimen consisted of an increased heptachlor exposure (8 $\mathrm{mg} / \mathrm{kg}$ ) in an effort to administer a loading dose to the dam. This was followed by smaller daily exposure to heptachlor which was calculated to result in pregnant dams receiving a total cumulative dose of $24 \mathrm{mg}$ of heptachlor per $\mathrm{kg}$ of body weight. This also meant that dams included in the Dosing Regimen B schedule were exposed to a greater daily maintenance dose of heptachlor than mice enrolled in Dosing Regimen A (since both dosage regimens were limited to a cumulative dose of $24 \mathrm{mg} / \mathrm{kg}$ ).

Our results revealed that exposure to heptachlor using Dosing Regimen A did not result in alteration of lymphopoiesis as detected on gestational day 17. However, administration of heptachlor of Dosing Regimen B resulted in dramatically increased numbers of lymphoid progenitor cells on day 17 . This difference suggests existence of both critical windows of vulnerability to heptachlor during hematopoietic development and a threshold effect of this pesticide. Heptachlor sensitivity appears to be limited to a particular cell type, that of committed lymphoid progenitor cells, that 
appear after migration of early stem cells to the fetal liver on day 10 of development (Landreth, 2002; Landreth and Dodson, 2004). Because the two dosing regimes used different concentrations of the daily maintenance exposure to heptachlor (Dosing Regimen A < Dosing Regimen B), it is also possible that our findings suggests a threshold toxic dose for prenatal exposure to heptachlor.

In order to examine the direct effects of this pesticide on lymphoid cells, we evaluated the effect of heptachlor exposure on two B lymphoid lineage cell lines selected as representatives of distinct stages of development: pre-B cells and pro-B cells. We first examined the effect of heptachlor exposure on the pre-B cell line 70Z/3. 70Z/3 cells expresses characteristic B linage markers and have completed rearrangement of both immunoglobulin (Ig) heavy and light chain genes but do not transcribe or translate light chain protein or express cell surface lg (slg) (Paige et al, 1978; Giri et al, 1984). $70 Z / 3$ pre-B cells exposed to heptachlor remained viable, but failed to proliferate, and expressed increased levels of immunoglobulin $\kappa$ light chain, which was an indicator of pre-B cell maturation (Chapter 3). When the established pro-B cell line $\mathrm{C} 1.92$ was exposed to heptachlor, these cells ceased proliferation and immediately initiated apoptosis (Chapter 4) (Gibson et al, 1993; Gibson et al, 1996). Differences in the response of these cells to heptachlor is likely related to specific cell signaling pathways in these cell lines which will be addressed later in this discussion.

The findings that direct in vitro exposure of lymphoid cells to heptachlor resulted in failure of these cells to proliferate and also that repeated indirect exposure 
to heptachlor in utero resulted in increased numbers of lymphoid progenitor cells is intriguing. One explanation may be that heptachlor is metabolized by the pregnant dam and the resulting metabolites have different effects on embryonic lymphopoiesis than the parent compound. However, several studies have reported a hematopoietic rebound phenomena following loss of erythrocyte progenitor cells (measured as CFU-e) due to bleeding or hypobaric conditions (Langdon and McDonald, 1977; Pospisil et al, 1999; Panetta et al, 2003). Following initial depletion of CFU-e, numbers of these progenitors rebound to excessive numbers in bone marrow before returning to normal values. This overproduction of erythrocyte progenitor cells following depletion results from homeostatic feedback production of erythropoietin, a cytokine which regulates cell expansion in the erythroid lineage (Klinken, 2002). It seems reasonable to propose a similar mechanism which operates following heptachlor damage to B lineage cells, resulting in our observation of increased numbers of CFU-IL-7 in fetal liver of embryonic mice in mothers exposed to this pesticide. While there is little existing evidence for this type of feedback regulation of lymphopoiesis in mammals, these studies suggest an experimental model to address the existence of this biological mechanism.

We also addressed the possibility that heptachlor affected the function of the hematopoietic microenvironment. Lymphoid cells require interaction with cells from the hematopoietic microenvironment for survival, proliferation and differentiation of hematopoietic cells. The fetal liver and bone marrow hematopoietic microenvironment consists of fibroblastic stromal cells that function to support 
hematopoietic progenitor cells (Dorshkind, 1990; Dorshkind and Landreth, 1992; Dorshkind, 2002). We determined the effect of heptachlor on S10 cells, an adherent bone marrow stromal cell line isolated from bone marrow of BALB/c mice (Collins and Dorshkind, 1987; Landreth and Dorshkind, 1988; Henderson et al, 1990). When C1.92 pro-B cells were co-cultured with $\mathrm{S} 10$ exposed to heptachlor, heptachlor exposure resulted in decreased the capacity of S10 cells to support proliferation and survival of pro-B cells (Chapter 5). We also demonstrated that direct exposure of heptachlor to stromal cells resulted in decreased expression of VCAM-1, an adhesion molecule essential for B lineage development (Lichtman, 1984; Miyake et al, 1991; Funk et al, 1994). Direct exposure of S10 to heptachlor resulted in altered SCF mRNA and protein abundance in stromal cells, but IGF-1 and IL-7 cytokines were not affected. Low concentrations $(5 \mu \mathrm{M})$ of heptachlor cultured in vitro with stromal cells yielded increased SCF mRNA and protein levels. At higher heptachlor concentrations $(25 \mu \mathrm{M})$, opposing data was generated with observations of decreased SCF mRNA and protein. These data were correlated with data from experiments demonstrating increased and decreased numbers of lymphoid cells in embryos exposed to different concentrations of heptachlor in utero. Because SCF supports both survival and proliferation of B lineage cells, increased SCF production by stromal cells treated with heptachlor in vitro can be correlated to increased lymphoid cells observed following in vivo heptachlor exposure.

We next focused on possible mechanisms of heptachlor hematotoxicity in hematopoietic cells. Lymphoid cells and stromal cells were both examined for altered 
cell signaling as a result of heptachlor exposure. $70 Z / 3$ cells have completed both heavy and light chain gene rearrangement but do not actively express surface Ig protein, however, these pre-B cells have been characterized for ability to differentiate in response to cell stimuli have been previously described (Paige et al, 1978). Heptachlor-induced maturation of pre-B cells, indicated by $\kappa$ light chain surface expression, directed our research toward examination of $\mathrm{NF}-\mathrm{\kappa B}$ in these cells following pesticide exposure. NF-kB was first described by Sen and Baltimore as a regulator of $\kappa$ gene transcription in pre-B cells (Sen and Baltimore, 1986a; Sen and Baltimore, 1986b). Regulation of $\kappa$ light chain gene transcription occurs through binding of NF-kB proteins to specific recognition sequences upstream of $\kappa$ genes (Gerondakis and Strasser, 2003). Members of the family of NF-kB cell signaling molecules are regulators of development, survival, and activation of many cells of the immune system (Giri et al, 1984). These specific signaling complexes are formed from homodimers or heterodimers of NF-kB family proteins. There are five known members of this family: p65 (RelA), p50, NF-kB1 (p50:p105), NF-kB2 (p52:p100), RelB, and c-Rel (Gerondakis and Strasser, 2003). All members of this family have a Rel homology domain (RHD) which is highly conserved and responsible for DNA

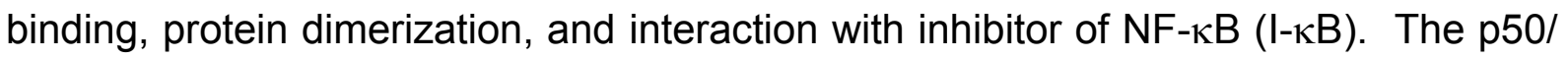
p65 heterodimer is the major NF-kB complex found in most cells. In this regulatory process, NF-kB complexes are retained in the cytoplasm of cells when bound by l-kB (Kucharczak et al, 2003). I-кB conceals the nuclear localization signal (NLS), preventing translocation of this signaling complex into the cell nucleus. However, following $\mathrm{I}-\kappa \mathrm{B}$ phosphorylation by the inhibitor of kappa kinase (IKK), $\mathrm{l}-\kappa \mathrm{B}$ is targeted 
for proteosomal degradation through addition of ubiquitin residues (Turco et al, 2004). IKK is a trimeric complex that is formed from three different IKK proteins: IKK $\alpha$, IKK $\beta$, and IKK $\gamma$. Cell stimulus can activate IKK, such as binding of inflammatory cytokines tumor necrosis factor alpha (TNF- $\alpha$ ) and interleukin-1 (IL-1) to their complementary receptors. Once IKK within the cytosol is activated, it is then capable of phosphorylating I-אB (Sen and Baltimore, 1986a; Sen and Baltimore, 1987). When not bound by $\mathrm{l}-\kappa \mathrm{B}, \mathrm{NF}-\kappa \mathrm{B}$ travels to the nucleus, specifically binds to DNA, and promotes gene transcription (Arenzana-Seisdedos et al, 1997).

We determined that NF-kB localization within pre-B cells, pro-B cells, and stromal cells was altered following heptachlor exposure. NF-kB was increased in nuclei of $70 Z / 3$ cells following exposure to heptachlor. This effect was further confirmed after heptachlor-induced pre-B cell maturation was inhibited by chemical inhibition of nuclear shuttling of NF-kB. These data suggest that heptachlor exposure interrupts pre-B cell proliferation and result in premature differentiation through alteration of NF-kB localization and subsequent surface Ig expression. In contrast, $\mathrm{NF}-\mathrm{kB}$ protein levels in C1.92 pro-B cells were decreased in nuclei of these cells following heptachlor treatment. We further determined that phosphorylated I-אB $\alpha$ was also decreased in heptachlor-treated pro-B cells. These studies suggest that direct exposure of these cells results in altered nuclear abundance of $\mathrm{NF}-\mathrm{kB}$, which induced premature differentiation of pre-B cells and decreased pro-B cell survival. $\mathrm{NF}-\mathrm{kB}$ nuclear shuttling was also affected in stromal cells which were correlated with diminished stromal cell function. Survival, proliferation, and differentiation are 
essential to lymphopoietic homeostasis. Disrupted regulation of cell signaling pathways resulting in impairment of these primary functions in developing hematopoietic cells can be fatal in animals.

It is worth reiterating that, even though lymphoid and myeloid cells both utilize NF-kB regulation of gene transcription, heptachlor exposure only affected lymphoid cells. In studies by Nagashima et al (2004), animals treated with pharmacological inhibitors of IKK resulted in depletion of lymphoid cells in bone marrow and spleen. However, similar to our studies, myeloid cell production was unaffected in these same animals (Nagashima et al, 2004). This suggests that NF-kB signaling is either not crucial to myeloid cell development or redundant cell signaling pathways exist which compensate for alterations of NF-кB signaling in myeloid cells (Nagashima et al, 2004). Additionally, it has been reported that NF-kB inhibition resulted in developmental arrest of pro-B to pre-B cells (Feng et al, 2004). These studies correlated with data presented in this dissertation describing heptachlor-induced hematotoxicity, resulting from altered NF-кB signaling.

Original research presented in this dissertation has led to construction of a unifying hypothesis of the effect of heptachlor on hematopoiesis: that heptachlor exposure results in alterations in NF-kB signaling in all cells. NF-kB is essential for many cell signaling pathways, and disruption of NF-kB signaling due to organochlorine pesticide exposure has enormous consequences for understanding biological damage caused by environmental pesticides. Given the fact that NF-kB is 
expressed in a wide array of cell types, differences in response to heptachlor exposure in different tissues or cell types are likely due, at least in part, to the importance of NF-kB regulation to the survival or function of the individual cell type, the ability of specific tissues to detoxify this compound, and the existence of intracellular compensatory mechanisms that can moderate the effect of altered NFкB function following heptachlor exposure. 


\section{References}

Arenzana-Seisdedos, F, P Turpin, M Rodriguez, D Thomas, RT Hay, JL Virelizier C

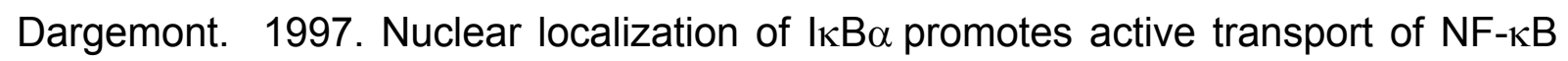
from the nucleus to the cytoplasm. J Cell Sci 110:369.

Barnett, JB. 1997. Age-related susceptibility to immunotoxicants: animal data and human parallels. Environ Toxicol Pharm. 4:315.

Barnett, J, B Blaylock, J Gandy, J Menna, R Denton, L Soderberg. 1990a. Long-term alteration of adult bone marrow colony formation by prenatal chlordane exposure. Fund Appl Toxicol 14:688.

Barnett, J. B Blaylock, J Gandy, J Menna, R Denton, L Soderberg. 1990b. Short Communication: Alteration of fetal liver colony formation by prenatal chlordane exposure. Fund Appli Toxicol 15:820.

Barnett, JB, KE Rodgers. 1994. Pesticides: In Immunotoxicology and Immunopharmacology, $2^{\text {nd }}$ edition, JH Dean, MI Luster, AE Munson, and I Kimber (eds), Raven Press, New York. p.191.

Barnett, JB, LF Gibson, KS Landreth. 2004. Developmental Immunotoxicity of Chlordane: In Developmental Toxicology, SD Holladay (ed). CRC Press, Boca Raton.

Barnett, J, L Soderberg, J Menna. 1985. The effect of prenatal chlordane exposure on the delayed hypersensitivity response of BALB/c mice. Toxicol Lett 25:173. 
Blaylock BL, L Soderberg, J Gandy, J Menna, R Denton, J Barnett. 1990. Cytotoxic T-lymphocyte and NK responses in mice treated prenatally with chlordane. Toxicol Lett 51(1):41.

Blyer, G, KS Landreth, and JB Barnett. 1994. Gender-specific effects of prenatal chlordane exposure on myeloid cell development. Fund Appl Toxicol 23:188.

Collins, L, and K Dorshkind. 1987. A stromal cell line from myeloid long-term bone marrow cultures can support myelopoiesis and B lymphopoiesis. J Immunol 138(4):1982.

Cumano, A, and I Godin. 2001. Pluripotent hematopoietic stem cell development during embryogenesis. Curr Opin Immunol 13:166.

Cumano, A, C Ferraz, M Klaine, J Santo, I Godin. 2001b. Intraembryonic, but not yolk sac hematopoietic precursors, isolated before circulation, provide long-term multilineage reconstitution. Immunity 15:477.

Dorshkind, K. 1990. Regulation of hemopoiesis by bone marrow stromal cells and their products. Annual Rev Immunol 8:111.

Dorshkind, K. 2002. Multilineage development from adult bone marrow cells. Nature Immunol 3(4):311.

Dorshkind, K, K Landreth. 1992. Regulation of B cell differentiation by bone marrow stromal cells. Internat J Cell Clon 10:12.

Feng, B, S Cheng, WS Pear, HC Liou. 2004. NF-kB inhibitor blocks B cell development at two checkpoints. Medical Immunol 3(1):1. 
Funk,PE, PW Kincade, PL Witte. 1994. Native associations of early hematopoietic stem cells and stromal cells isolated in bone marrow cell aggregates. Blood 83:361.

Furie, B, and S Trubwitz. 1976. Insecticides and blood dyscrasias: Chlordane exposure and self-limited refractory megaloblastic anemia. JAMA. 235:1720.

Ghatpande, S, A Ghatpande, J Sher, MH Zile, T Evans. 2002. Retinoid signaling regulates primitive (yolk sac) hematopoiesis. Blood 99(7):2379.

Gibson, L, D Piktel, R Narayanan, G Nunez, K Landreth. 1996. Stromal cells regulate bcl-2 and bax expression in pro-B cells. Exp Hematol 24:628.

Gibson, LF, D Piktel, KS Landreth. 1993. Insulin-like growth factor-1 potentiates expansion of interleukin-7-dependent pro-B cells. Blood 82(10):3005.

Gerondakis S, and A Strasser. 2003. The role of Rel/NF-kappaB transcription factors in B lymphocyte survival. Semin Immunol 15(3):159.

Giri, JG, PW Kincade, and SB Mizel. 1984 Interleukin 1-mediated induction of $\kappa$-light chain synthesis and surface immunoglobulin expression on pre-B cells. J Immunol 132(1): 223.

Godin, I, J Garcia-Porrero, F Dieterlen-Lievre, A Cumano. 1999. Stem cell emergence and hemopoietic activity are incompatible in mouse intraembryonic sites. J Exp Med 190(1):43.

Henderson, AJ, A Johnson, K Dorshkind. 1990. Functional characterization of two stromal cell lines that support B lymphopoiesis. J Immunol 145(2):423.

Johnson K, M Holsapple, A Munson. 1986. An immunotoxicological evaluation of gamma-chlordane. Fundam Appl Toxicol 6(2):317. 
Klinken PS. 2002. Red blood cells. Int J Biochem Cell Biol 34(12):1513.

Kucharczak J, MJ Simmons, Y Fan, C Gelinas. 2003. To be, or not to be: NF-kappaB is the answer--role of Rel/NF-kappaB in the regulation of apoptosis. Oncogene 22(56):8961.

Landreth, KS. 2002. Critical windows in development of the rodent immune system. Human and Exp Toxicol 21:493.

Landreth, K, K Dorshkind. 1988. Pre-B cell generation potentiated by soluble factors from a bone marrow stromal cell line. J Immunol 140(3):845.

Landreth,KS, SVM Dodson. 2004. The Rodent Immune System: In Developmental Toxicology, SD Holladay (ed). CRC Press, Boca Raton, p.1.

Langdon, JR, TP McDonald. 1977. Effects of chronic hypoxia on platelet production in mice. Exp Hematol 5(3):191.

Lichtman, M. 1984. The relationship of stromal cells to hemopoietic cells in marrow. Kroc Found Ser 18:3.

Ling, KW, E Dzierzak. 2002. Ontogeny and genetics of the hemato/lymphopoietic system. Curr Opin Immunol 14(2):186.

Miyake, K, K Medina, K Ishihara, M Kimoto, R Auerbach, PW Kincade. 1991. A VCAM-like adhesion molecule on murine bone marrow stromal cells mediates binding of lymphocyte precursors in culture. J Cell Biol 114:557. 
Nagashima, K, V Sasseville, J Deeds, A McDonald, K Kishimoto, JC GutierrezRamos, Y Xu, C Simpson, CC Fraser. 2004. Selective rapid B cell depletion in vivo by pharmacologic IKK2 inhibition. $12^{\text {th }}$ Internal Congress Immunol July 18. Montreal, CA.

Page, C, P Kincade, P Ralph. 1978. Murine B cell leukemia line with inducible surface immunoglobulin expression. J Immunol 121(2):641.

Panetta, JC, MN Kirstein, AJ Gajjar, G Nair, M Fouladi, CF Stewart. 2003. A mechanistic mathematical model of temozolomide myelosuppression in children with high-grade gliomas. Math Biosci 186(1):29.

Pospisil, M, M Hofer, J Netikova, J Hola, V Znojil, J Vacha, A Vacek. 1999. Pretreatment with granulocyte colony-stimulating factor reduces myelopoiesis in irradiated mice. Radiat Res 151(3):363.

Sen, R, D Baltimore. 1986a. Inducibility of kappa immunoglobulin enhancer-binding protein NF-kB by a posttranslational mechanism. Cell 47:921.

Sen R, D Baltimore.1986b. Multiple nuclear factors interact with the immunoglobulin enhancer sequences. Cell 46(5):705.

Sen R, D Baltimore. 1987. In vitro transcription of immunoglobulin genes in a B-cell extract: effects of enhancer and promoter sequences. Mol Cell Biol 7(5):1989.

Tavassoli, M. 1991. Embryonic and fetal hemopoiesis: An overview. Blood Cells 17(2):282.

Turco MC, MF Romano, A Petrella, R Bisogni, P Tassone, and S Venuta. 2004. NF$\kappa \mathrm{B} /$ Rel-mediated regulation of apoptosis in hematologic malignancies and normal hematopoietic progenitors. Leukemia 18:11. 
Weissman, I. 2000. Stem cells: Units of development, units of regeneration and units in evolution. Cell 100:157. 


\section{Curriculum Vitae}




\title{
Sarah Vanessa Meads Dodson
}

\author{
PO Box 9300, Mary Babb Randolph Cancer Center \\ West Virginia University, Morgantown, WV 26506 \\ Office: (304) 293-0503
}

\section{-Education:}

West Virginia University, Morgantown, WV

Doctor of Philosophy, August 1998 - December 2004

Department of Microbiology, Immunology, \& Cell Biology, School of Medicine

Dissertation: Hematotoxicity of Heptachlor

The University of Georgia, Athens, GA

Master of Science, January 1997 - July 1998

Department of Medical Microbiology \& Parasitology, College of Veterinary Medicine

Thesis: Molecular typing of veterinary pathogens: Streptococcus iniae and Salmonella pullorum

Shepherd College, Shepherdstown, WV

Bachelor of Science, August 1991 - December 1995

Major: Biology Minor: Chemistry

\section{-Publications:}

Dodson, SVM, D Piktel, JB Barnett, KS Landreth. (in progress). In Vitro Heptachlor Exposure Induces Maturation of 70Z/3 Pre-B Cells.

Dodson, SVM, JB Barnett, D Piktel, KS Landreth. (in progress). In Vitro Heptachlor Exposure Alters NF- $\kappa \mathrm{B}$ in Pro-B Cells.

Dodson, SVM, JB Barnett, D Piktel, KS Landreth. (in progress). In Vitro Heptachlor Exposure Alters Stromal Cell Function.

Landreth, KS, and SVM Dodson. 2004 (in press). Development of the Rodent Immune System. In: Vohr, HW (ed); Encyclopedic Reference of Immunotoxicology. Springer.

Landreth, KS, and SVM Dodson. 2004 (in press). Neonatal Immune Response. In: Vohr, HW (ed); Encyclopedic Reference of Immunotoxicology. Springer.

Landreth, KS, and SVM Dodson. 2004. Development of the Rodent Immune System: In Developmental Immunology, Holladay, SD (ed). CRC Press, LLC. 
Hudson, C R, C Quist, MD Lee, K Keyes, SV Dodson, C Morales, S Sanchez, DG White, and JJ Maurer. 2000. The genetic-relatedness of Salmonella from non-domestic birds in the Southeastern United States. Journal of Clinical Microbiology 38:1860-1865.

Dodson, SV, JJ Maurer, PS Holt, and MD Lee. 1999. Temporal changes in the population genetics of Salmonella pullorum. Avian Disease 43:685-695.

Dodson, SV, JJ Maurer, and EB Shotts. 1999. Biochemical and molecular typing of Streptococcus iniae isolated from fish and human cases. Journal of Fish Disease 22:331-336.

\section{-Collaborative Acknowledgements:}

Li, C, L Corum D Morgan, EL Rosey, TB Stanton, and NW Charon. 2000. The spirochete FlaA periplasmic sheath protein impacts flagellar helicity. J Bacteriol 182(23):6698. (Dodson, SVM acknowledged)

\section{-Presentations:}

$4^{\text {rd }}$ Annual Society of Toxicology Meeting, March 2004, Baltimore, MD.

"Hematotoxic effects of heptachlor on B lymphopoiesis." SVM Dodson (poster presenter), D Piktel, JB Barnett, and KS Landreth. West Virginia University, Department of Microbiology, Immunology \& Cell Biology Morgantown, WV.

31st Annual Mid-Atlantic Immunobiology Meeting, May 2003, McHenry, MD.

"Effect of heptachlor on B lymphopoiesis." SVM Dodson (oral presenter), JB Barnett, D Piktel, LF Gibson, and KS Landreth. West Virginia University, Morgantown, WV

E.J. Van Liere Memorial Research Convocation, April 2003. Morgantown, WV.

"Bone marrow stromal cells protect pro-B cells from heptachlor toxicity." Sarah Dodson (presenter). West Virginia University, Morgantown, WV.

E.J. Van Liere Memorial Research Convocation, April 2001. Morgantown, WV.

"Hematotoxic effects of prenatal exposure to heptachlor." Sarah Dodson (oral presenter). West Virginia University, Morgantown, WV.

$4^{\text {th }}$ Annual Society of Toxicology Meeting, March 2001, San Francisco, CA.

"Hematotoxic effects of prenatal exposure to heptachlor." SVM Dodson (poster presenter), JB Barnett, LF Gibson, D Piktel, and KS Landreth. West Virginia University, Morgantown, WV. 
$39^{\text {th }}$ Annual Society of Toxicology Meeting, March 2000, Philadelphia, PA.

"Hematotoxic effects of prenatal exposure of mice to chlordane." SVM Dodson (poster presenter), KS Landreth, D Pikel, W Zhoa, LF Gibson, and JB Barnett. West Virginia University, Morgantown, WV.

International Association for Aquatic Animal Medicine, May 1998, San Diego, CA.

"Biochemical and molecular typing of Streptococcus iniae isolates from fish and human case." $\mathbf{S ~ V}$ Meads (oral presenter), and JJ Maurer. The University of Georgia, Athens, GA.

American Society for Microbiology, May 1998, Atlanta, GA.

"Molecular typing of Streptococus iniae by random amplification of polymorphic DNA." S V Meads (poster presenter), JJ Maurer, and EB Shotts,Jr. The University of Georgia, Athens, GA.

Eastern Fish Health Workshop, March 1998, Plymouth, MA.

"Biochemical and molecular typing of Streptococcus iniae isolates from fish and human cases." $\mathbf{S} \mathbf{V}$ Meads (oral presenter), E Shotts, Jr., and JJ Maurer. The University of Georgia, Athens, GA.

Southeast branch of the American Society for Microbiology, October, 1997, Athens, GA. "Biochemical and molecular typing of Streptococcus iniae isolates from fish and human cases." $\mathbf{S ~ V}$ Meads (oral presenter), EB Shotts, Jr., and JJ Maurer. The University of Georgia, Athens, GA.

European Association of Fish Pathologists, September 1997, Edinburgh, England.

"Biochemical anaylsis of isolates of Streptococcus cultured from fish." EB Shotts, Jr. (oral presenter) and SV Meads. The University of Georgia, Athens, GA.

Southern Conference of Reserachers in Aquatic Diseases, March 1997, Athens, GA.

"Biochemical analysis of isolates of Streptococcus cultured from fish." SV Meads (oral presenter) and EB Shotts, Jr. The University of Georgia, Athens, GA.

Proceedings of the West Virginia Science Academy. 1995, Huntington, WV.

"Prevalence and contagion of Aeromonas salmonicda in hatchery and free-ranging fish." SV Meads (oral presenter), C Starlipper, and R Cipriano. USGS/Leetown Science Center, Kearneysville, WV.

\section{-Teaching Experience:}

Mary Babb Randolph Center, Mentor, 1999 to present.

Provided lab training and guidance to undergraduate students, medical students, residents, and physician-scientists.

Microbiology 200, Exam Proctor, 2000-2004 Fall and Spring Semesters.

Assisted in monitoring and handling exams for approximately 200 undergraduate students. 
Microbiology \& Immunology 701, Teaching Assistant, 2001 Fall Semester.

Prepared technology for lecturers and made audio recorded lectures available to medical students.

Microbiology \& Immunology 701 Clinical Correlations, Discussion Leader, 2001 \& 2004 Fall Semesters.

Reviewed and discussed problem-based immunology clinical vignettes with medical students.

Microbiology 26/223 Laboratory, Teaching Assistant, 2000 Spring Semester.

Assisted in preparing and teaching the molecular techniques section of the lab to medical technology students.

Community Mini Medical School: Med School 101, Volunteer Instructor, October 1999.

Instructed and lead community members in culturing and identifying bacteria, similar to a clinical diagnostic laboratory.

Microbiology 26/223 Laboratory, Teaching Assistant, 1999 Spring Semester.

Prepared microbiology lab cultures and instructed medical technology students.

\section{-Professional Societies:}

Society of Toxicology, member, 2001 - present

Immunotoxicology Specialty Section: Society of Toxicology, member, 2001 - present

Molecular Biology Specialty Section: Society of Toxicology, member, 2002 - present

Allegheny-Erie Branch of the Society of Toxicology, member, 2002 - present

American Society of Microbiology, member, 1997-1998 


\section{- Experimental Techniques:}

\section{General Laboratory Procedures:}

Tissue culture techniques

Aerobic bacterial culture techniques

Anaerobic bacterial culture techniques

Bacterial and eukaryotic cell staining and morphologic analysis

Molecular cloning techniques

DNA and RNA extraction

RT-PCR

Radioactive isotope handling

Hematopoietic colony forming unit assays

Cell fractionation and nuclear protein extraction

Gel electrophoresis and analysis

Western blot and Southern blot hybridization techniques

Flow cytometric staining and analysis

Fluorescence microscopy

Cell cycle analysis

Bacterial diagnostic analysis of veterinary samples

Official grant progress reports

Statistical analysis of data

\section{Animal Experience:}

Prepared and implemented ACUC-approved animal protocols

Extracted from murine bone marrow and other organs

Extracted and utilized liver cells from embryonic mice

Conducted murine oral and inhalation dosing regimens

Performed murine and fish animal handling and husbandry

Obtained and diagnosed pathogenic bacterial isolates from fish

Treated infected, priceless fish owned by a prominent international koi trader 